\title{
MODELAGEM E SIMULAÇÃO DA PROTEÇÃO DIFERENCIAL DE ALTA IMPEDÂNCIA DE BARRAMENTOS NO SOFTWARE ATP
}

Mardênnia Társis Silva Alvarenga

Brasília, Dezembro de 2014.

\section{UNIVERSIDADE DE BRASÍLIA}

FACULDADE DE TECNOLOGIA 
UNIVERSIDADE DE BRASÍLIA

FACULDADE DE TECNOLOGIA

DEPARTAMENTO DE ENGENHARIA ELÉTRICA

MODELAGEM E SIMULAÇÃO DA PROTEÇÃO

DIFERENCIAL DE ALTA IMPEDÂNCIA DE

BARRAMENTOS NO SOFTWARE ATP

MARDÊNNIA TÁRSIS SILVA ALVARENGA

ORIENTADOR: KLEBER MELO E SILVA

DISSERTAÇÃO DE MESTRADO EM ENGENHARIA ELÉTRICA

PUBLICAÇÃO: PPGEE.584/14-DM

BRASÍLIA/DF: DEZEMBRO - 2014 


\section{UNIVERSIDADE DE BRASILIA \\ FACULDADE DE TECNOLOGIA \\ DEPARTAMENTO DE ENGENHARIA ELÉTRICA}

\section{MODELAGEM E SIMULAÇÃO DA PROTEÇÃO DIFERENCIAL DE ALTA IMPEDÂNCIA DE BARRAMENTOS NO SOFTWARE ATP}

\section{MARDÊNNIA TÁRSIS SILVA ALAVRENGA}

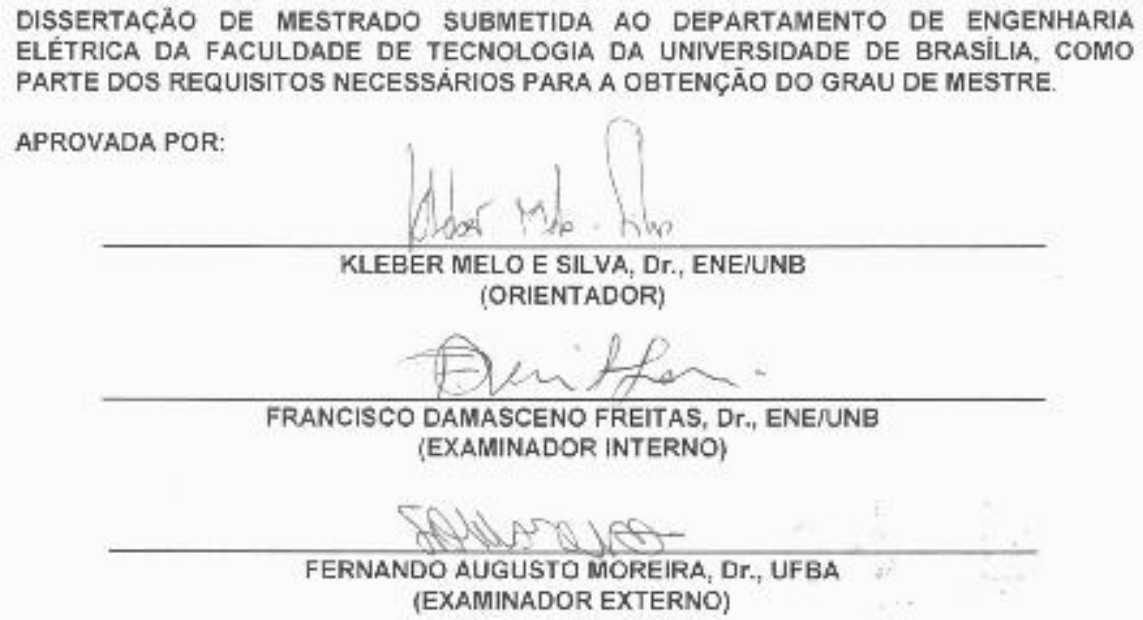

Brasilia, 18 de dezembro de 2014. 


\section{FICHA CATALOGRÁFICA}

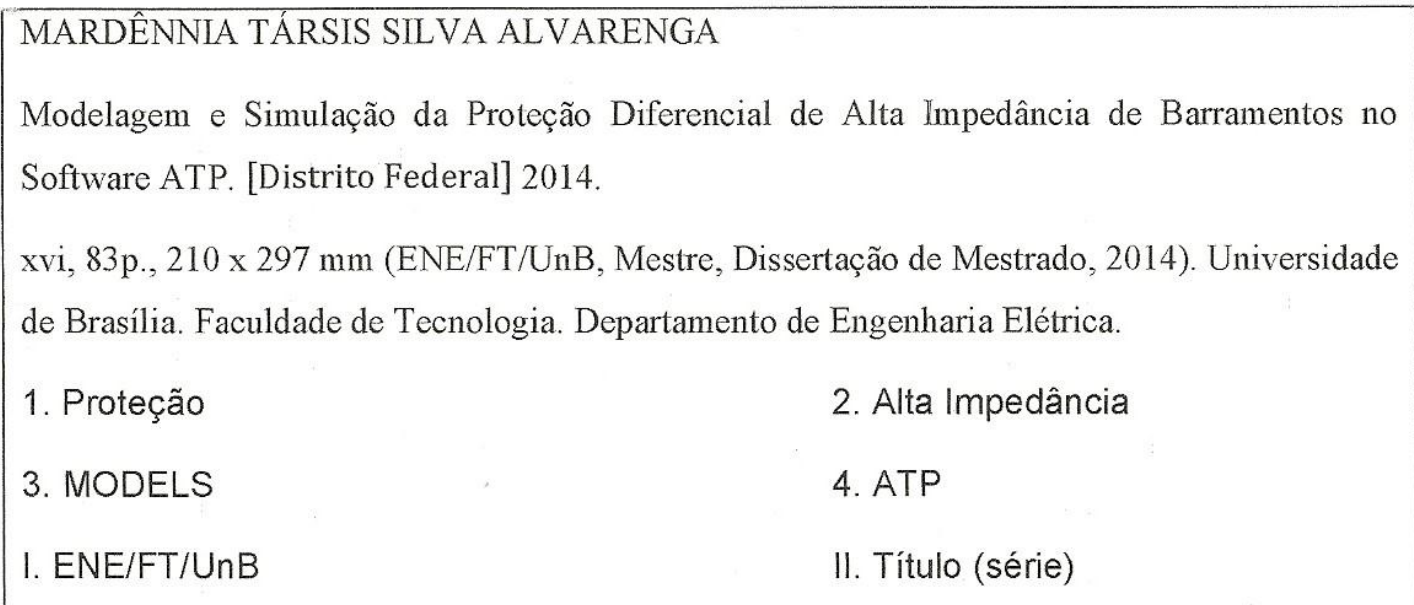

\section{REFERÊNCIA BIBLIOGRÁFICA}

ALVARENGA, M. T. S. (2014). Modelagem e Simulação da Proteção Diferencial de Alta Impedância de Barramentos no Software ATP. Dissertação de Mestrado em Engenharia Elétrica, Publicação: PPGEE.584/14-DM, Departamento de Engenharia Elétrica, Universidade de Brasília, Brasília, DF, 83p.

\section{CESSÃO DE DIREITOS}

AUTOR: Mardênnia Társis Silva Alvarenga

TÍTULO: Modelagem e Simulação da Proteção Diferencial de Alta Impedância de Barramentos no Software ATP.

\section{GRAU: Mestre ANO: 2014}

É concedida à Universidade de Brasília permissão para reproduzir cópias dessa dissertação de mestrado e para emprestar ou vender tais cópias somente para propósitos acadêmicos e científicos. $\mathrm{O}$ autor reserva outros direitos de publicação e nenhuma parte dessa dissertação de mestrado pode ser reproduzida sem autorização por escrito do autor.

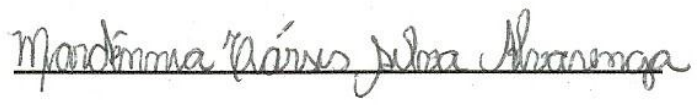

Mardênnia Társis Silva Alvarenga

Universidade de Brasília - UnB

Faculdade de Tecnologia - FT

Departamento de Engenharia Elétrica

Brasília - DF

70910-900 


\section{DEDICATÓRIA}

A Deus por tudo que me proporciona na vida.

Aos meus pais Jader e Elisete, e as minhas irmãs Priscilla e Yorranna. 


\section{AGRADECIMENTOS}

A Deus, o grande mestre do universo, por ter me dado saúde e força durante todos esses anos e ter me concedido a oportunidade de evoluir como pessoa e como profissional.

Aos meus pais, pelo amor, incentivo e apoio incondicional. Eles foram a peça fundamental para a concretização de um sonho.

Ao meu namorado Rennan, que de forma especial e carinhosa me deu força e coragem, me apoiando nos momentos de dificuldades.

Ao meu orientador, professor Kleber Melo e Silva, pelos ensinamentos, dedicação e suporte à elaboração desta dissertação de mestrado. Pela orientação em minha formação acadêmica desde a graduação até o mestrado.

A todos que, de alguma maneira, apoiaram e fizeram parte da minha formação, muito obrigada. 


\section{RESUMO}

A proteção diferencial de alta impedância tem sido historicamente empregada na proteção de barramentos com arranjos que não apresenta grandes mudanças de topologia durante a realização de manobras. Nesse sentido, o objetivo dessa dissertação de mestrado é avaliar o desempenho desse tipo de proteção, frente a vários tipos de curtos-circuitos em barramentos. Para tanto, a proteção diferencial de alta impedância foi modelada e simulada utilizando-se a linguagem MODELS do software ATP (Alternative Transients Program). Para tanto, escolheu-se simular um sistema elétrico constituído de quatro linhas de transmissão e dois transformadores conectados ao barramento com arranjo de barra simples seccionado. A proteção é feita em duas zonas, sendo cada uma delas responsável por proteger duas linhas de transmissão e um transformador. O foco deste trabalho consiste na análise do desempenho da proteção diferencial de alta impedância e não aspectos relacionados à confiabilidade e versatilidade dos arranjos de barramento. Os resultados obtidos ilustram as vantagens da utilização desse tipo de proteção para barramentos, como a velocidade e a segurança na operação, mesmo em situações adversas como a de saturação do núcleo magnético dos transformadores de correntes utilizados no esquema, quando da ocorrência de curtoscircuitos externos à zona da proteção diferencial. Além disso, evidencia-se a importância desse tipo de abordagem de estudo, uma vez que ela permite a avaliação do impacto da atuação da proteção na mudança dos estados do sistema elétrico de potência e vice-versa.

Palavras-chave: proteção de barramentos, proteção diferencial de alta impedância, ATP, MODELS. 


\section{ABSTRACT}

The high impedance differential protection has historically been used in the busbar protection with static arrangements due to the fact it is not required to perform current transformers secondary switching. Thus, the objective of this work is to evaluate the performance of this type of protection, against various types of short circuits in buses. In order to do so, the high impedance differential protection was modeled and simulated using the MODELS language in software ATP (Alternative Transients Program). So, it was chosen simulate an electrical system consisting of four transmission lines and two transformers connected to the busbar with single busbar with sectionalisation topology. The protection is accomplished in two zones, each one is responsible for protecting two transmission lines and one transformer. The focus of this master dissertation is to analyze the performance of high impedance differential protection and no aspects related to the reliability and versatility of busbar arrangements. The obtained results illustrate the advantages of using this type of busbar protection, as speed and safety in operation even in adverse situations such as the saturation of the magnetic core current transformers used in the scheme, upon the occurrence of external short-circuits to the differential protection zone. In addition, it was evidenced the importance of this type of study approach, since it allows to evaluate the impact of the protection performance in changing the state of the electric power system and contrariwise.

Index Terms: busbar protection, high-impedance bus differential protection, relays modeling, ATP, MODELS. 


\section{SUMÁRIO}

1. INTRODUÇÃO

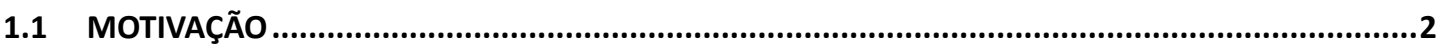

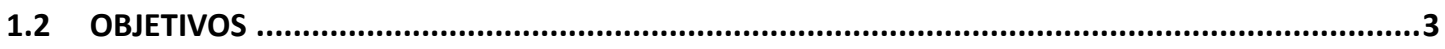

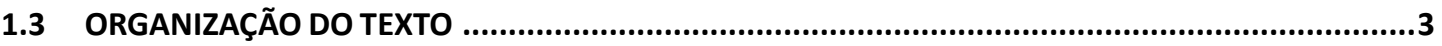

2. ESTADO DA ARTE DA MODELAGEM DE RELÉS EM SOFTWARES DO TIPO EMTP..........................4

3. FUNDAMENTOS DA PROTEÇÃO DIFERENCIAL DE ALTA IMPEDÂNCIA DE BARRAMENTOS ........10

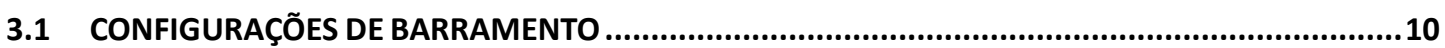

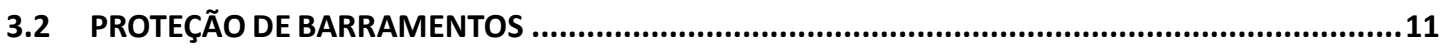

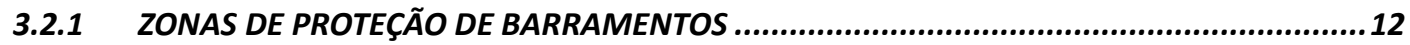

3.3 TRANSFORMADORES DE CORRENTE (TCS) ..............................................................................13

3.4 BARRAMENTO SIMPLES E O ESQUEMA DA PROTEÇÃO DIFERENCIAL DE ALTA IMPEDÂNCIA......15

3.5 OPERAÇÃO DO RELÉ DIFERENCIAL DE ALTA IMPEDÂNCIA DE BARRAMENTO ............................17

3.5.1 CONDIÇÃO NORMAL DE CARGA E DE FALTAS EXTERNAS SEM SATURAÇÃO DOS TCS ......19

3.5.2 CONDIÇÃO DE FALTA EXTERNA COM SATURAÇÃO DOS TCS...........................................20

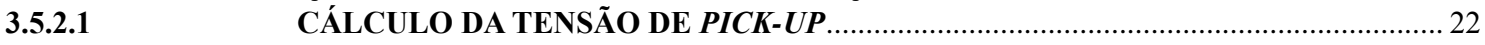

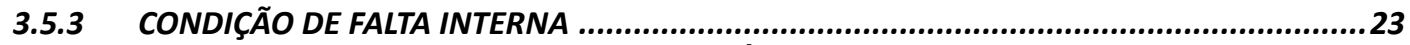

3.5.3.1 SENSIBILIDADE DA CORRENTE MÍNIMA ……………………………………......... 24

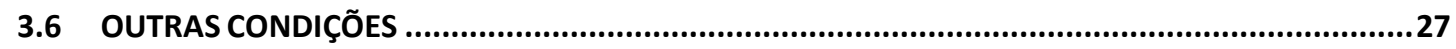

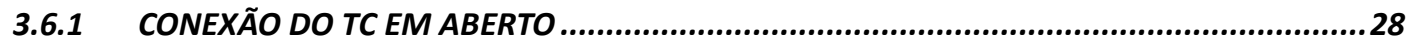

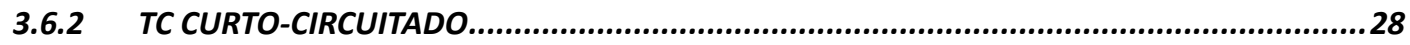

3.7 INFORMAÇÕES RELEVANTES ACERCA DA PROTEÇÃO DIFERENCIAL DE ALTA IMPEDÂNCIA DE BARRAMENTOS . .30

4. MODELAGEM DA PROTEÇÃO DIFERENCIAL DE ALTA IMPEDÂNCIA DE BARRAMENTOS NO ATP

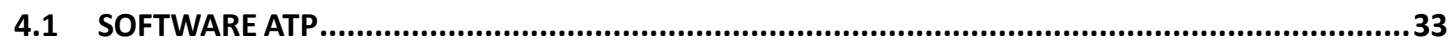

4.2 MODELS ...................................................................................................................................35

4.3 MODELO DO RELÉ DIFERENCIAL DE ALTA IMPEDÂNCIA DE BARRAMENTO ...............................36

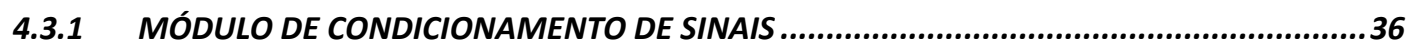

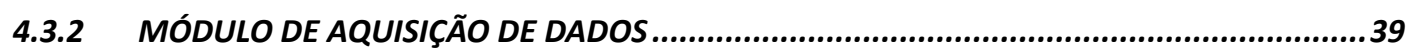

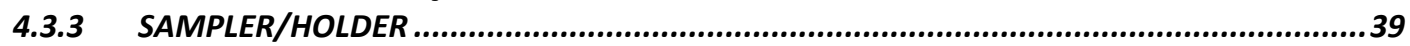

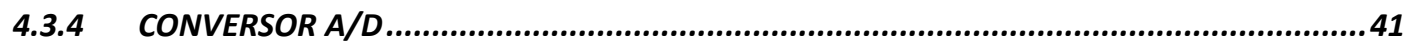

4.3.5 ESTIMAÇÃO DE FASORES .......................................................................................... 42

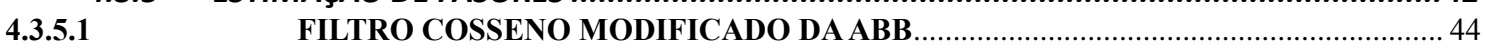

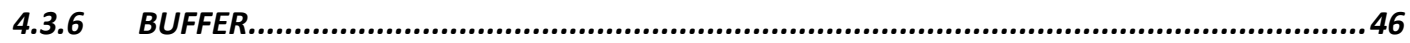

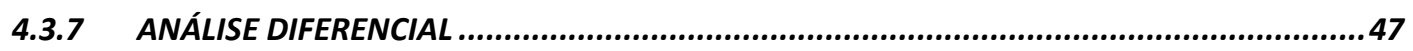

4.4 DISJUNTOR

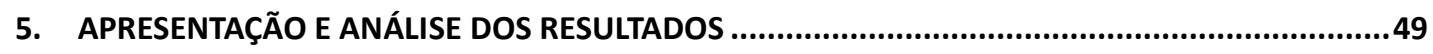

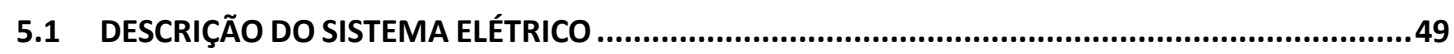

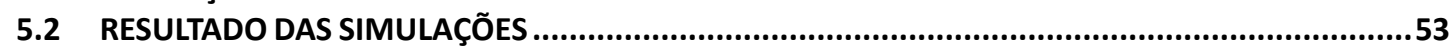

5.2.1 CASO 1: CURTO-CIRCUITO MONOFÁSICO FRANCO NA FASE A NO BARRAMENTO - ZONA

1

5.2.2 CASO 2: CURTO-CIRCUITO TRIFÁSICO EM UM PONTO IMEDIATAMENTE A FRENTE DO TC

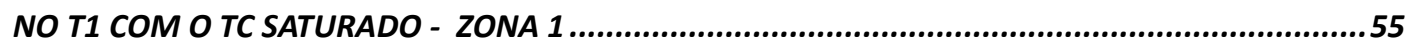

5.2.3 CASO 3: CURTO-CIRCUITO TRIFÁSICO NO BARRAMENTO NA PRESENÇA DE

MANUTENÇÃO DO DISJUNTOR DA LT1 - ZONA 1 .....................................................................57

5.2.4 CASO 4: CURTO-CIRCUITO NO BARRAMENTO COM O TC DA LT 1 CURTO-CIRCUITADO -

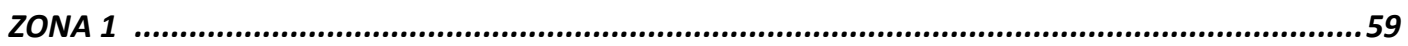

5.2.5 CASO 5: CURTO-CIRCUITO MONOFÁSICO NA FASE A NA LT1 EM UM PONTO

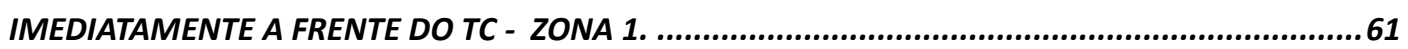

5.2.6 CASO 6: CURTO-CIRCUITO TRIFÁSICO NO BARRAMENTO - ZONA 2 ............................63 
5.2.7 CASO 7: CURTO-CIRCUITO TRIFÁSICO NA LT 4 EM UM PONTO IMEDIATAMENTE A FRENTE

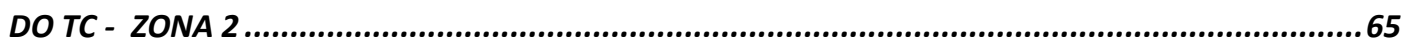

6. CONCLUSÕES E PROPOSTAS DE TRABALHOS FUTUROS....................................................68

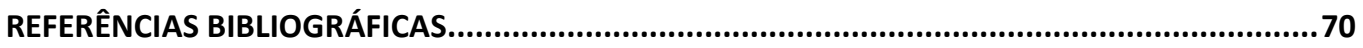

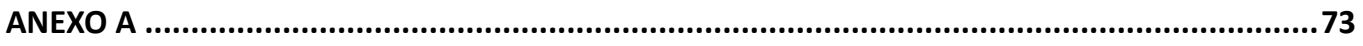

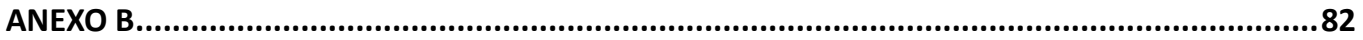




\section{LISTA DE FIGURAS}

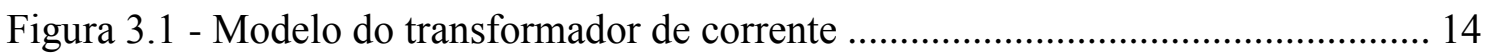

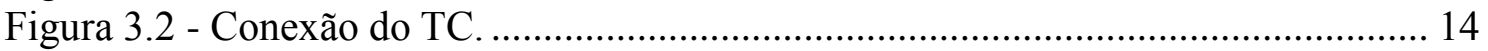

Figura 3.3 - Conexão em paralelo dos TCs e ilustração dos componentes internos a um

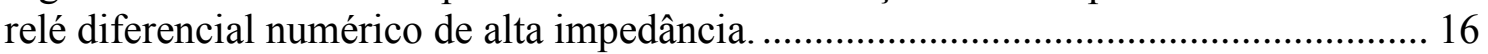

Figura 3.4 - Característica tensão (V) x corrente (I) do MOV....................................... 18

Figura 3.5 - Fluxo de corrente para condição normal de carga e falta externa sem

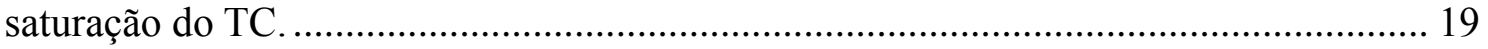

Figura 3.6 - Circuito equivalente de TCs em paralelo para condição normal de carga e de falta externa sem saturação do TC do circuito defeituoso. ......................................... 20

Figura 3.7 - Fluxo de corrente para uma falta externa à barra..................................... 21

Figura 3.8 - Circuito equivalente de TCs em paralelo para condição de falta externa à

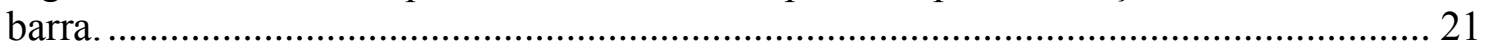

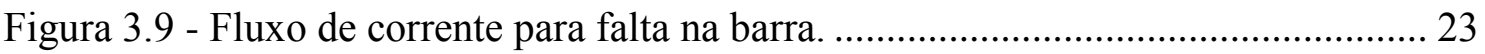

Figura 3.10 - Circuito equivalente para condição de falta na barra................................ 24

Figura 3.11 - Curva medida e publicada da caracterísitica da corrente de excitação de um TC da classe C200, 1200/5 com $\mathrm{V}_{\text {pick-up }}$ igual a $100 \mathrm{~V}$ [21] ............................... 25

Figura 3.12 - Curva medida e publicada da característica da corrente de excitação de um TC da classe C200, 1200/5 com $\mathrm{V}_{\text {pick-up }}$ igual a $100 \mathrm{~V}$ [21] ................................... 26

Figura 3.13 - Fluxo de corrente para o caso de TC em aberto. ...................................... 28

Figura 3.14 - Fluxo de corrente para o caso de TC curto-circuitado.............................. 29

Figura 3.15 - Disjuntor com terminais aterrado. ....................................................... 29

Figura 3.16 - Conexão dos TCs no relé diferencial de alta impedância de barramento,

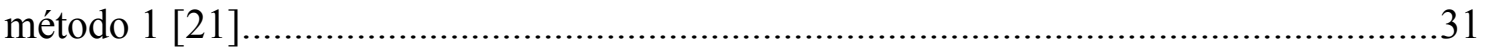

Figura 3.17 - Conexão dos TCs no relé diferencial de alta impedância de barramento,

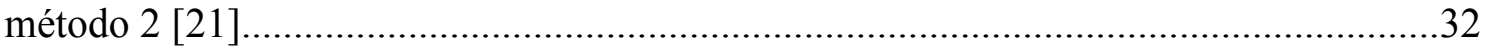

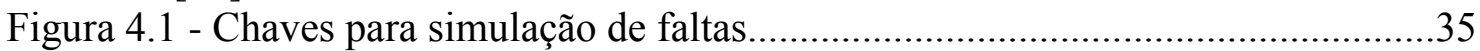

Figura 4.2 - Modelo do relé diferencial de alta impedância de barramento.................... 36

Figura 4.3 - Resposta em frequência do filtro Butterworth...........................................37

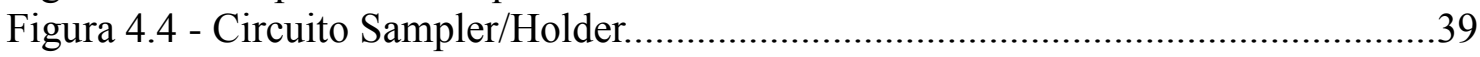

Figura 4.5 - Saídas do conversor A/D e do Sampler/Holder...........................................42

Figura 4.6 - Processo de janelamento de um sinal de corrente.....................................42

Figura 5.1 - Diagrama unifilar do sistema elétrico simulado.....................................50

Figura 5.2 - Característica fluxo x corrente dos transformadores. a) T1. b) T2 ..............51

Figura 5.3 - Esquema de ligação da proteção diferencial de alta impedância de

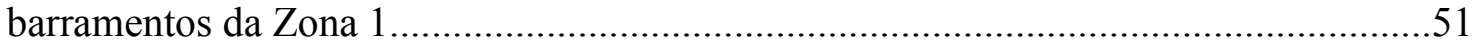

Figura 5.4 - Zona 1. Tensão nos terminais do relé quando de um curto-circuito monofásico franco na fase A no barramento: (a)Fase A. (b)Fase B. (c)Fase C................54 Figura 5.5 - Zona 2. Tensão nos terminais do relé quando de um curto-circuito monofásico franco na fase A no barramento: (a)Fase A. (b)Fase B. (c)Fase C................55 Figura 5.6 - Zona 1. Tensão nos terminais do relé quando de um curto-circuito trifásico em um ponto imediatamente a frente do TC no T1 com o TC saturado: (a)Fase A.

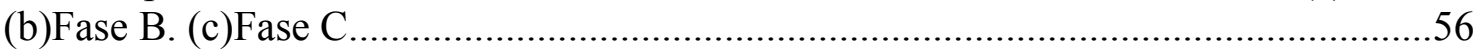

Figura 5.7 - Zona 2. Tensão nos terminais do relé quando de um curto-circuito trifásico em um ponto imediatamente a frente do TC no T1 com o TC saturado: (a)Fase A.

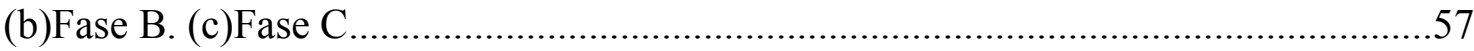
Figura 5.8 - Zona 1. Corrente no secundário do TC da LT 1 (a) Fase A, B e C. Tensão nos terminais do relé quando na manutenção do Disjuntor da LT1: (b)Fase A. (c)Fase B. 
(d)Fase C

Figura 5.9 - Zona 2. Tensão nos terminais do relé quando na manutenção do Disjuntor da LT1: (a)Fase A. (b)Fase B. (c)Fase C..

Figura 5.10 - Zona 1. Tensão nos terminais do relé quando de um curto-circuito trifásico no barramento com o TC da LT1 curto-circuitado: (a)Fase A. (b)Fase B. (c)Fase C. 60

Figura 5.11 - Zona 2. Tensão nos terminais do relé quando de um curto-circuito trifásico no barramento com o TC da LT1 curto-circuitado: (a)Fase A. (b)Fase B. (c)Fase C......

Figura 5.12 - Zona 1. Tensão nos terminais do relé quando de um curto-circuito monofásico na Fase A na LT1 em um ponto imediatamente a frente do TC: (a)Fase A. (b)Fase B. (c)Fase C. 62

Figura 5.13 - Zona 2. Tensão nos terminais do relé quando de um curto-circuito monofásico na Fase A na LT1 em um ponto imediatamente a frente do TC: (a)Fase A. (b)Fase B. (c)Fase C. 63

Figura 5.14 - Zona 1. Tensão nos terminais do relé quando de um curto-circuito trifásico no barramento: (a)Fase A. (b)Fase B. (c)Fase C. 64

Figura 5.15 - Zona 2. Tensão nos terminais do relé quando de um curto-circuito trifásico no barramento: (a)Fase A. (b)Fase B. (c)Fase C. .65 Figura 5.16 - Zona 1. Tensão nos terminais do relé quando de um curto-circuito trifásico na LT 4 em um ponto imediatamente a frente do TC: (a)Fase A. (b)Fase B. (c)Fase C..66 Figura 5.17 - Zona 2. Tensão nos terminais do relé quando de um curto-circuito trifásico na LT 4 em um ponto imediatamente a frente do TC: (a)Fase A. (b)Fase B. (c)Fase C..67 


\section{LISTA DE TABELAS}

Tabela 3.1 - Cargas nominais e tensões máximas para TCs de proteção [Norma da

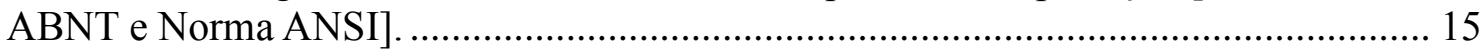

Tabela 4.1 - Parâmetros do filtro Butterworth. .................................................................. 37

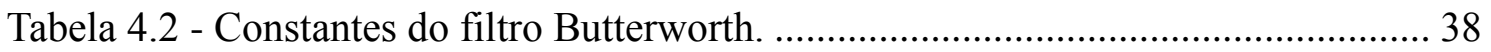

Tabela 5.1 - Parâmetros dos transformadores............................................................ 51

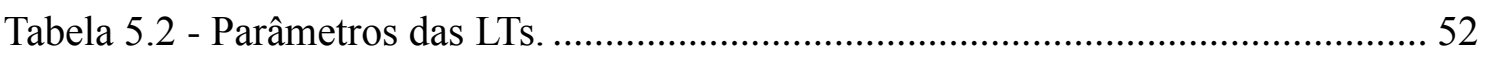

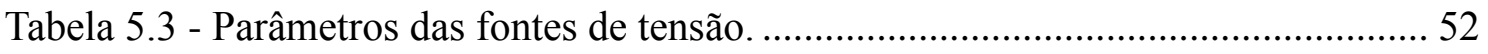

Tabela 5.4 - Contribuições de corrente no barramento................................................ 52

Tabela 5.5 - Contribuições de corrente no barramento................................................ 52

Tabela 5.6 - Casos de curtos-circuitos no sistema elétrico simulado ............................ 53 


\section{LISTA DE QUADROS}

Quadro 4.1 - Código do Modelo - MODEL Filtragem Analógica................................. 38

Quadro 4.2 - Código do Modelo - MODEL Sampler/Holder. ....................................... 40

Quadro 4.3 - Código do Modelo - MODEL Conversor A/D ......................................... 43

Quadro 4.4 - Código do Modelo - MODEL Estimação de Fasores................................ 45

Quadro 4.5 - Código do Modelo - MODEL Buffer....................................................... 46

Quadro 4.6 - Código do Modelo - MODEL Disjuntor..................................................... 48 


\section{LISTA DE SÍMBOLOS}

$N_{1} \quad$ Números de espiras dos enrolamentos primário do transformador de corrente.

$\mathrm{N}_{2} \quad$ Números de espiras dos enrolamentos secundário do transformador de corrente.

$I_{1} \quad$ Corrente primária do transformador de corrente.

$I_{2} \quad$ Corrente secundária do transformador de corrente.

RTC Relação de transformação do transformador de corrente.

$\boldsymbol{I}_{1 \mathrm{n}} \quad$ Valor da corrente nominal primária.

$\boldsymbol{I}_{2 n} \quad$ Valor da corrente nominal secundária.

$\boldsymbol{I}_{\mathbf{1}, \boldsymbol{m a ́ x}} \quad$ Corrente máxima no primário do transformador de corrente.

$I_{2, \text { máx }} \quad$ Corrente máxima no secundário do transformador de corrente.

$\boldsymbol{V}_{\boldsymbol{m a ́ x}} \quad$ Máxima tensão admissível no secundário do transformador de corrente.

$\boldsymbol{Z}_{\text {burden }}$ Valor de carga nominal do relé conectada ao secundário do transformador de corrente.

$I_{\mathbf{8 7}} \quad$ Soma das correntes nos secundários dos transformadores de corrente.

50 Unidade de sobrecorrente instantânea.

51 Unidade de sobrecorrente temporizada.

$\widehat{I}_{n} \quad$ Fluxo de corrente.

$\widehat{I}_{T}^{\prime} \quad$ Fluxo de corrente resultante dos circuitos 1,2 e 3.

$\hat{I}_{1} \quad$ Fluxo de corrente no circuito 1 .

$\hat{I}_{2} \quad$ Fluxo de corrente no circuito 2.

$\hat{I}_{3} \quad$ Fluxo de corrente no circuito 3 .

$\widehat{I}_{4} \quad$ Fluxo de corrente no circuito 4 .

$V_{R} \quad$ Magnitude do fasor tensão nos terminais do relé.

$\boldsymbol{k} \quad$ Igual a 1 para faltas trifásicas e 2 para faltas monofásicas.

$\boldsymbol{R}_{\boldsymbol{l}} \quad$ Resistência do cabo no secundário do transformador de corrente.

$\hat{I}_{f} \quad$ Máxima corrente de falta, no secundário do transformador de corrente.

$\boldsymbol{R}_{T C} \quad$ Resistência do enrolamento do secundário do transformador de corrente.

$\boldsymbol{V}_{\text {pick-up }}$ Tensão de pick-up.

$\boldsymbol{V}_{\boldsymbol{R}, \boldsymbol{m a x}}$ Máxima tensão $\boldsymbol{V}_{\boldsymbol{R}}$ para curtos-circuitos externos.

$I_{\text {min }} \quad$ Mínima corrente de sensibilidade.

$I_{e x}$ Soma das correntes de excitação dos transformadores de corrente.

$I_{\text {mov }} \quad$ Corrente através do MOV.

$\boldsymbol{R}_{\boldsymbol{s}} \quad$ Resistência de estabilização.

$I_{\operatorname{min100}}$ Mínima corrente de sensibilidade para $100 \mathrm{~V}$.

$I_{\text {min200 }}$ Mínima corrente de sensibilidade para $200 \mathrm{~V}$.

$I_{\text {ex100 }}$ Corrente de excitação para $100 \mathrm{~V}$.

$I_{\text {ex } 200}$ Corrente de excitação para $200 \mathrm{~V}$.

$\boldsymbol{H}(\boldsymbol{s}) \quad$ Função de transferência do filtro analógico. 
$\boldsymbol{T}_{\boldsymbol{a m o s t r a !}}$ Taxa de amostragem.

$\boldsymbol{f}_{\boldsymbol{s}} \quad$ Frequência de amostragem.

$\boldsymbol{f}_{0} \quad$ Frequência fundamental.

$\boldsymbol{P}_{\text {amostra! }}$ Período de amostragem.

Res Resolução do conversor A/D.

$Y \quad$ Valor de pico aceito pelo conversor A/D.

b Numero de bits da palavra binária

$\boldsymbol{Z}_{\mathbf{1 0}} \quad$ Valor quantizado.

RON Função de arredondamento para o inteiro mais próximo.

INT Função de truncamento.

$\boldsymbol{x} \quad$ Entrada do conversor A/D.

Res Resolução do conversor A/D.

PF Número em ponto flutuante.

$\boldsymbol{x}(\boldsymbol{t}) \quad$ Sinal cujo fasor está sendo estimado.

$\boldsymbol{Y}_{\mathbf{0}} \quad$ Componente DC da série de Fourier.

$\boldsymbol{Y}_{\boldsymbol{c n}} \quad$ Coeficiente do cosseno da série de Fourier.

$\boldsymbol{Y}_{\boldsymbol{s n}} \quad$ Coeficiente do seno da série de Fourier.

$\boldsymbol{n}$ N-ésima harmônica do sinal.

f Frequência do sinal.

$T \quad$ Período do sinal $x(t)$.

w Frequência angular.

$\boldsymbol{A}_{\boldsymbol{n}} \quad$ Coeficientes da série compacta de Fourier.

$\varphi_{n} \quad$ Fase dos termos da série compacta de Fourier.

$\boldsymbol{Y}_{\boldsymbol{c 1}} \quad$ Parte real do fasor estimado pelo algoritmo de Fourier de um ciclo.

$\boldsymbol{Y}_{\boldsymbol{s 1}} \quad$ Parte imaginária do fasor estimado pelo algoritmo de Fourier de um ciclo.

$N \quad$ Número de amostras por ciclo.

$\boldsymbol{A}_{1} \quad$ Amplitude do fasor estimado pelo algoritmo de Fourier de um ciclo.

$\boldsymbol{\varphi}_{1} \quad$ Fase do fasor estimado pelo algoritmo de Fourier de um ciclo.

$\boldsymbol{C}_{1} \quad$ Coeficiente do filtro cosseno modificado.

$\boldsymbol{C}_{2} \quad$ Coeficiente do filtro cosseno modificado.

$\boldsymbol{x}_{\boldsymbol{k}} \quad$ Amostra de $x(t)$ para $k$-ésima posição da janela de dados.

$\widehat{\boldsymbol{X}}_{1} \quad$ Fasor estimado para algoritmo do filtro cosseno modificado.

$Z_{f o} \quad$ Impedância do equivalente de Thévenin de sequência zero.

$Z_{f 1} \quad$ Impedância do equivalente de Thévenin de sequência positiva.

$Z_{0} \quad$ Impedância por quilômetro das linhas de transmissão de sequência zero.

$Z_{1} \quad$ Impedância por quilômetro das linhas de transmissão de sequência positiva.

$Y_{O} \quad$ Admitância por quilômetro das linhas de transmissão de sequência zero.

$Y_{1} \quad$ Admitância por quilômetro das linhas de transmissão de sequência positiva.

$\boldsymbol{V}_{\mathbf{3} \boldsymbol{\phi}} \quad$ Tensão nos terminais do relé, para curto-circuito trifásico externo. 
$\boldsymbol{V}_{\mathbf{1 \phi}} \quad$ Tensão nos terminais do relé, para curto-circuito monofásico externo.

$\widehat{\boldsymbol{I}}_{L T 1,3 \phi}$ Contribuição de corrente na barra para curto-circuito trifásico na linha de transmissão 1.

$\widehat{I}_{L T 2,3 \phi}$ Contribuição de corrente na barra para curto-circuito trifásico na linha de transmissão 2.

$\widehat{\boldsymbol{I}}_{T \mathbf{1}, 3 \phi} \quad$ Contribuição de corrente na barra para curto-circuito trifásico no transformador 1.

$\widehat{\boldsymbol{I}}_{T I E, 3 \phi}$ Contribuição de corrente na barra para curto-circuito trifásico no tie.

$\widehat{\boldsymbol{I}}_{L T 2,1 \phi}$ Contribuição de corrente na barra para curto-circuito monofásico na linha de transmissão 3.

$\widehat{\boldsymbol{I}}_{\boldsymbol{L T 3 , 1 \phi}}$ Contribuição de corrente na barra para curto-circuito monofásico na linha de transmissão 4.

$\widehat{I}_{T 2,1 \phi}$ Contribuição de corrente na barra para curto-circuito monofásico no transformador 2.

$\widehat{I}_{T I E, 1 \phi}$ Contribuição de corrente na barra para curto-circuito monofásico no tie. 


\section{CAPÍTULO 1}

\section{INTRODUÇÃO}

O ascendente consumo por energia elétrica no mundo atual levam os sistemas de energia a operar próximos dos seus limites. Embora esta expansão possa refletir o aquecimento econômico e a melhoria da qualidade de vida, possui aspectos negativos. Um deles é a possibilidade do esgotamento dos recursos utilizados para a produção de energia. Outro é o impacto do meio ambiente produzido por esta atividade. Finalmente, um terceiro são os elevados investimentos exigidos na pesquisa de novas fontes e construção de novas usinas.

As usinas de geração de energia elétrica, geralmente, são construídas em locais afastados dos grandes centros urbanos. Desta forma a eletricidade necessita percorrer longas distâncias até chegar aos grandes centros consumidores o que exige um sistema de transmissão e distribuição longo e complexo, apoiado em uma estrutura de planejamento, operação e manutenção.

As faltas em sistemas elétricos de potência caracterizam-se como condições anormais de sua operação, que provocam desligamentos não programados de seus componentes. Elas são decorrentes de problemas de naturezas diversas, tais como mecânica, elétrica e térmica. Os principais problemas mecânicos são causados pela ação do vento, corrosão, erosão e arborização. Os de natureza elétrica, por sua vez, são provocados por falha de isolamento, descargas atmosféricas e surtos de chaveamento. Por outro lado, os de natureza térmica são ocasionados por sobrecorrentes em consequência de sobrecarga no sistema elétrico [1].

Dentre todas as faltas que podem ocorrer em um sistema elétrico de potência, destacam-se as que ocorrem nos barramentos das subestações. Embora as faltas nesses componentes sejam raras, aproximadamente 5\% segundo [2], seus efeitos são bastante danosos ao sistema, não raro podendo leva-lo à instabilidade em virtude do grande número de desconexões de componentes do sistema a fim de extingui-las.

Nesse sentido, justifica-se a utilização de modernos sistemas de proteção de barramentos, a fim de garantir a segurança, confiabilidade e continuidade do fornecimento da energia elétrica. 
No que concerne à proteção de barramentos, dois tipos de técnicas são largamente empregadas, a saber: proteção diferencial de baixa impedância e proteção diferencial de alta impedância. As denominações baixa e alta impedância dizem respeito ao valor da impedância que o relé impõe ao ser conectado em série com secundário dos transformadores de corrente (TCs).

A escolha da técnica a ser empregada para a proteção de um barramento é baseada, principalmente, no seu tipo de arranjo. De fato, em arranjos que possibilitem uma grande variação de topologias, tradicionalmente, é empregada a proteção diferencial de baixa impedância, enquanto que em barramentos cujos arranjos têm uma topologia fixa, historicamente é utilizada a proteção diferencial de alta impedância. Isto evita manobras de chaveamento dos circuitos secundários dos TCs, que podem produzir elevadas tensões nos terminais dos enrolamentos secundários e assim danificá-los. Contudo, a proteção diferencial de baixa impedância tem sido largamente empregada em subestações de menor porte, mesmo que configurem topologia fixa por ser uma proteção mais viável economicamente. Este tipo de proteção apresenta vantagens em relação à proteção diferencial de alta impedância sobretudo por conta da flexibilidade de instalação de forma distribuída, que admite a inserção de demais vãos aos barramentos.

\subsection{MOTIVAÇÃO}

Estudos relativos à proteção de sistemas elétricos são feitos constantemente. Objetiva-se manter o bom funcionamento dos sistemas elétricos de potência, a preservação da segurança de seus equipamentos e o suprimento de energia aos consumidores de forma satisfatória. Faltas decorrentes de falhas humanas, vandalismos ou fenômenos da natureza podem causar blackouts de energia de grandes proporções, trazendo grandes prejuízos financeiros à economia do país. Nesse sentido, tais defeitos devem ser eliminados de forma rápida e seletiva pelo sistema de proteção.

Os barramentos, componentes fundamentais do sistema elétrico, são responsáveis pela conexão de vários componentes em um mesmo nível de tensão.

A proteção diferencial de alta impedância de barramentos é empregada, tipicamente, em SEs com tensão nominal igual ou superior a $500 \mathrm{kV}$, nas quais o arranjo de barramento é geralmente o de disjuntor e meio. Esse tipo de arranjo possui uma topologia fixa, o que evita manobras de chaveamento de circuitos secundários de TCs, pelo fato de que a proteção diferencial de alta impedância requerer que os TCs tenham 
seus enrolamentos secundários conectados fisicamente em paralelo. De fato, esse tipo de proteção ainda é bastante usada em SEs de $500 \mathrm{kV}$ do Sistema Interligado Nacional (SIN), o que serviu de motivação para a realização do presente trabalho.

\subsection{OBJETIVOS}

O objetivo dessa dissertação de mestrado é apresentar a modelagem e a simulação de um relé diferencial numérico microprocessado no ATP (Alternative Transients Program), a fim de avaliar o seu desempenho quando aplicado na proteção diferencial de alta impedância de barramentos frente às mais diversas situações de operação às quais o sistema elétrico está constantemente sujeito.

Os objetivos específicos deste projeto são:

- Modelar e simular a proteção diferencial de alta impedância de barramentos utilizando a linguagem MODELS do ATP;

- Avaliar o desempenho da proteção de barramentos para diferentes situações de operação às quais o sistema elétrico está sujeito;

\subsection{ORGANIZAÇÃO DO TEXTO}

No Capítulo 2, é apresentado o estado da arte de simulações e avaliações da proteção utilizando softwares do tipo EMTP;

No Capítulo 3, é apresentada a fundamentação teórica da proteção diferencial de alta impedância aplicada aos barramentos de SEs.

No Capítulo 4, é descrita a modelagem do sistema de potência no ATP, a saber: modelos que constituem o relé individualmente e o modelo do disjuntor. Os códigos que foram utilizados na simulação são apresentados ao longo do capítulo.

No Capítulo 5, inicialmente é descrito o sistema elétrico que será analisado e seus respectivos parâmetros e dispositivos com a implementação da proteção. As diversas simulações para curto-circuito no barramento, na linha e em um ponto próximo ao TC localizado na linha são apresentadas e posteriormente analisadas. Desta forma, a proteção diferencial de alta impedância de barramentos pode ser avaliada, de modo a verificar suas vantagens e desvantagens.

No Capítulo 6, são apresentadas as conclusões obtidas a partir da análise dos resultados obtidos. São apresentadas também algumas propostas de trabalhos futuros, visando complementar e melhorar o presente estudo. 


\section{CAPÍTULO 2}

\section{ESTADO DA ARTE DA MODELAGEM DE RELÉS EM SOFTWARES DO TIPO EMTP}

Os relés de proteção são destinados a detectar anormalidades de operação no sistema elétrico de potência (SEP) que excedam limites toleráveis e realizar ações corretivas que reestabeleçam as condições normais do mesmo. Desta forma, através da análise das grandezas elétricas, por exemplo, tensão e corrente, os relés fornecem a lógica necessária para a tomada de decisão pelo SEP. Eles sofreram uma evolução considerável em seus aspectos construtivos, dimensionais e operacionais passando pelos relés eletromecânicos até chegarem aos modernos relés numéricos microprocessados. $\mathrm{O}$ avanço da tecnologia direcionada a obtenção de melhorias na medição, supervisão e controle foi fundamental na modernização dos relés. Além de minimizar os efeitos dos curtos-circuitos e outras condições de anormalidade do sistema elétrico de potência, os relés são capazes de estimar o tipo de falha que esta ocorrendo no sistema, como também sua localização.

Os relés numéricos microprocessados concentram uma diversidade de funções em um único equipamento. São altamente confiáveis, uma vez que apresentam algoritmos de autodiagnostico, o qual possibilita uma verificação contínua em seu hardware e software de modo a detectar possíveis falhas em seus componentes isentando a possibilidade de desligamentos periódicos para testes de confiabilidade.

Algumas importantes características dos relés numéricos microprocessados são:

- Auto-monitoramento: permite que o relé averigue constantemente a existência de defeitos de hardware e software e emita mensagens de alerta ao operador, aumentando a confiabilidade do dispositivo.

- Integração Digital: permite a comunicação com diversos dispositivos possibilitando acesso remoto e esquemas elaborados de proteção.

- Programabilidade: permite a programação de diversas tarefas com a função simultânea de medição, monitoramento e controle.

- Flexibilidade: integração de diversas funções em um único equipamento.

A modelagem de relés em softwares do tipo EMTP (Eletromagnetic Transients Program), se faz presente em estudos de análise em frequência, estudos de curto- 
circuito, estudos de regime transitório, análise de harmônicos, análises estatísticas, entre outros, voltados para a proteção de sistemas elétricos. Estes tipos de softwares possibilitam a simulação em malha fechada (do inglês closed-loop simulation), sendo possível, portanto, analisar o comportamento do sistema elétrico diante da atuação de sua proteção. Contudo, não se apresenta na literatura registros contendo a modelagem e simulação da proteção diferencial de barramentos em softwares do tipo EMTP.

Encontra-se presente na literatura diversos trabalhos relacionados com o estudo de demais tipos proteção que utilizam softwares do tipo EMTP juntamente com rotinas implementadas em linguagens de programação como C, C++ e FORTRAN.

O ATP, concebido em 1984 por iniciativa de W. Scott Meyer e Tsu-Huei Liu, consiste em uma versão alternativa do EMTP. O programa utiliza o método de integração trapezoidal na solução de equações diferenciais dos elementos do sistema elétrico no domínio do tempo. Adicionalmente, são utilizadas as funções DBM (Data Base Modularization) e as rotinas TACS (Transient Analysis of Control Systems) e a MODELS. Através do ATP, é possível a modelagem de não-linearidades, de elementos a parâmetros concentrados e distribuídos, transformadores, TCs, entre outros.

A TACS é uma rotina utilizada no software ATP para a análise de sistemas de controle no domínio do tempo. Elaborada originalmente para a simulação de sistemas de excitação de máquinas síncronas e do comando de chaveamento de conversores usados em HVDC (High Voltage DC Transmission), permite atualmente uma gama de funções dentre elas o controle do sistema elétrico por meio de comando de operação de chaves, ou ainda a criação de fontes de tensão ou nó, fontes de corrente e elementos não lineares.

A MODELS, uma linguagem descritiva, se utiliza de módulos independentes de decomposição e algoritmos genéricos na representação de sistemas variantes no tempo, o que simplifica a representação de sistemas complexos.

Muito embora, atualmente, a modelagem de sistemas de proteção utilizando a TACS esteja obsoleta, haja vista as facilidades introduzidas pela linguagem MODELS, as primeiras pesquisas em modelagens de relés foram feitas utilizando a TACS. Isso ocorreu por volta do início da década de 1980, quando o uso do EMTP para a simulação de transitórios eletromagnéticos em sistemas de potência passou a ganhar mais popularidade, começando a substituir o uso dos TNAs (Transient Network Analysers), que eram uma ferramenta tradicional da época para esta finalidade [3].

Alguns dos trabalhos presentes na literatura voltados aos estudos de proteção 
utilizando softwares do tipo EMTP para a modelagem de rede de sistemas de potência são apresentados neste capítulo.

Em [4], os autores apresentam detalhes de uma interface implementada em FORTRAN em conjunto com a rotina TACS do EMTP. O trabalho foi motivado pelo fato de a TACS possuir limitações como o número de funções lógicas e a dificuldade de modelar tarefas cíclicas. Apresentam a flexibilidade da linguagem FORTRAN na modelagem de controles digitais. Fornecem resultados satisfatórios que confirmam as vantagens da utilização das rotinas através de simulações de um modelo de controle digital HVDC para os componentes do sistema elétrico como compensadores estáticos, relés. A interface foi projetada sem que houvesse atraso de tempo entre as rotinas TACS e as sub-rotinas em FORTRAN.

Em [5], os autores exibem a modelagem e a validação do relé BDD15B da GE em software do tipo EMTP visando à proteção diferencial de transformadores. Uma vantagem do modelo é permitir ao usuário a configuração do relé. $\mathrm{O}$ modelo apresentado fornece a característica percentual da proteção e a restrição por harmônicos. São detalhados ao longo do trabalho os diversos componentes do relé. A validação foi feita para um circuito R-L com um TC alimentando o relé a partir de testes realizados no simulador do sistema de potência do American Eletric Power Company. A alimentação do relé era oriunda da variação da resistência, da indutância, do instante de falta e de ajustes na tensão do circuito em análise. Os resultados obtidos foram satisfatórios.

Em [6], os autores apresentam o incremento de transformadores para instrumento e relés a um sistema de proteção no EMTP. Foram desenvolvidos e incorporados ao EPRI / DCG EMTP Versão 2.0 modelos de TCs e TPCs que apresentavam limitações quando na sua resposta em frequência. Os parâmetros dos TCs e TPCs podem ser definidos pelo usuário. Para permitir a simulação de algoritmos do relé, toda a capacidade do FORTRAN foi adicionada ao EMTP. Além disso, foram criadas subrotinas para a transferência de variáveis entre os modelos e a TACS, de forma a se obter uma simulação em malha fechada.

Em [7], é apresentado pelos autores a modelagem de um relé eletromecânico de sobrecorrente instantâneo do tipo plunger através do EMTP/ATP utilizando a TACS. Foram apresentadas características mecânicas e magnéticas implementadas na TACS e elétricas implementadas no ATP através de modelos matemáticos simples que possibilitam o estudo de respostas dinâmicas do relé de sobrecorrente. Estas respostas dinâmicas foram, então, incorporadas a uma análise transitória do sistema elétrico. Os 
autores apresentam, por fim, uma comparação das simulações do modelo com testes realizados em um simulador do sistema elétrico e observam que os resultados são influenciados, mesmo que suavemente, por componentes DC. Mas, ao combinar o DC offset com a saturação de TC, obteve-se uma atuação atrasada.

Em [8], um modelo de transformador trifásico é apresentado pelos autores para o cálculo de transitórios eletromagnéticos voltados para o estudo da proteção diferencial O ATP/EMTP foi a ferramenta utilizada pelos autores para a simulações de diversos tipos de situações na qual o sistema elétrico esta sujeito, quais sejam: falhas internas, energização do transformador e remoção de faltas externas a zona de proteção. Foi representado no software um sistema radial composto por um gerador, uma linha de transmissão, um transformador de 25 MVA $138 / 13.8 \mathrm{kV}$, e uma carga. A partir da modelagem do transformador foram obtidas as correntes e seus conteúdos harmônicos e verificou-se sua interação com os diversos componentes do sistema. Foram também obtidas diferentes formas de onda para diferentes tempos de abertura e fechamento de chaves no sistema em análise demonstrando que é de suma importância modelar corretamente o transformador voltado à proteção.

A implementação de um relé de distância a partir da MODELS no ATP pode ser observada em [9]. Os autores apresentam uma simplificação dos procedimentos necessários à simulação de um relé de distância utilizando uma única estrutura de modelagem. A técnica utilizada consiste em integrar o sistema de potência ao sistema de proteção em um único módulo. O objetivo do trabalho consiste em fornecer conceitos sobre a modelagem de relés digitais utilizando modelos em malha fechada dentro da MODELS de modo a facilitar a compreensão de conceitos básicos de relé de distância a alunos de graduação, pós-graduação, estudantes e novos engenheiros. Foram modelados os filtros anti-aliasing, de remoção da componente DC e de extração da componente fundamental, além da própria função de distância. Os diversos estudos de casos abordaram desde faltas monofásicas e bifásicas até a variação do ponto e ângulos de incidência da falta.

Os autores em [10] analisam os antigos e atuais modelos do relé. Apresentam as informações necessárias à construção e validação dos diversos modelos. Demonstram que a quantidade de detalhes necessários para a representação de um relé é determinada pelo objetivo no qual seu modelo será utilizado e que estes modelos possuem limitações. Descrevem diversos tipos de modelos de relé, incluindo modelos genéricos e modelos detalhados. 
Em [11], é apresentada uma nova abordagem para simulação de proteção interativa, ou seja, o sistema de potência é modelado no software ATP, enquanto a MODELS e modelos externos do relé são feitos em $\mathrm{C}++$. Isto permite uma modelagem simples e menos limitada do relé orientada a objeto, bem como a construção de uma interface perfeita entre o modelo de rede do sistema de potência e o modelo do relé. O relé presente no sistema simulado possui as funções de proteção de fase, distância de neutro, sobrecorrente instantânea de fase e sobrecorrente instantânea de neutro. A partir dos resultados obtidos pelos autores, verifica-se uma considerável flexibilidade e facilidade da abordagem utilizada.

Em [12], o desempenho de um esquema de proteção aplicado a uma linha de 230 $\mathrm{kV}$ de três terminais alimentadas por três barramentos foi avaliado através da simulação utilizando o EMTP. Diversos esquemas de proteção de distância foram considerados na modelagem dos relés digitais. O EMTP se mostra uma ferramenta imprescindível que permite a identificação de limitações na aplicabilidade destes esquemas de proteção. Foram simulados casos de corrente de infeed e outfeed de modo a verificar as limitações de esquemas de proteção antes mesmo de serem utilizados em campo.

Em [13], os autores apresentam a modelagem através do software ATP de um sistema elétrico visando analisar o comportamento da operação de transformadores de potência em paralelo. Diversas condições de operação foram simuladas como faltas internas entre espiras e entre fases, externas e de energização solidária dos transformadores presentes no sistema. A partir dessas condições, dois relés digitais comerciais aplicados à proteção primária de transformadores foram avaliados. Estabeleceram, para tanto, um arranjo experimental em laboratório contendo ambos os relés, um simulador, um relógio GPS e um microcomputador. No caso de energização solidária é produzida uma corrente que flui para os demais equipamentos do sistema e gera um fluxo CC que se sobrepõe ao fluxo CA norma de magnetização que causa correntes de magnetização de magnitudes elevadas nos transformadores vizinhos. Os resultados mostram que pode haver operação indevida dos relés digitais em condições de paralelismo. Os autores afirmam que a operação pode ser causada pela forma de como cada fabricante utiliza os componentes harmônicos para realizar a restrição.

Uma metodologia para a obtenção de um ambiente interativo de simulação para a realização de análises de sistemas de proteção é apresentada em [14]. As ferramentas utilizadas, derivadas do EMTP/ATP e da linguagem de programação ANSI C, possibilitam estudos de coordenação e analises pós falta. Um relé de distância foi 
modelado através de modelos externos (do inglês foreign models). $\mathrm{O}$ autor demonstra como podem ser utilizados arquivos no formato COMTRADE no estudo realizado. Sinais de tensão e corrente correspondentes a eventos reais são utilizados como entradas na implementação do relé. Os sinais de disparo, assim como os demais componentes do relé, foram testados usando um sistema teste de referência do Power System Relaying Committee da PES-IEEE e os sinais de faltas reais do Sistema Elétrico Interligado da Colômbia. Os resultados obtidos verificam que a metodologia proposta é eficaz para desenvolver componente ou elemento de controle dentro de um sistema elétrico que necessite ser simulado no EMTP/ATP.

O desenvolvimento de um novo algoritmo visando melhorar o desempenho da proteção diferencial de transformadores, a partir da lógica Fuzzy e transformada de Clarke, é apresentado pelos autores em [15]. Foi modelado um sistema de potência através do software ATP objetivando obter as condições de operação e de falta suficientes para testar o algoritmo criado. Os enrolamentos dos transformadores foram particionados para a simulação de faltas internas. A validação do novo algoritmo foi feita comparando os resultados obtidos com um relé comercial.

Os procedimentos necessários para descrever componentes indispensáveis à simulação de relés digitais de proteção são apresentados em [16]. Tais componentes possuem a função de medição, supervisão e controle dos sistemas de potência. Inúmeras funções são modeladas, como por exemplo, componentes simétricas, componentes de sequencia zero, positiva e negativa, entre outros. Apresentando os procedimentos para o desenvolvimento de componentes para uso em simulações no ATP, busca facilitar aos leitores a análise e o estudo dos fenômenos no qual o sistema elétrico está propicio e a parametrização de relés de proteção.

Já em [17], é apresentada a modelagem e simulação da proteção diferencial de linhas de transmissão através do ATP e do ambiente MODELS através de um sistema de potência onde estão presentes uma linha de transmissão de $180 \mathrm{~km}$ e dois equivalentes de Thévenin. O tempo de envio de dados entre relés foi considerado. Os resultados podem ser apresentados através de duas ferramentas gráficas: o plano operacional e o plano alfa. Porém foram apresentados no plano alfa uma vez que este plano pode definir regiões que caracterizam certas condições do sistema que não se pode definir pela análise do plano operacional. A modelagem realizada permite a simulação em malha fechada em que é possível avaliar o desempenho do sistema a partir das diversas situações de operação em que o sistema pode se submeter. 


\section{CAPÍTULO 3}

\section{FUNDAMENTOS DA PROTEÇÃO DIFERENCIAL DE ALTA IMPEDÂNCIA DE BARRAMENTOS}

O funcionamento inadequado do sistema de proteção de barramentos pode comprometer toda a integridade do sistema elétrico de potência. De fato, ele deve ser capaz de diferenciar situações anormais de curto-circuito. Deve ser capaz, se necessário, de desconectar rápida e apropriadamente a parte defeituosa do sistema, com o intuito de evitar que distúrbios se propagem para outras partes não defeituosas do sistema.

De acordo com os Procedimentos de Rede do Operador Nacional do Sistema Elétrico (ONS) [18], o tempo total de eliminação de faltas, incluindo o tempo de operação do sistema de proteção do barramento, dos relés auxiliares e o tempo de abertura dos disjuntores, não deve ser superior a100 ms, para barramentos de tensões nominais iguais ou superiores a $345 \mathrm{kV}$ e a $150 \mathrm{~ms}$ para os níveis de tensão nominal inferiores a $345 \mathrm{kV}$.

O esquema de proteção é projetado para monitorar o sistema elétrico de potência continuamente, a fim de assegurar a máxima continuidade de suprimento de energia com mínimos danos aos equipamentos, à vida e à propriedade [19].

Barramento são os nervos centrais em um sistema de potência, onde vários circuitos de um mesmo nível de tensão estão conectados [20]. Os barramentos, ou simplesmente barras, são elementos da subestação que representam um nó em um circuito elétrico. São constituídas por cabos ou tubulações de alumínio ou cobre.

\subsection{CONFIGURAÇÕES DE BARRAMENTO}

Há uma série de considerações na concepção de uma barra [20]:

- Requisitos de confiabilidade em termos de continuidade de serviço para o barramento comum todo ou para um elemento essencial da rede alimentado a partir do barramento;

- Considerações operacionais em termos de manutenção de equipamentos e flexibilidade de manobras na rede;

- Restrições econômicas e ambientais; 
- Requisitos de seccionamento para evitar a falha excessiva do disjuntor e ciclos operacionais;

- Facilidade de futuras expansões dos barramentos.

É essencial compreender as configurações de barramentos antes de escolher um esquema de proteção adequado para uma dada configuração de barra. As configurações mais tipicamente encontradas em barramentos de SEs são apresentadas a seguir:

- Barra simples.

- Barra simples seccionada.

- Barra principal e de transferência.

- Barra dupla e disjuntor duplo

- Barra disjuntor e meio.

- Barra disjuntor e um terço.

- Barra dupla e disjuntor simples a 4 chaves.

- Barra dupla e disjuntor simples a 5 chaves.

- Barra em anel seccionada.

\subsection{PROTEÇÃO DE BARRAMENTOS}

O esquema de proteção utilizado na barra depende tanto do grau de importância da SE, quanto do porte da mesma. De acordo com o primeiro critério, podem ser empregados, tipicamente, três esquemas de proteção:

- Proteção temporizada feita pela $2^{\mathrm{a}}$ zona de relés de distância, ou pela proteção de retaguarda de sistemas tradicionais de proteção.

- Proteção de distância local com recuo para cobrir também a barra.

- Proteção diferencial para a própria barra. Usada em barras mais importantes.

E de acordo com o porte da $\mathrm{SE}$, os esquemas de proteção utilizados são, tipicamente, os seguintes:

- Proteção diferencial de barras com relés de sobrecorrente;

- Proteção diferencial de barras com relé diferencial percentual;

- Proteção diferencial de baixa impedância de barras;

- Proteção diferencial de alta impedância de barras;

- Proteção diferencial de barras com relés de sobrecorrente direcional;

- Proteção diferencial de barras com acopladores lineares. 
O monitoramento elétrico de um barramento pode ser realizado, essencialmente, de três formas distintas:

- $\quad 1^{\text {a }}$ Lei de Kirchhoff - a soma das correntes entrando e saindo nos nós de um circuito deve ser nula;

- Análise da tensão e corrente no barramento;

- Carregamento existente.

Um esquema de proteção diferencial, independente do tipo de relé utilizado, simplesmente compara a corrente de entrada no barramento com a corrente de saída. Qualquer diferença na corrente de entrada e saída da barra, acima de algum limiar prédeterminado, é uma indicação de uma falha na barra que deve ser isolada rapidamente. Relés diferenciais de barras executam essa função por detectar uma corrente diferencial e envia um trip para os disjuntores diretamente associados com a barra, a fim de extinguir a falta [21].

\subsubsection{ZONAS DE PROTEÇÃO DE BARRAMENTOS}

A zona de proteção de barramento é um conceito muito importante, no que diz respeito à detecção e eliminação de faltas.

Em relação à detecção, a zona de proteção é definida através da localização dos TCs em torno do barramento. Já em relação à eliminação, uma vez que já foi detectada a falha, a zona de proteção é definida pela localização dos disjuntores que se encontram próximos ao barramento.

As zonas são projetadas de forma a cobrir todo o esquema para que não haja pontos cegos, ou seja, pontos nos quais se ocorrer uma falta, a proteção possa vir a não atuar. Entretanto, por razões técnicas e econômicas, muitas vezes admite-se a existência de zonas de pontos cegos, para as quais são utilizadas funções de proteção especiais, a fim de garantir o bom funcionamento do sistema de proteção como um todo.

Com exceção da configuração de barramento com arranjo em anel, cada barramento presente em uma subestação, deve possuir pelo menos um conjunto independente de proteção unitária ou restrita, ou seja, o sistema de proteção existente deve detectar e eliminar, seletivamente e sem retardo de tempo intencional, falhas que ocorram somente no componente protegido, a saber, o barramento.

A função 50 do relé de sobrecorrente tem por objetivo eliminar a falta 
instantaneamente. Como normalmente os barramentos estão nas entradas, esta função é raramente utilizada, pois para falta em uma das saídas, desligam-se todos os circuitos.

Para diferenciar faltas na barra e nos alimentadores, lança-se mão da proteção 87B, diferencial de barra, que opera instantaneamente, desde que a falta esteja dentro da zona de proteção definida entre os TCs de entrada e de saída .

A proteção diferencial de barramento deve atuar de forma rápida e seletiva para faltas dentro da zona de proteção e não deve também operar para faltas fora de zona de proteção ou manobras feitas voluntariamente, como, por exemplo, manobra de transferências de vãos entre barras. Deve também permitir o monitoramento dos TCs.

\subsection{TRANSFORMADORES DE CORRENTE (TCs)}

Os TCs têm por finalidade principal reduzir a intensidade da corrente primária do sistema a níveis adequados no seu secundário, para que estas possam ser lidas pelos relés de proteção e outros dispositivos de medição e controle. O modelo do TC é mostrado na Figura 3.1.

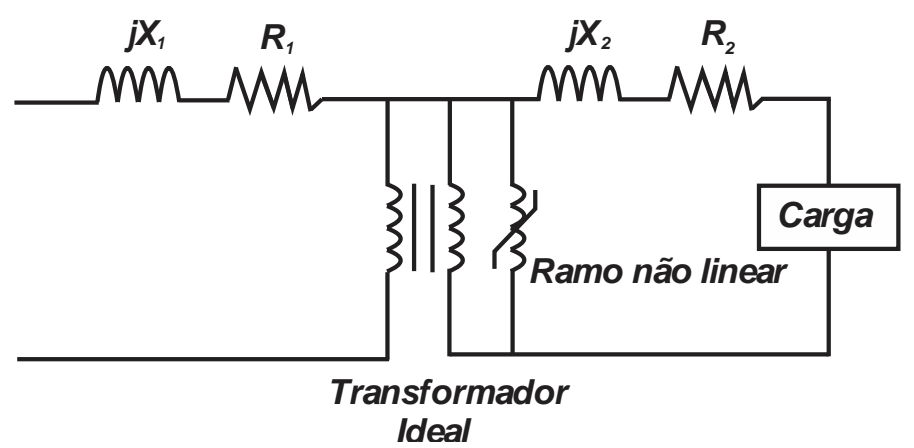

Figura 3.1 - Modelo do transformador de corrente

No sistema de potência, o enrolamento primário do TC é conectado em série com o circuito do qual se pretende medir a corrente. Os TCs utilizados para a proteção de barramentos são, tipicamente, instalados após o disjuntor de cada circuito, conforme ilustrado na Figura 3.2. 


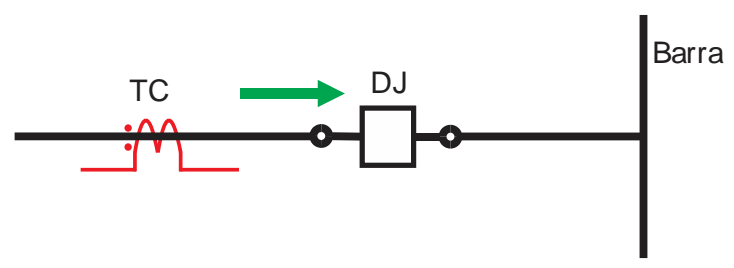

Figura 3.2 - Conexão do TC.

Considerando-se um TC ideal, a relação ampéres-espiras do seu enrolamento primário é igual à magnitude da relação ampéres-espiras do seu enrolamento secundário:

$$
N_{1} I_{1}=N_{2} I_{2}
$$

Na qual $N_{1}$ e $N_{2}$ representam os números de espiras dos enrolamentos primário e secundário, enquanto que $I_{1}$ e $I_{2}$ representam as suas correntes.

A relação de transformação do TC pode então ser definida por:

$$
R T C=\frac{N_{2}}{N_{1}}=\frac{I_{1 n}}{I_{2 n}}
$$

A corrente secundária nominal é normalizada ou em 5 A (normas ANSI, ABNT e IEC) ou em 1 A (norma IEC).

O TC pode ser de alta reatância, tipo A de acordo com a ABNT, ou tipo T de acordo com a norma ANSI, que se refere à Tested. Neste tipo de TC o fluxo de dispersão influencia de maneira significativa na relação de transformação do TC. O TC também pode ser de baixa reatância, tipo B (ABNT) ou tipo $\mathrm{C}$ do termo Calculated (ANSI). Diferentemente do TC de alta reatância, nesse tipo de TC, a influência do fluxo de dispersão na sua relação de transformação é desprezível. Assim, em um TC do tipo C, a impedância primária e a reatância secundária são desprezíveis, devendo ser considerada, além do ramo de magnetização, apenas a resistência do seu enrolamento secundário na sua modelagem [22].

Segundo os padrões ANSI, a corrente simétrica máxima no primário do TC para proteção deve ser 20 vezes o valor da corrente nominal, sendo este o denominado fator de sobrecorrente (FS). Pela ABNT, o FS pode assumir valores iguais a 5, 10, 15, 20. Contudo, a tendência no Brasil é também utilizar FS igual a 20 [23]:

$$
I_{1, m a ́ x}=20 I_{1 n}
$$


A partir da equação acima, pode-se encontrar o valor da corrente máxima no secundário do TC, quando da circulação em seu primário da máxima corrente simétrica admissível. No caso de se considerar a corrente nominal secundária de $5 \mathrm{~A}$, tem-se que:

$$
I_{2, \text { máx }}=\frac{I_{1, \text { máx }}}{R T C}=\frac{I_{1, \text { máx }}}{\frac{I_{1 n}}{I_{2 n}}}=\frac{20 I_{1 n}}{\frac{I_{1 n}}{5}}=100 \mathrm{~A}
$$

Assim, a máxima corrente simétrica admissível no secundário do TC é de $100 \mathrm{~A}$, de modo a garantir que seu erro de relação continue dentro da especificação de sua classe de exatidão.

Para cada valor de carga nominal do relé $\left(Z_{\text {burden }}\right)$ que pode ser conectada ao secundário do TC, é obtido um valor para a máxima tensão admissível em seu secundário:

$$
V_{\text {máx }}=Z_{\text {burden }} \cdot 100(V)
$$

As cargas nominais são definidas pela norma ANSI como B-X, sendo X o valor da impedância em ohms e pela norma da ABNT como C-Y, sendo Y o valor da potência aparente do TC. Na Tabela 3.1, podem ser visualizados os dados referentes às cargas nominais tipicamente utilizadas para TCs de proteção.

Tabela 3.1 - Cargas nominais e tensões máximas para TCs de proteção [21].

\begin{tabular}{cccccccc}
\hline \multicolumn{3}{c}{ Cargas Nominais } & \multicolumn{5}{c}{$\mathrm{f}=60 \mathrm{~Hz}$ e I=5A } \\
\hline ABNT & ANSI & Potência Aparente $(\mathrm{VA})$ & $\mathrm{Cos}(\varphi)$ & $\mathrm{R}(\Omega)$ & $\mathrm{X}(\Omega)$ & $\mathrm{Z}(\Omega)$ & Tensão Máxima \\
\hline C25 & B-1 & 25 & 0,5 & 0,5 & 0,866 & 1 & 100 \\
C50 & B-2 & 50 & 0,5 & 1 & 1,732 & 2 & 200 \\
C100 & B-4 & 100 & 0,5 & 2 & 3,464 & 4 & 400 \\
C200 & B-8 & 200 & 0,5 & 4 & 6,928 & 8 & 800 \\
\hline
\end{tabular}

\section{$\begin{array}{lllllll}\text { 3.4 BARRAMENTO SIMPLES } & \text { E } & \text { O ESQUEMA } & \text { DA } & \text { PROTEÇÃO }\end{array}$ DIFERENCIAL DE ALTA IMPEDÂNCIA}

Os relés diferenciais de alta impedância de barramentos apresentam vantagens em relação aos demais relés nos quesitos velocidade, segurança e elevada quantidade de disjuntores que podem ser incluídos em sua zona de proteção.

A sistemática da proteção diferencial de alta impedância de barramentos será desenvolvida a partir de um sistema elétrico com barramento simples onde estão conectadas 4 linhas de transmissão cujo diagrama unifilar pode ser visualizado na Figura 3.3. 
Para realizar o fechamento da malha da proteção diferencial de alta impedância do sistema ilustrado na Figura 3.3, faz-se necessária a conexão física dos secundários dos TCs em paralelo. De fato, uma vez que a proteção é segmentada por fase, o secundário do TC da fase A da linha 1 deve ser conectado em paralelo com os secundários dos TCs da fase A das linhas 2, 3 e 4. O mesmo ocorre com os TCs das fases B e C de cada linha.

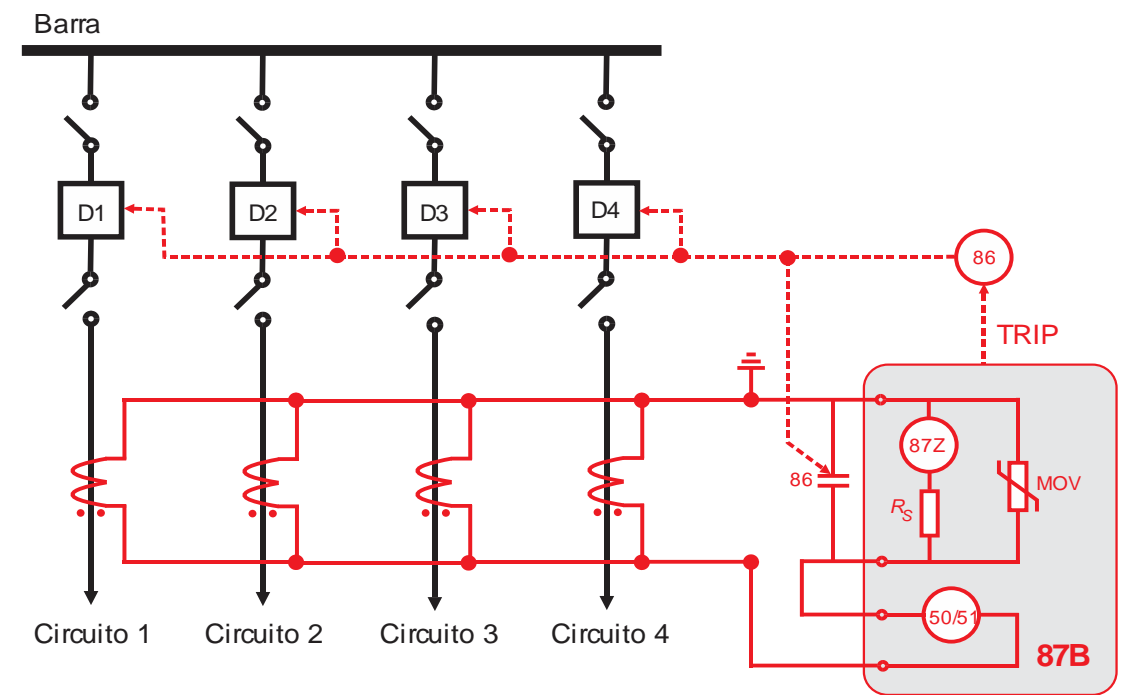

Figura 3.3 - Conexão em paralelo dos TCs e ilustração dos componentes internos a um relé diferencial numérico de alta impedância.

O termo alta impedância se refere à alta impedância imposta ao fluxo de corrente no secundário dos TCs. A fim de garantir que a soma vetorial das correntes secundárias que entram e saem da zona de proteção seja nula em condições normais de operação, os TCs devem ser conectados em paralelo e possuir a mesma relação de transformação e ligação de polaridade. $\mathrm{Na}$ presença de qualquer corrente diferencial é forçado um fluxo nas extremidades do relé provocando uma queda de tensão em seus terminais. O relé é ajustado para atuar baseado na tensão desenvolvida no relé, que deve ser superior ao valor pré-determinado da tensão de pick-up $\left(V_{\text {pick-up }}\right)$ sendo, portanto, extremamente sensível à corrente diferencial.

O termo pick-up se refere à tensão que deixa o relé em seu limite de operação, ou seja, a partir desse valor, o relé diferencial de alta impedância de barras envia um sinal de trip aos disjuntores para que estes possam abrir e desta maneira eliminar a falta. 


\subsection{OPERAÇÃO DO RELÉ DIFERENCIAL DE ALTA IMPEDÂNCIA DE BARRAMENTO}

Os elementos internos do relé diferencial de alta impedância de barras podem ser visualizados na Figura 3.3.

A alta impedância de entrada do relé é determinada por uma impedância interna, normalmente resistiva, de $2000 \mathrm{ohms}$, representada pelo elemento $R_{S}$, conhecido como resistor de estabilização. A proteção diferencial de alta impedância oferece imunidade à saturação do núcleo magnético do TC, desde que o resistor de estabilização do circuito tenha um valor suficientemente alto [24].

A característica da disposição dos TCs neste tipo de proteção limita o tipo de configuração de barramento a ser utilizada em uma subestação. Torna-se muito complexa sua utilização em barramentos com a topologia variável, pois seria necessário chaveamento dos circuitos secundários dos TCs. Assim, um único nó, referente à junção do conjunto dos TCs por fase é conectado ao resistor de estabilização $R_{S}$.

O elemento $87 \mathrm{Z}$, conectado em série com $R_{S}$, possui uma baixa impedância e é altamente sensível. Uma vez que a corrente que circula pelo ramo formado por esses dois componentes é muito baixa, o trip do relé de alta impedância passa a ser baseado na tensão em seus terminais. Assim, pode-se dizer que esse tipo de relé implementa a função diferencial de tensão. De fato, o relé é bastante sensível à corrente que passa por ele, de modo que na presença de curtos-circuitos na barra, uma queda de tensão de magnitude elevada surge devido ao resistor de estabilização.

É de suma importância verificar a ligação da polaridade dos TCs dispostos em paralelo, de forma que a soma das correntes nos secundários dos TCs vindas dos diferentes circuitos conectados à barra seja vetorialmente nula no caso de operação normal do sistema ou de curtos-circuitos externos sem a saturação do núcleo dos TCs, ou seja:

$$
I_{87}=\sum_{n=1}^{N} \hat{I}_{n}=0
$$

na qual $N$ é o número de linhas conectadas ao barramento.

O elemento varistor de óxido metálico, do inglês Metal Oxide Varistor - MOV é uma resistência não linear, que é disposta em paralelo com o ramo formado com a combinação em série do resistor de estabilização $R_{S}$ com o elemento $87 Z$ e tem a 
finalidade de prevenir que altas tensões danifiquem o relé e os TCs. A capacidade de absorção de energia do MOV deve ser suficiente para tolerar a energia liberada pelos TCs em paralelo por um período de vários ciclos. Nos piores casos, o disjuntor não consegue interromper a corrente de falta que pode continuar fluindo pelo circuito durante 20 a 30 ciclos. Alguns relés diferenciais de alta impedância oferecem MOVs capazes de absorver a energia liberada pelos TCs durante um longo período de tempo. Já outros conectam em paralelo aos ramos de alta impedância e do MOV um contato normalmente aberto de um relé de bloqueio 86 [21]. Esse contato, basicamente, serve como contato de selo que providenciará o bypass dos ramos de alta impedância e do MOV quando da detecção de um curto-circuito na barra. Assim, diminui-se o tempo de condução do MOV, podendo-se reduzir a sua capacidade de absorção do MOV e, consequentemente, suas dimensões e o seu custo. Uma curva característica tensão versus corrente de um MOV é mostrada na Figura 3.4.

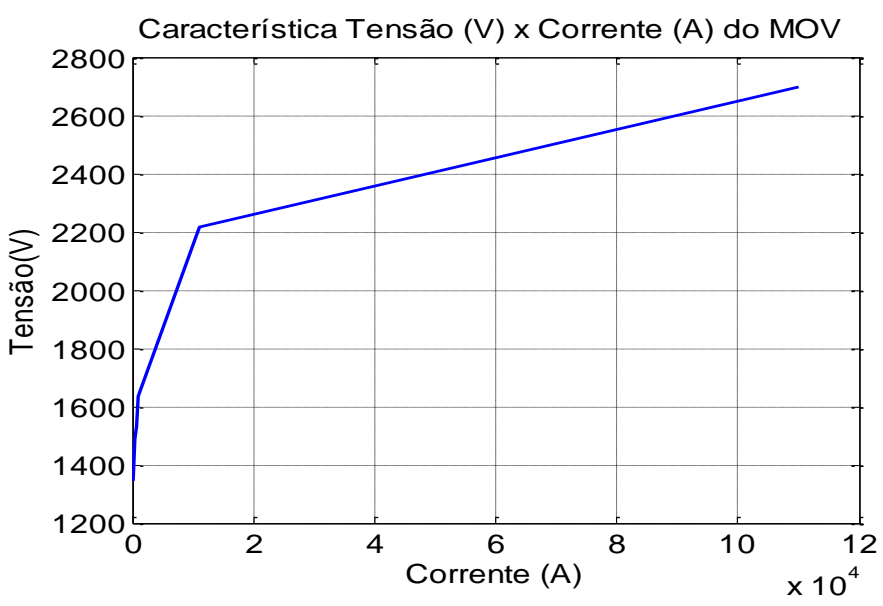

Figura 3.4 - Característica tensão (V) x corrente (I) do MOV.

Conectado em série, estão dispostos os relés de sobrecorrente instantâneo (50) e temporizado (51), que possuem a função de comandar a abertura de disjuntor, em condições anormais de operação do sistema que ocasionem correntes de magnitudes elevadas.

É necessário compreender quando na análise da proteção de sistemas elétricos a distinção entre as determinadas situações de operação do sistema:

- $\quad$ situação normal de funcionamento;

- situação anormal de funcionamento;

- $\quad$ situações de curto-circuito. 
Operações normais de funcionamento dizem respeito à operação do sistema com ausência de falhas nos equipamentos e faltas aleatórias. Em situações anormais, as falhas podem provocar distúrbios na rede elétrica, tais como oscilações de tensão, sem, contudo, apresentar elevações de corrente elétrica em termos de curto-circuito. Já as condições de curto-circuito, que são mais críticas, podem provocar desligamentos não programados dos componentes do sistema o que pode comprometer todo o sistema de geração, transmissão e distribuição de energia elétrica.

Será analisada, portanto, a atuação do relé diferencial de alta impedância frente às diferentes condições de operação que o sistema elétrico está sujeito.

\subsubsection{CONDIÇÃO NORMAL DE CARGA E DE FALTAS EXTERNAS SEM SATURAÇÃO DOS TCs}

O fluxo de corrente para condições normais de carga ou de faltas sem saturação dos TCs pode ser visualizado na Figura 3.5.

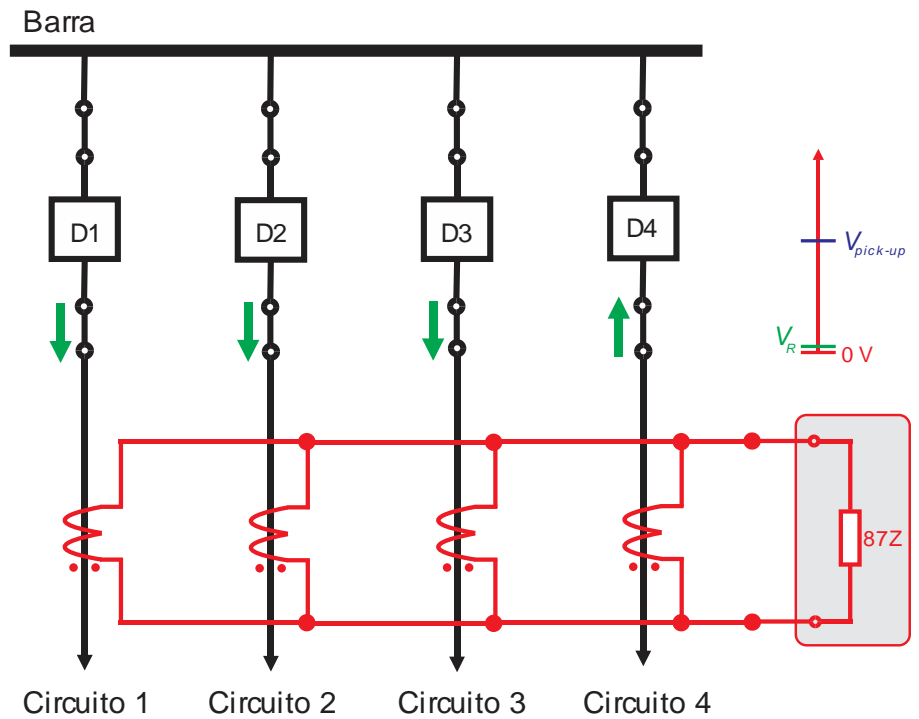

Figura 3.5 - Fluxo de corrente para condição normal de carga e falta externa sem saturação do TC.

Em condições normais de carga, considerando que todos os TCs possuem a mesma relação de transformação de modo a aproximar a performance destes, a corrente secundária resultante do paralelo dos TCs é aproximadamente zero, de modo que a corrente pelo elemento $87 \mathrm{Z}$ e, consequentemente, a tensão sobre o resistor de estabilização também serão aproximadamente zero. 
Na Figura 3.6, a fonte de corrente $\hat{I}_{T}^{\prime}$ para o TC A representa a soma das correntes secundárias de todos os TCs exceto um. A fonte de corrente $\hat{\mathrm{I}}_{4}$ do TC B representa a corrente que flui através do TC remanescente.

Na presença de faltas externas sem saturação dos TCs ou em condições normais de carga, a corrente que flui pelo TC A será igual a corrente que flui pelo TC B em módulo porém em sentido oposto. Desta maneira, a corrente somente fluirá pelos TCs, não fluindo, portanto, pelo relé diferencial de alta impedância e consequentemente não é criada uma tensão em seus terminais, independentemente da impedância interna do relé.

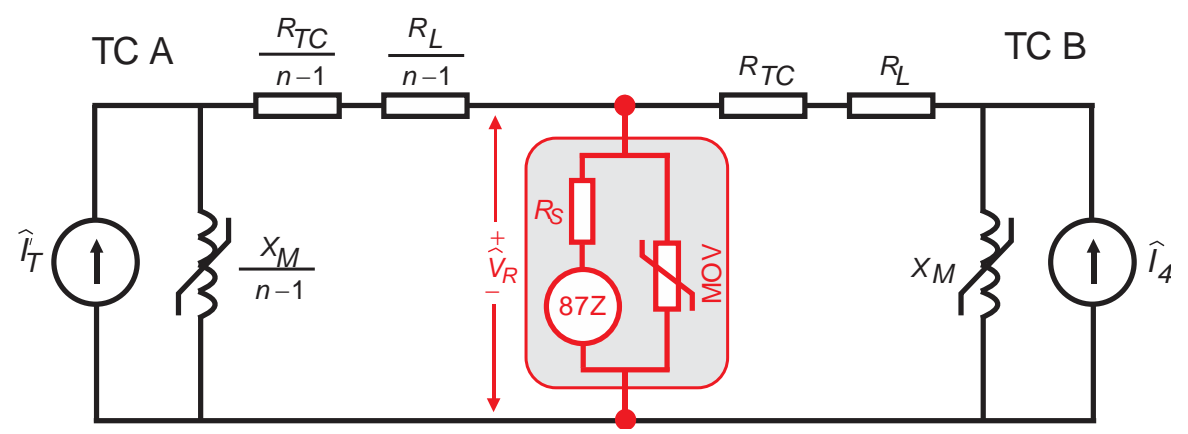

Figura 3.6- Circuito equivalente de TCs em paralelo para condição normal de carga e de falta externa sem saturação do TC do circuito defeituoso.

$$
\begin{gathered}
\hat{I}^{\prime}{ }_{T}=\hat{I}_{1}+\hat{I}_{2}+\hat{I}_{3} \\
\hat{I}^{\prime}{ }_{T}+\hat{I}_{4}=0 \\
\hat{V}_{R} \approx 0
\end{gathered}
$$

Uma vez que a tensão desenvolvida nos terminais do relé é inferior à tensão de pick-up, a proteção não atua.

\subsubsection{CONDIÇÃO DE FALTA EXTERNA COM SATURAÇÃO DOS TCS}

$\mathrm{Na}$ presença de falta externa, como visualizada na Figura 3.7, a corrente resultante do somatório das correntes dos circuitos 1,2 e 3 flui pelo TC do circuito 4 tornando-o mais propenso a saturar. 


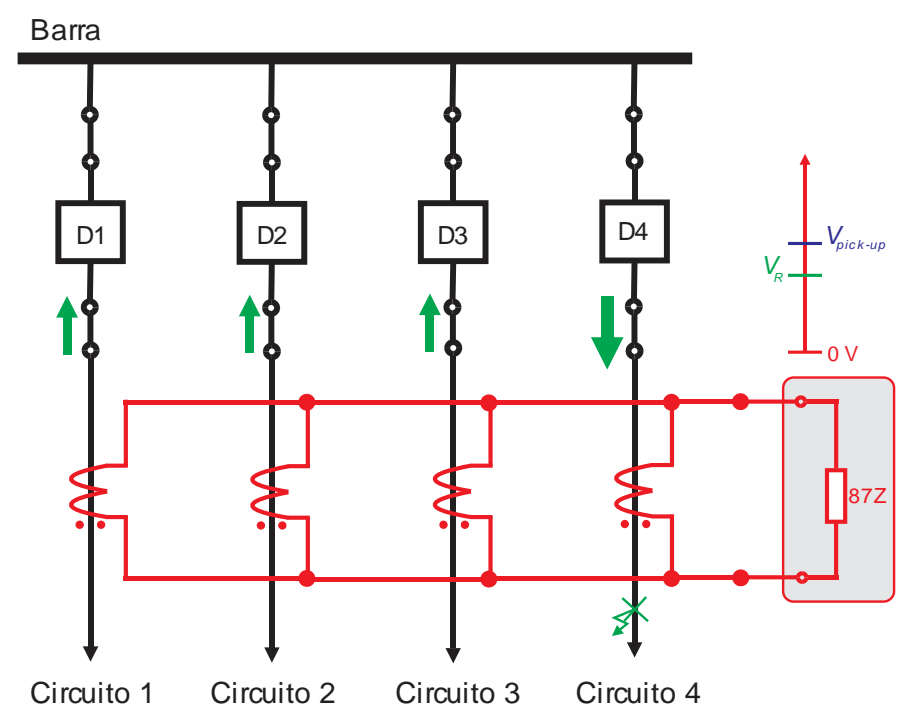

Figura 3.7 - Fluxo de corrente para uma falta externa à barra.

O limiar da tensão de pick-up do relé diferencial de alta impedância de barras deve ser ajustado considerando faltas externas onde o núcleo magnético do TC do circuito em falha esteja completamente saturado.

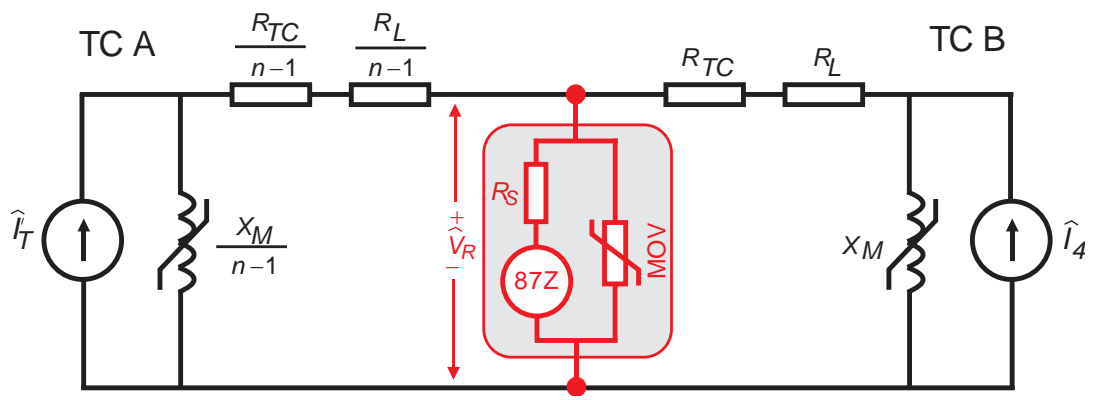

Figura 3.8 - Circuito equivalente de TCs em paralelo para condição de falta externa à barra.

Quando da presença de falta externa, o TCA na Figura 3.8 representa a combinação do paralelo de TCs 1, 2 e 3. O TCB representa o TC do circuito 4 que se encontra em falha. Nessa condição, o núcleo do TC do circuito 4 se torna mais propenso a saturar, uma vez que a corrente que passa por ele é muito maior que a dos demais TCs do esquema.

Uma vez que a resistência de estabilização $R_{S}$ é consideravelmente maior que as resistências do enrolamento e cabos no secundário do TC, a tensão $\widehat{V}_{R}$ através dos terminais do relé é a maior possível para o caso de falta externa.

A Figura 3.8 mostra o fluxo de corrente no barramento devido a uma falta externa no circuito 4 e a tensão $\widehat{V}_{R}$ desenvolvida nos terminais do relé. Verifica-se que esta tensão é inferior ao valor de pick-up o que não leva a proteção a atuar. 


\subsubsection{CÁLCULO DA TENSÃO DE PICK-UP}

As combinações entre corrente de falta e queda de tensão obtida nos terminais do relé para condição de falta externa devem ser analisadas para cada circuito conectado ao barramento central. Deve ser analisado, para o cálculo de $V_{\text {pick-up }}$, o curto-circuito externo à zona de proteção da barra mais severo, considerando a saturação total do núcleo magnético do TC do circuito sob defeito. Assim, garante-se a segurança da proteção contra faltas-externas. Desta forma, pode-se obter o valor da tensão $V_{R}$ :

$$
V_{R}=\left(R_{T C}+k R_{l}\right) \frac{\left|\hat{I}_{f}\right|}{R T C}
$$

na qual,

$R_{T C}$ é resistência do enrolamento do secundário do TC.

$k=1$ para faltas trifásicas e bifásicas e $k=2$ para faltas monofásicas.

$R_{l}$ é a resistência do cabo no secundário do TC.

$R T C$ é a relação de transformação dos TCs.

$\hat{I}_{f}$ é a máxima corrente de falta, no secundário do TC.

A obtenção da corrente $\hat{I}_{f}$ é feita a partir de simulações de curtos-circuitos trifásicos e monofásicos externos ao barramento. $\mathrm{O}$ seu valor corresponde ao somatório das correntes das linhas onde não ocorreu o curto. Por exemplo, considerando o curtocircuito na linha de transmissão 4, conforme visualizado na Figura 3.7, a corrente $\hat{I}_{f}$ é dada por:

$$
\hat{I}_{f}=\hat{I}_{1}+\hat{I}_{2}+\hat{I}_{3}
$$

Considerar-se-á para obter a tensão de pick-up a corrente de falta externa máxima que leve a saturação total do núcleo magnético do TC do circuito sob defeito obtida a partir da análise de curtos-circuitos trifásicos e monofásicos.

Para obter o valor de $V_{\text {pick-up }}$ é comum utilizar um fator de sobretensão de 1,5, de modo a garantir uma margem de segurança à proteção. Desta forma o valor de $V_{\text {pick-up }}$ é dado por:

$$
V_{\text {pick-up }}=1,5 V_{R, \max }
$$

Na qual, $V_{R, \max }$ é a máxima tensão obtida dentre as todas as tensões $V_{R}$ medidas no relé para os curtos-circuitos externos, considerando a saturação total do núcleo magnético do TC do circuito sob defeito. 
De modo a garantir uma atuação rápida e confiável para o caso de falta interna no barramento protegido é fundamental que a tensão do ponto de joelho dos transformadores de corrente seja pelo menos o dobro da tensão de ajuste $\left(V_{\text {pick-up }}\right)$ do relé diferencial de alta impedância de barramento.

\subsubsection{CONDIÇÃO DE FALTA INTERNA}

Durante uma falta interna ao barramento as correntes de todas as linhas se dirigem para o ponto de falta, conforme se pode visualizar na Figura 3.9. Desta forma as fontes de corrente primária dos quatro circuitos contribuem para a corrente resultante total.

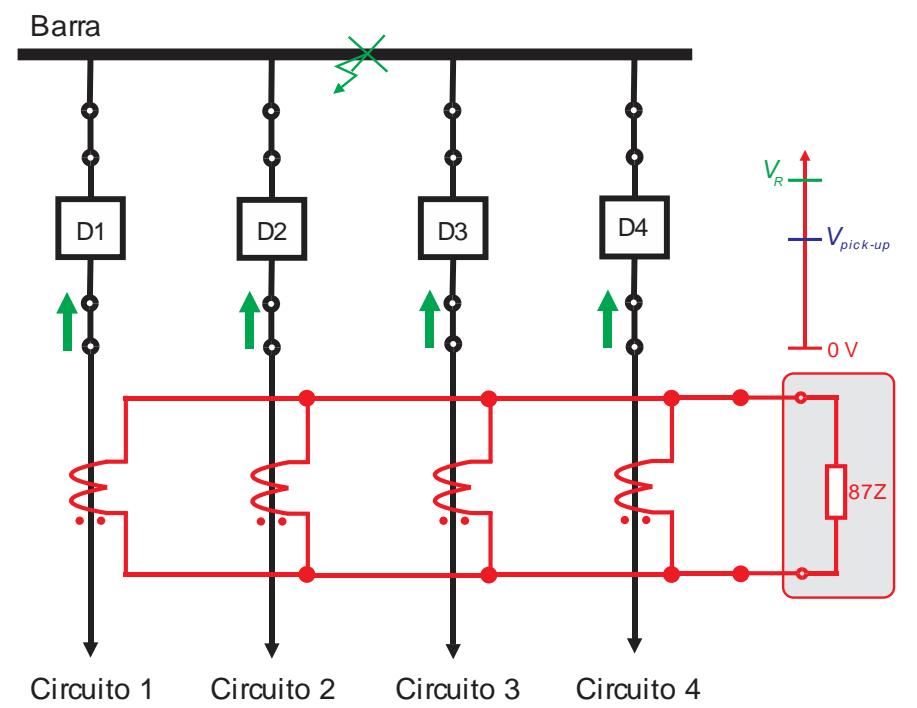

Figura 3.9 - Fluxo de corrente para falta na barra.

A corrente secundária total é forçada a fluir pelo relé diferencial de alta impedância de barramentos. A alta impedância interna presente no relé se assemelha ao comportamento de um circuito aberto aos TCs em paralelo. Este fato normalmente produziria altas tensões que podem ser prejudiciais e danosas ao relé, como também aos cabos de conexão. Para evitar esta situação, conecta-se em paralelo ao relé o MOV que grampeia altas tensões de pico a cada meio ciclo e garante a proteção do relé. Tipicamente, utilizam-se MOVs com tensões nominais de $1 \mathrm{kV}$ a $2 \mathrm{kV}$. 


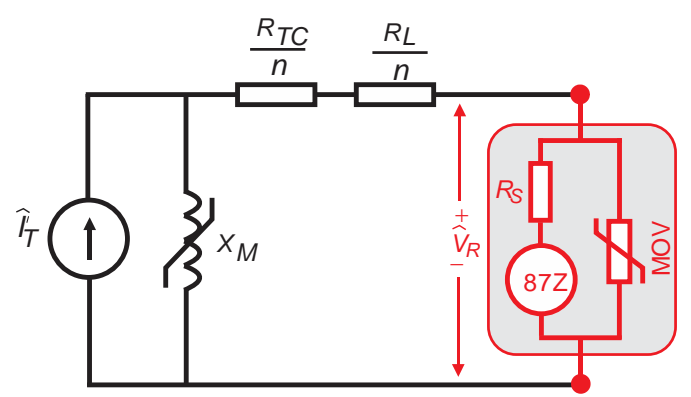

Figura 3.10 - Circuito equivalente para condição de falta na barra.

Uma proteção bem dimensionada e segura deve atuar somente na condição de falta interna de modo a garantir a segurança do sistema elétrico como um todo. Verificada uma falta interna onde a tensão obtida dos terminais do relé excede o valor da tensão de pick-up, o relé enviará um comando de trip aos disjuntores que abrirão seus contatos de modo a isolar o defeito.

\subsubsection{SENSIBILIDADE DA CORRENTE MÍNIMA}

Para o caso de falta interna, pode-se obter a corrente mínima de operação do relé desde que já esteja pré-determinado o valor da tensão de pick-up. $A$ sensibilidade da corrente primária mínima pode ser obtida da seguinte forma:

$$
I_{\text {min }}=\left(I_{\text {ex }}+I_{m o v}+\frac{V_{p i c k-u p}}{R_{s}}\right) R T C
$$

na qual,

$I_{\min }$ é a corrente mínima;

$I_{e x}$ é a soma das correntes de excitação do TCs;

$\frac{V_{p i c k-u p}}{R_{S}}$ é a corrente através do relé na tensão de ajuste, $V_{p i c k-u p}$;

$I_{m o v}$ é a corrente através do MOV na tensão de ajuste, $V_{\text {pick-up; }}$

$R T C$ é a relação de transformação do TC.

A corrente através do MOV é desprezível para tensões menores que a sua tensão nominal, assim o valor de $I_{\text {mov }}$ pode ser ignorado. Por outro lado, testes e simulações dos TCs podem ser realizados a fim de determinar os valores de $I_{\text {ex }}$ para obter a corrente mínima. Primeiramente, é necessário conhecer as informações das características de excitação de todos os TCs utilizados no esquema. É usual utilizar na implementação da proteção TCs da mesma classe de exatidão. Assim, uma única curva de excitação pode 
ser utilizada para determinar a corrente de excitação para todos os TCs do circuito.

As características de excitação de um TC podem variar para uma mesma classe de exatidão. Curvas de excitação publicadas por fabricantes podem ser genéricas para uma determinada classe de TC. Testes de excitação de TCs podem ser necessários para determinar com precisão o valor da corrente mínima.

Para fins de exemplificação da obtenção da corrente mínima, suponha que no sistema elétrico da Figura 3.3, sejam utilizados TCs da classe C200, com relação de transformação igual a 240 e que, inicialmente, a tensão de pick-up seja igual a $100 \mathrm{~V}$.

Serão obtidos os valores da corrente mínima a partir das curvas de excitação dos TCs publicadas por fabricantes e por curvas medidas. Estes valores serão comparados com os valores obtidos com testes de performance do circuito e verificada a validade dos mesmos.

A corrente de excitação medida é 0.0349 A e a corrente de excitação a partir da curva publicada é $0.0379 \mathrm{~A}$, dada a tensão de pick-up igual a $100 \mathrm{~V}$.

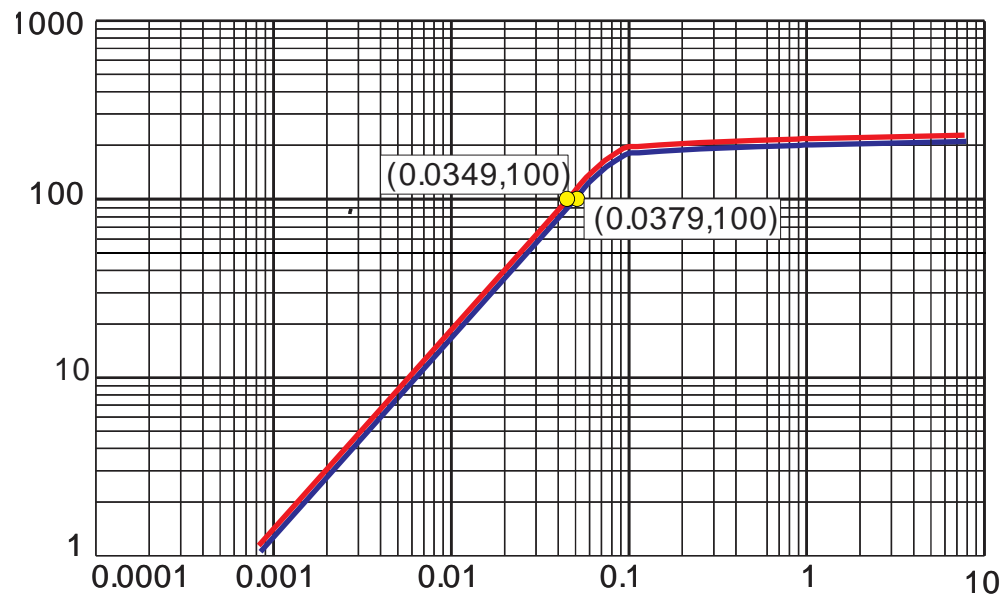

Figura 3.11 - Curva medida e publicada da característica da corrente de excitação de um TC da classe C200, 1200/5 com $\boldsymbol{V}_{\text {pick-up }}$ igual a $100 \mathrm{~V}$ [21].

Desta forma, a corrente mínima é dada por:

A partir de dados da curva publicada:

$$
I_{\min 100}=(4 \cdot(0,0379)+0,052) \cdot 240=48.9 \mathrm{~A}
$$

A partir de dados da curva medida:

$$
I_{\min 100}=(4 \cdot(0,0349)+0,052) \cdot 240=45.98 \mathrm{~A}
$$


Na qual, $I_{e x}$ e $\frac{V_{p i c k-u p}}{R_{S}}$ são dados em valores rms.

A partir de testes de perfomance do circuito verifica-se que a corrente mínima é aproximadamente 47, confirmando que os valores obtidos nas Equações 3.14 e 3.15 são válidos.

Para o mesmo circuito da Figura 3.3, a corrente mínima foi calculada novamente considerando, neste momento, a tensão de pick-up igual a $200 \mathrm{~V}$. Neste caso, a corrente de excitação medida é 0.1 A e a corrente de excitação a partir da curva publicada é 0.4 A.

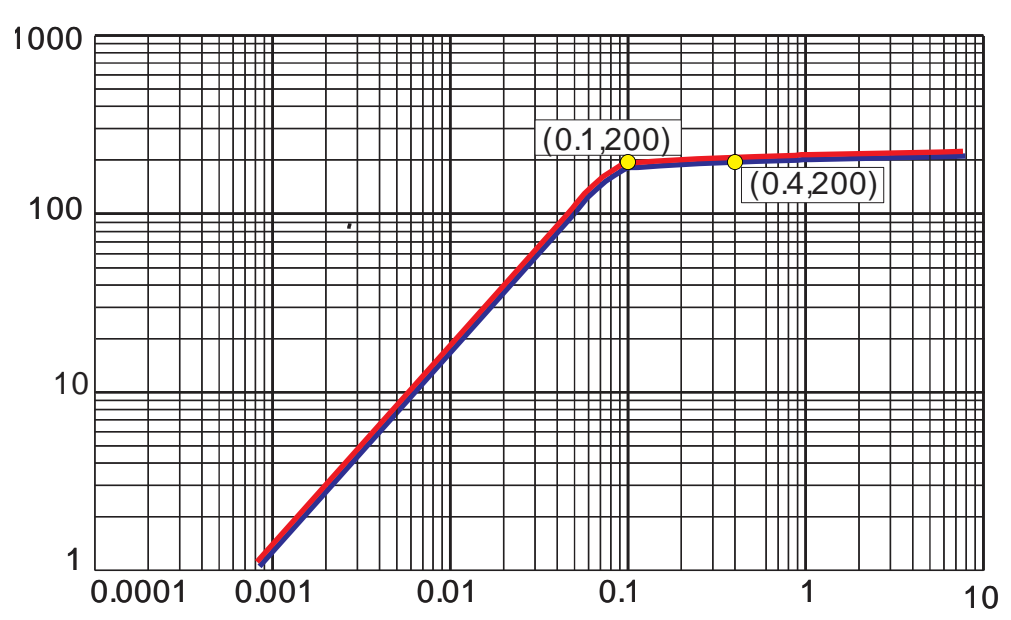

Figura 3.12 - Curva medida e publicada da característica da corrente de excitação de um TC da classe C200, 1200/5 com $\boldsymbol{V}_{\text {pick-up }}$ igual a $100 \mathrm{~V}$ [21].

Temos, portanto:

A partir de dados da curva publicada:

$$
I_{\min 200}=(4 \cdot(0,4)+0,1) \cdot 240=408 \mathrm{~A}
$$

A partir de dados da curva medida:

$$
I_{\min 200}=(4 \cdot(0,1)+0,1) \cdot 240=120 \mathrm{~A}
$$

A partir de testes de performance do circuito da Figura 3.3, verifica-se que a corrente mínima é aproximadamente 88, que é um valor consideravelmente inferior aos obtidos nas Equações 3.16 e 3.17. Desta maneira, o cálculo da aproximação foi superestimado e a leitura, portanto, é imprecisa. Escolher esse valor como correto para a magnitude da mínima corrente de sensibilidade teria como consequências comprometer a sensibilidade e os rendimentos do relé. 
Estas discrepâncias são devidas a alguns pontos. As curvas de excitação dos TCs publicadas por fabricantes e por curvas medidas são derivadas de tensões senoidais aplicadas sobre o TC. Quando se deseja determinar a curva de excitação do TC é aplicada uma tensão senoidal sobre ele e mensurado o valor da corrente, com a qual resulta a curva de excitação. Testes realizados para a obtenção da corrente mínima com tensões de pick-up do relé acima da tensão de joelho, a tensão aplicada já não é mais senoidal, é distorcida devido ao fato do TC estar operando em sua região não linear. Assim, não é mais simples encontrar a corrente de excitação e, consequentemente, o valor da corrente $I_{\min }$.

Nesse sentido, para valores de tensão acima do valor da tensão de joelho, como 200 V, a obtenção da corrente mínima através da curva publicada por fabricantes ou pela curva medida é errônea, uma vez que ela não corresponde ao resultado de testes de performance do circuito.

Desta forma, o valor da corrente de excitação para $200 \mathrm{~V}$ pode ser estimado pelo dobro da corrente para $100 \mathrm{~V}$, ou seja,

A partir de dados da curva publicada:

$$
I_{\min 200}=(4 \cdot(0,0379 \cdot 2)+0,052) \cdot 240=98 \mathrm{~A}
$$

A partir de dados da curva medida:

$$
I_{\min 200}=(4 \cdot(0,0349 \cdot 2)+0,052) \cdot 240=92 \mathrm{~A}
$$

Verifica-se que os resultados obtidos nas Equações 3.18 e 3.19 são próximos do valor resultante de testes de performance do circuito da Figura 3.3.

Para outros valores de tensão acima da tensão de joelho, o processo de obtenção da mínima corrente de sensibilidade é análogo. Para tensões abaixo da tensão de joelho, utiliza-se a Equação 3.13.

\subsection{OUTRAS CONDIÇÕES}

A proteção diferencial da alta impedância de barras é bastante afetada pelos equipamentos conectados em paralelo, tais como para-raios, transformadores auxiliares que ocasionalmente ou frequentemente fornecem um escape ao caminho natural da corrente dentro da zona de proteção.

Relés diferenciais de alta impedância podem considerar um pequeno atraso em sua operação, geralmente de um ciclo, para evitar um trip durante a operação do pára- 
raios. No caso dos transformadores auxiliares, aumenta-se a tensão de limiar $\left(\mathrm{V}_{\text {pick-up }}\right)$ de disparo do relé, quando na energização de transformadores devido à elevada corrente de inrush ou na partida de motores.

\subsubsection{CONEXÃO DO TC EM ABERTO}

A abertura da conexão de um dos TCs do circuito pode criar uma tensão perigosa em seus terminais. Em razão do circuito aberto, esta tensão não é aplicada ao relé diferencial de alta impedância. Entretanto, a corrente secundária desbalanceada gerada pela saída de um dos TCs em paralelo cria uma tensão através do relé proporcional à corrente de carga do circuito com o TC em aberto.

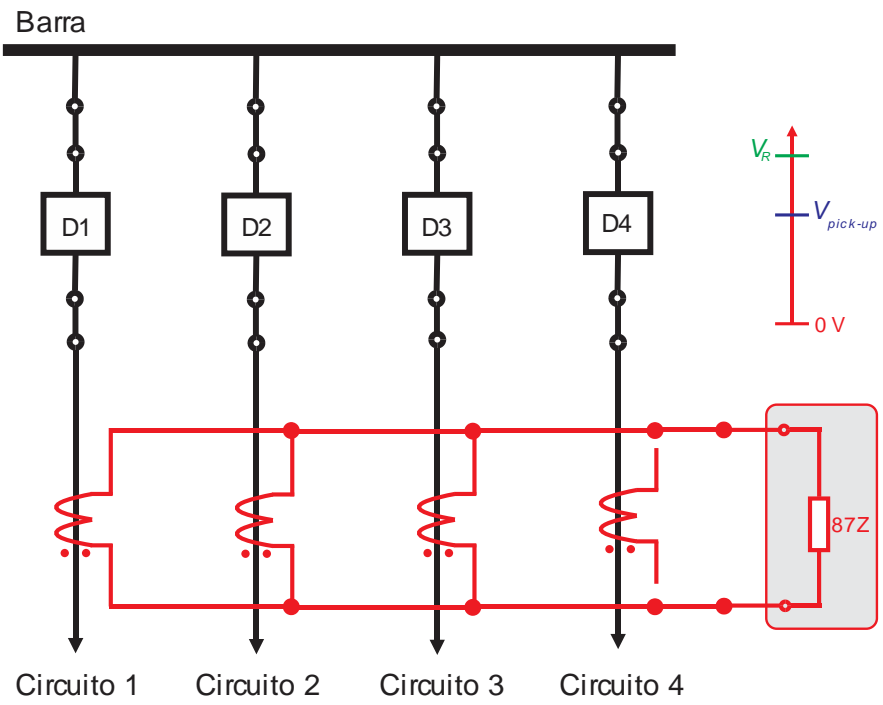

Figura 3.13 - Fluxo de corrente para o caso de TC em aberto.

A corrente diferencial fluirá pela alta impedância interna do relé, criando uma tensão acima da tensão de pick-up levando o relé a atuar. Levando em consideração que a situação de um TC em aberto é perigosa, um trip do relé de modo a isolar o barramento pode ser, neste caso, desejável.

\subsubsection{TC CURTO-CIRCUITADO}

Quando os TCs são curto-circuitados, como pode ser visualizado na Figura 3.14, o relé diferencial de alta impedância passa a não mais atuar. Uma vez que a tensão nos terminais do relé é nula, este não consegue detectar este tipo de situação. Desta forma, 
mesmo na presença de faltas internas, a corrente no relé é nula, não criando uma tensão em seus terminais e consequentemente a proteção não atua.

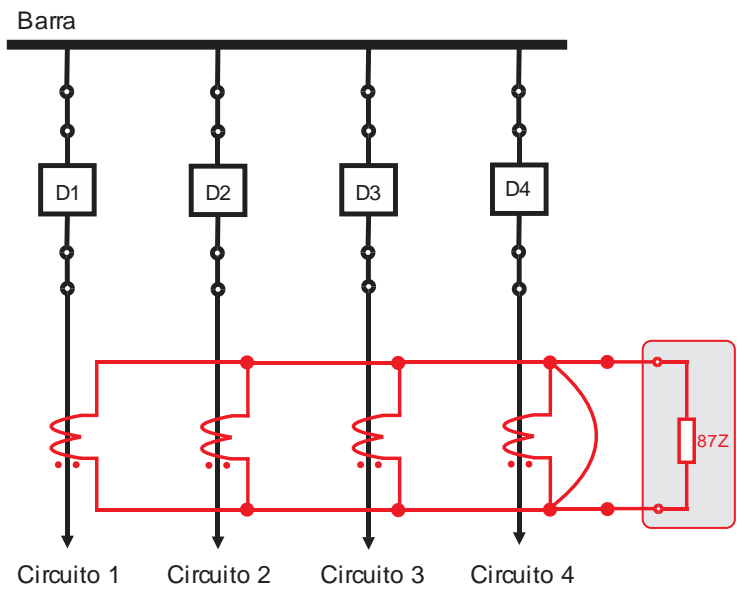

Figura 3.14 - Fluxo de corrente para o caso de TC curto-circuitado.

A manutenção do disjuntor pode ser preocupante para a proteção diferencial de alta impedância.

Como mostrado na Figura 3.15, aterram-se ambos os lados do disjuntor de modo a isolá-los durante o seu período de manutenção. No caso do disjuntor de tanque morto, devido às suas próprias configurações construtivas, seu isolamento é feito juntamente com o TC. Se seus contatos estiverem fechados, o aterramento de seus terminais é capaz de proporcionar uma circulação de corrente. Geralmente, a resistência de aterramento é pequena e quando refletida ao secundário do $\mathrm{TC}$ através de sua relação de transformação se torna menor ainda, criando uma espécie de resistência de bypass à corrente que deveria passar pelo relé. Esta situação pode reduzir, portanto, a sensibilidade do relé diferencial de alta impedância de barramento, fazendo que com ele não atue quando deveria atuar.

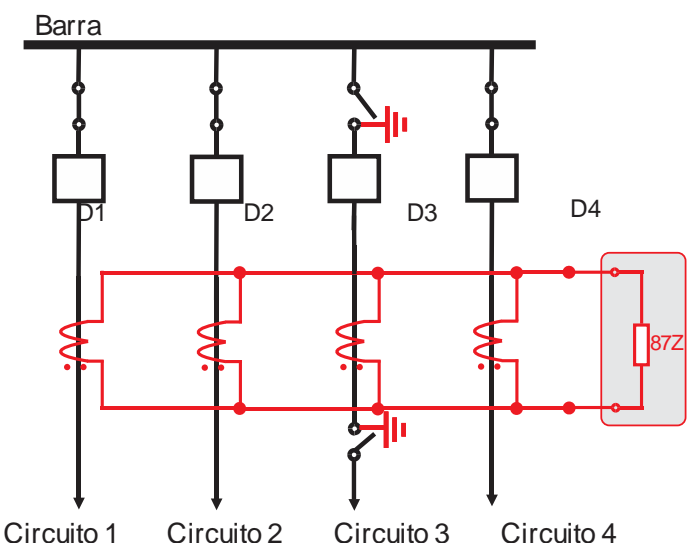

Figura 3.15 - Disjuntor com terminais aterrado. 
Alternadamente, se uma falta externa vier a ocorrer durante o período de manutenção de um disjuntor, uma corrente pode circular pelos aterramentos do disjuntor e causar a operação indevida do relé diferencial de alta impedância de barras. Para evitar esta situação, é recomendável conectar os aterramentos de ambos os lados do disjuntor em um mesmo potencial. Além disso, sempre que possível, deve-se deixar os contatos do disjuntor aberto durante a sua manutenção de modo a evitar que as duas situações anteriormente citadas possam ocorrer.

\subsection{INFORMAÇÕES RELEVANTES ACERCA DA PROTEÇÃO DIFERENCIAL DE ALTA IMPEDÂNCIA DE BARRAMENTOS}

Dois aspectos muito importantes que devem ser analisados quando da implementação do esquema da proteção diferencial de alta impedância são a classificação e a relação de transformação dos TCs que serão utilizados. Essas características influenciam sobremaneira o desempenho da proteção.

Segundo Zocholl e Costello [25], a perfomance da proteção diferencial de alta impedância é limitada pela classificação do TC. O sinal de tensão filtrado pelo relé para faltas internas com corrente da ordem de $20 \mathrm{kA}, 40 \mathrm{kA}$ e $60 \mathrm{kA}$, é uma onda quadrada com magnitude limitada pelo MOV e largura de pulso determinada pela classificação do TC e limitada pelo fluxo de saturação do núcleo. O nível do sinal de tensão filtrado para o TC C200 atinge $400 \mathrm{~V}$. O nível do sinal de tensão filtrado para o TC C400 atinge 800 V. Já o TC C100 produz um pulso de largura muito estreita para uma amostragem confiável, não sendo possível , portanto, filtrar o sinal de tensão. Desta forma, um TC com classificação menor que C200 não é recomendado para aplicações da proteção diferencial de alta impedância.

Diferentes tipos de TCs podem ser dispostos em paralelo, porém isso não é recomendado. Entretanto, segundo Behrendt et al. [21], alguns fatores devem ser obedecidos, quais sejam: a classificação dos TCs não deve ser menor que C200, os enrolamentos devem ser totalmente distribuídos, os cabos de conexão dos TCs devem ser curtos e terem aproximadamente o mesmo tamanho e os TCs devem estar conectados no TAP de modo a igualar as relações de transformação. O TC de menor relação de transformação determina a forma de onda da tensão. Para evitar que algum desses fatores não seja satisfeito, recomenda-se a utilização de TCs de mesma classe de exatidão. 
De acordo com Behrendt et al. [21], existem dois métodos para igualar as relações de transformação de TCs de classe diferentes, quando o TAP máximo de um possui maior relação de transformação que o TAP máximo do outro.

Suponha que sejam utilizados dois TCs com TAP máximo de 2000-5A e 12005A. O primeiro método consiste em conectar o TAP máximo do TC 1200-5A no TAP intermediário do TC 2000-5A de modo a igualar suas relações de transformação. Esse método pode ser visualizado na Figura 3.16. Entretanto, existe uma desvantagem em utilizar esse método. Na presença de faltas internas ou externas, a tensão que é desenvolvida através do relé diferencial de alta impedância de barra pode ser amplificada devido à presença do autotransformador formado pelos enrolamentos desconectados do TC de maior relação de transformação. Contudo, essa tensão é de curta duração e o MOV consegue mantê-la dentro dos limites aceitáveis para os cabos e para o relé.

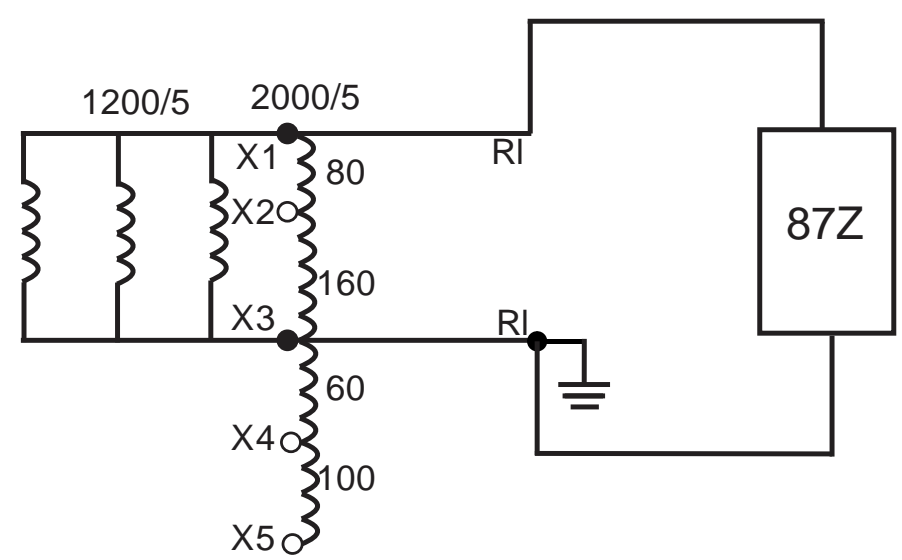

Figura 3.16 - Conexão dos TCs no relé diferencial de alta impedância de barramento, método 1 [21].

O segundo método consiste em conectar ao relé o TAP máximo do TC 2000-5A e conectar o TAP máximo do TC 1200-5A no TAP intermediário do TC 2000-5A, conforme ilustrado na Figura 3.17. Esse método exclui a possibilidade de amplificar a tensão nos terminais do relé uma vez que não existem enrolamentos isolados. 


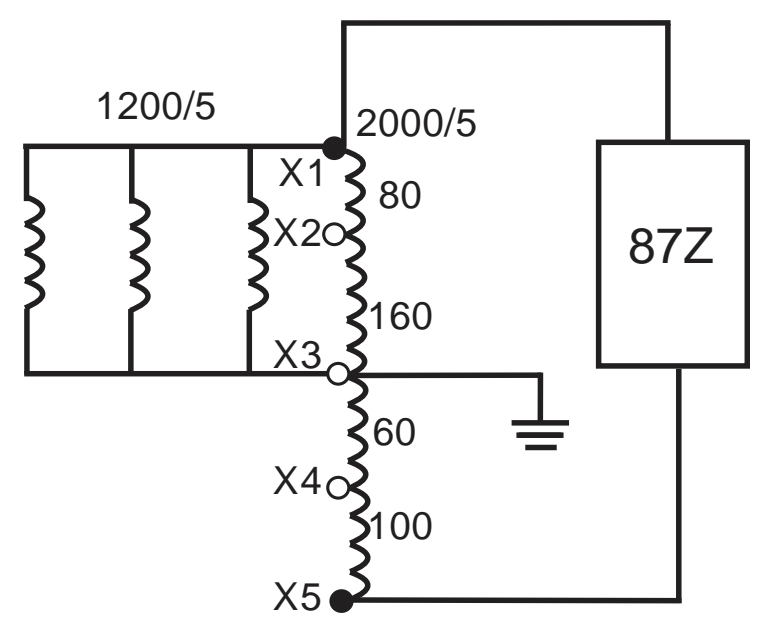

Figura 3.17 - Conexão dos TCs no relé diferencial de alta impedância de barramento, método 2 [21]. 


\section{CAPÍTULO 4}

\section{MODELAGEM DA PROTEÇÃO DIFERENCIAL DE ALTA IMPEDÂNCIA DE BARRAMENTOS NO ATP}

\subsection{SOFTWARE ATP}

Distúrbios no sistema elétrico de potência como descargas atmosféricas, curtoscircuitos, manobras em chaves ou disjuntores podem ocasionar elevações severas nas correntes e tensões, tendo sido a causa de inúmeros estudos relacionados ao melhoramento de esquemas de proteção.

A grande complexidade da análise de processos operacionais levou ao desenvolvimento de sofisticados e modernos programas computacionais que possuem enorme capacidade de processamento e quantidade de memória. Equipamentos mais modernos e sofisticados têm sido utilizados a fim de garantir eficiência e qualidade ao sistema elétrico como um todo. Destaca-se, portanto, os relés, equipamentos essenciais utilizados nos esquemas de proteção que combinam a tecnologia analógica de alta impedância, já consolidada, com a tecnologia baseada em microprocessadores. A grande vantagem destes relés é que eles são programáveis, e, portanto, garantem que algoritmos de proteção sofisticados possam ser aplicados sem que a haja a necessidade de troca do equipamento que pode ser, muitas vezes, de alto dispêndio.

Através do estudo dos transitórios eletromagnéticos é possível chegar a uma conclusão precisa sobre quais dispositivos são necessários à proteção, quais as causas das perturbações e quais medidas devem ser tomadas visando uma proteção segura e eficaz.

Neste contexto, surge o software ATP (Alternative Transient Program), o qual é derivado do EMTP (Eletromagnetic Transient Program), que possibilita aos estudiosos da área de proteção de sistemas elétricos realizarem estudos aprofundados através de simulações de transitórios eletromagnéticos em redes polifásicas complexas.

Através do ATP é possível avaliar e prover análises de simultaneidade de contingências, de correntes de curto-circuito em diferentes barras do sistema, de fluxo de carga e de estabilidade, interfaceamentos de redes AC com sistemas DC, além de 
análises de comportamentos transitórios de redes e outras perturbações a mais [26].

Os modelos de sistemas e componentes que apresentam características não lineares podem ser simulados no ATP, assim como distúrbios, simétricos ou assimétricos, como falhas, descargas atmosféricas ou surtos de manobra.

O programa ATP, por ser digital, não determina uma solução contínua no tempo. De fato, seus resultados são obtidos através de intervalos de tempo discretos. Assim, para minimizar efeitos indesejados nas soluções apresentadas pelo programa, recomenda-se utilizar um passo de cálculo pequeno, da ordem de dez vezes menor que a menor constante de tempo envolvida no fenômeno transitório a ser analisado.

No ATP estão disponíveis diversos modelos pré-definidos para serem usados na montagem e simulação de sistemas elétricos de potência. Alguns deles são listados a seguir [27]:

- Elementos a parâmetros concentrados;

- Elementos RL acoplados;

- Modelos PI-Equivalentes Polifásicos;

- Transformadores;

- Linhas de transmissão;

- Elementos não-lineares;

- Chaves;

- Fontes;

- Pára-raios;

- Compensadores estáticos e válvulas conversoras.

No ATP, a simulação dos curtos simétricos ou assimétricos está condicionada ao fechamento de chaves, controladas por tempo pré-determinados na rotina. Impedâncias são dispostas entre as chaves relativas às fases e neutro. Para cada tipo de curto, existe uma combinação de fechamento de chaves e de valores de resistência. Na Figura 4.1 é demonstrado um exemplo de configuração de chaves pra simulação de faltas, o qual foi empregado nas simulações descritas nessa dissertação. Para cada caso de curto-circuito, há um esquema de abertura e fechamento destas chaves. 


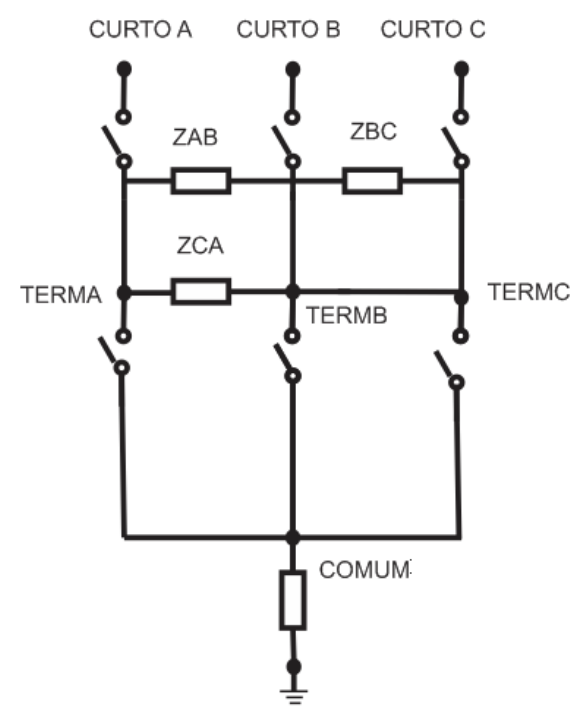

Figura 4.1 - Chaves para simulação de faltas.

\subsection{MODELS}

A MODELS é uma linguagem de programação estruturada anexa ao ATP, voltada para a simulação no domínio do tempo e pode ser usada para fazer a descrição da dinâmica do comportamento de complexos sistemas físicos [28]. Sua linguagem foca na descrição da estrutura do modelo e das funções dos seus elementos.

Cada bloco descritivo da MODELS possui quatro aspectos principais [29]:

- Quais elementos estão presentes no modelo;

- Como estes elementos interagem entre si;

- Como estes elementos interagem com o ambiente externo em que estão inseridos;

- Como o modelo deve ser simulado.

A descrição de cada modelo na MODELS possui uma sintaxe que possibilita o interfaceamento com o programa ATP. Esta conexão é realizada através de comandos de INPUT e OUTPUT, ou seja, entrada e saída. Apresenta-se no Anexo A uma breve descrição da MODELS. 


\subsection{MODELO DO RELÉ DIFERENCIAL DE ALTA IMPEDÂNCIA DE BARRAMENTO}

No presente trabalho, a linguagem MODELS foi utilizada para modelar a proteção diferencial numérica de alta impedância de barramentos. Para tanto, os seguintes modelos foram implementados:

- Condicionamento de sinais;

- Aquisição de Dados;

- Modelo de Estimação de Fasores.

O relé faz a leitura dos sinais de corrente vindos dos secundários dos TCs localizados nas linhas de transmissão. Inicialmente esses sinais são transformados em fasores com módulo e fase e posteriormente são digitalizados.

Um resumo da simulação pode ser visualizado em um diagrama de blocos, que está apresentado na Figura 4.2.

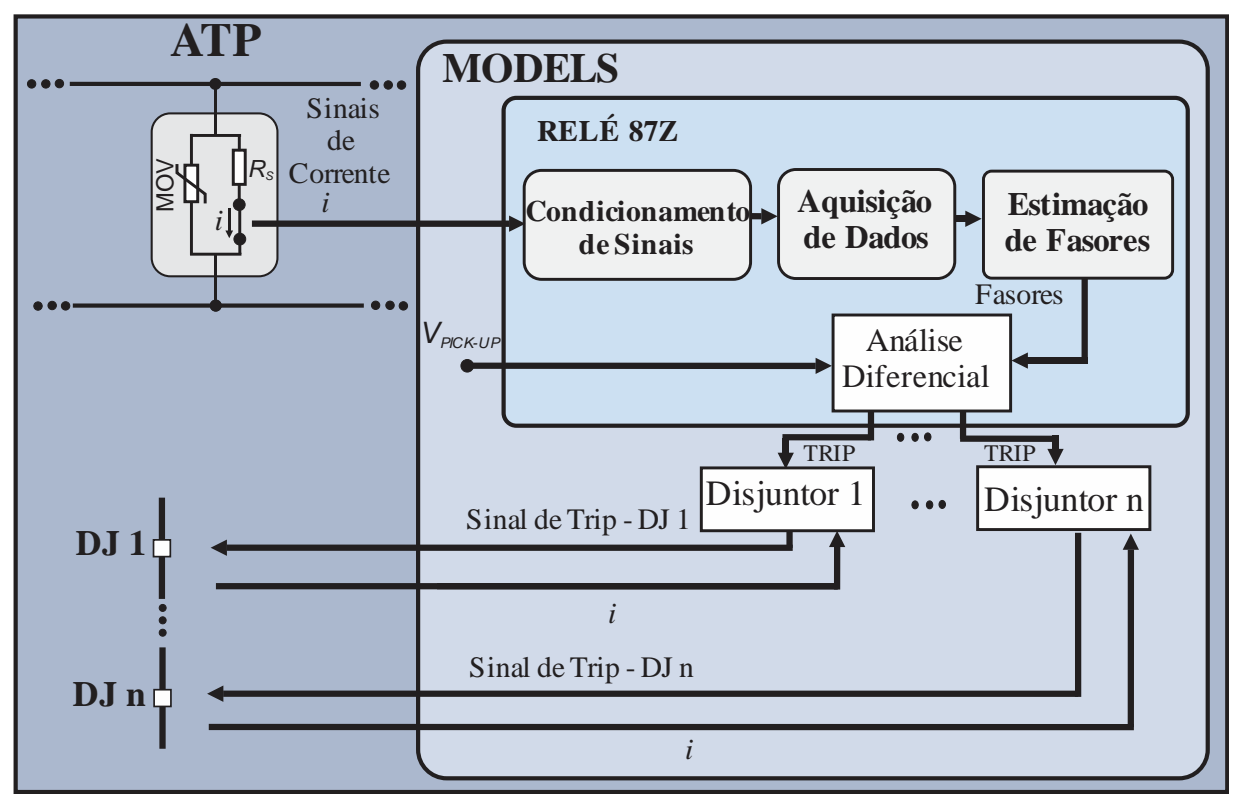

Figura 4.2 - Modelo do relé diferencial de alta impedância de barramento.

\subsubsection{MÓDULO DE CONDICIONAMENTO DE SINAIS}

O módulo de condicionamento de sinais realiza, basicamente, a filtragem analógica dos sinais de corrente oriundos dos TCs. Contudo, aqui se faz a ressalva de que, por se tratar de uma simulação digital, de fato, não é feita uma filtragem analógica. 
O que é de fato feito é uma filtragem digital equivalente à filtragem analógica, mas para fazer menção ao processo real, mantêm-se o termo filtragem analógica. Até porque emprega-se na MODELS um modelo denominado LAPLACE, o qual tem como parâmetros de ajuste os coeficientes da função de transferência $H(s)$ do componente a ser simulado, que nesse caso é o filtro analógico.

A filtragem analógica é responsável por filtrar as componentes de alta frequência dos sinais de tensão e corrente. Nesse trabalho adotou-se um filtro passa-baixas do tipo Butterworth de $3^{\mathrm{a}}$ ordem. Este filtro evita que durante a amostragem dos sinais ocorra $\mathrm{o}$ aliasing (sobreposição de espectros). A resposta em frequência do filtro é dada pela Figura 4.3.

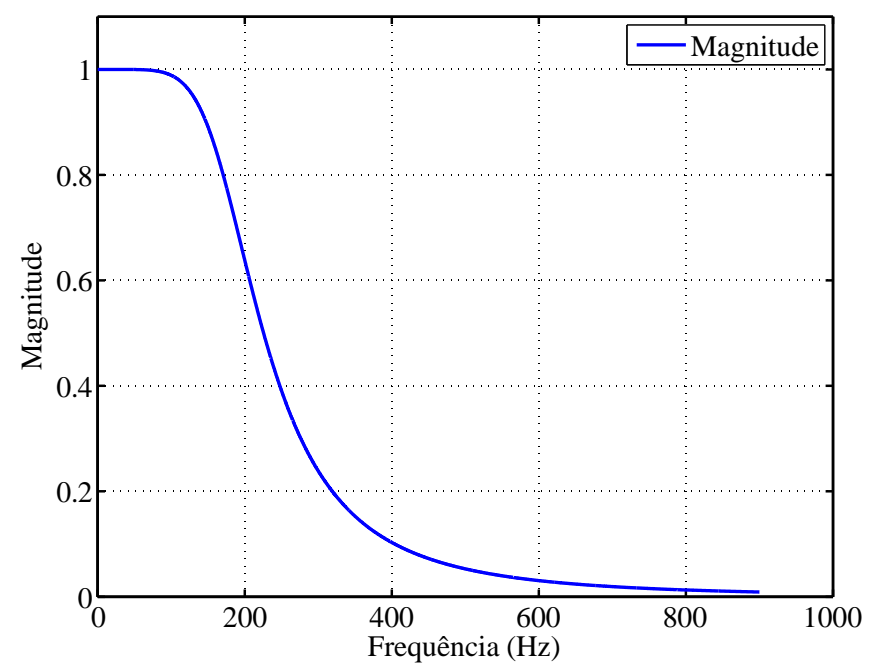

Figura 4.3 - Resposta em frequência do filtro Butterworth.

Os parâmetros e as constantes do filtro são inseridos no modelo da seguinte forma:

Tabela 4.1 - Parâmetros do filtro Butterworth.

$$
\begin{gathered}
\hline \text { Parâmetros } \\
\hline N=3 \\
W_{c}=187.9 \mathrm{~Hz} \\
W_{p}=150 \mathrm{~Hz} \\
W_{s}=240 \mathrm{~Hz} \\
A \max D B=1 \mathrm{~dB} \\
A \min D B=60 \mathrm{~dB}
\end{gathered}
$$

No Quadro 4.1 é apresentado o código do modelo da Filtragem Analógica. 
Tabela 4.2 - Constantes do filtro Butterworth.

\begin{tabular}{c}
\hline Parâmetros \\
\hline$b_{0}\{$ val: $1.6452 e 9\}$ \\
$a_{0}\{$ val: $1.6452 e 9\}$ \\
$a_{1}\{$ val: $2.7873 e 6\}$ \\
$a_{2}\{$ val: $2.3611 e 3\}$ \\
$a_{23}\{$ val: 1.0$\}$ \\
\hline
\end{tabular}

A função de transferência do filtro é dada por:

$H(s)=\frac{1,6452 \cdot 10^{9}}{s^{5}+2,3611 \cdot 10^{3} \cdot s^{3}+2,7873.10^{6} \cdot s+1,6452 \cdot 10^{9}}$

O filtro apresenta algumas características de vantagem em relação a outros tipos de filtro, como por exemplo, o ganho constante na sua faixa de passagem, como se pode visualizar na Figura 4.3. Entretanto, é gerado um atraso na saída do sinal após a passagem pelo filtro, em relação ao sinal original.

Quadro 4.1 - Código do Modelo - MODEL Filtragem Analógica.

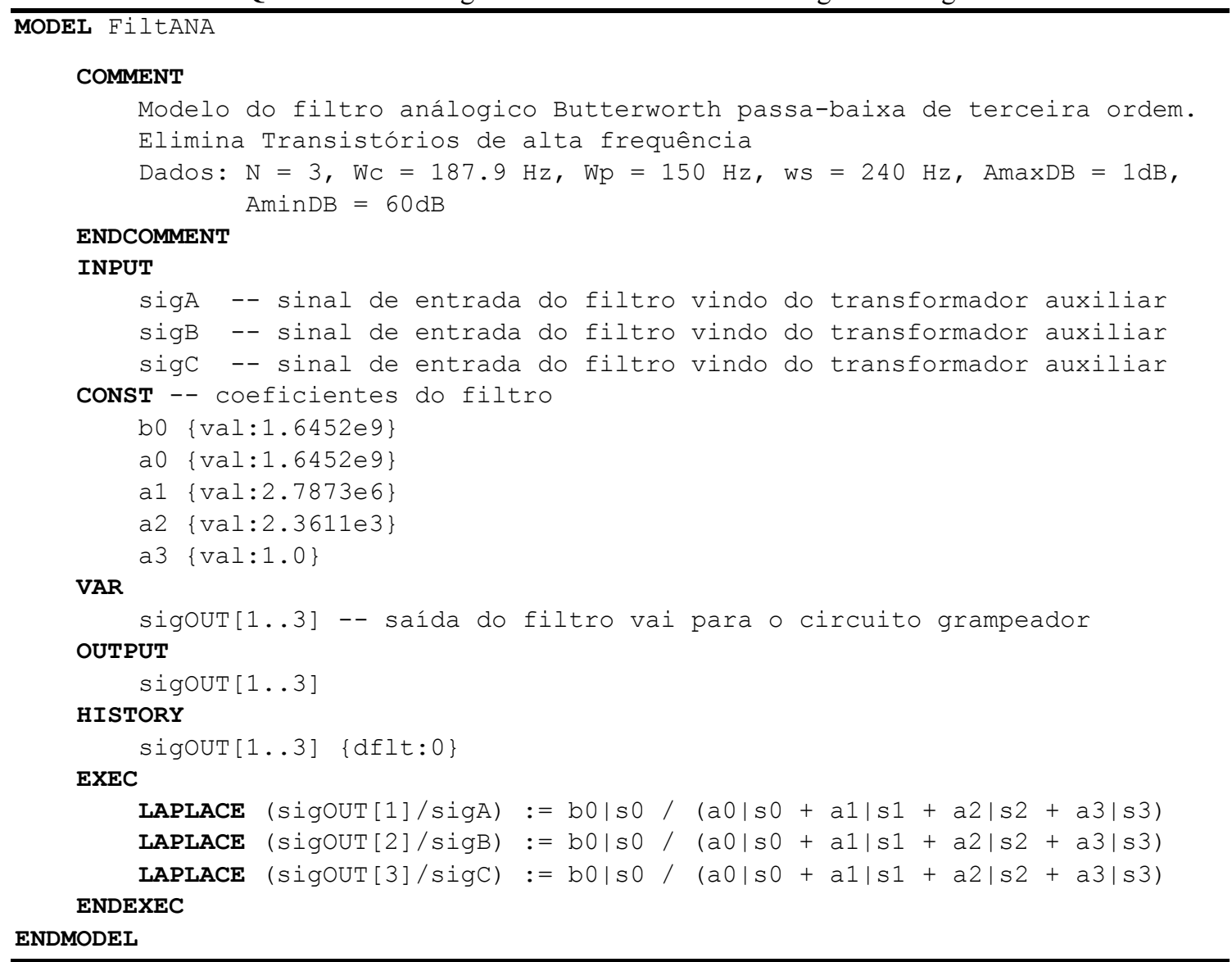




\subsubsection{MÓDULO DE AQUISIÇÃO DE DADOS}

Este módulo tem como objetivo converter o sinal de tensão ou corrente vindo do módulo de condicionamento em um sinal digital. Desta forma, os sinais serão amostrados e digitalizados. Aplicando-se uma frequência de amostragem $f_{s}$, a amostragem é realizada pela aquisição de sinais a intervalos de tempos definidos. As amostras dos sinais são então quantizadas, levando-se em consideração a precisão do conversor A/D.

\subsubsection{SAMPLER/HOLDER}

O submódulo Sampler/Holder, primeira etapa do módulo de aquisição de dados, é responsável por inicializar a conversão do sinal analógico em sinal digital. O circuito associado a este módulo é composto de uma chave em série a um capacitor, onde é captada a tensão em seus terminais, como pode ser visualizado na Figura 4.4. Uma vez que a chave estiver fechada, o capacitor carrega o sinal de entrada até a saída. Quando a chave se abre, o capacitor se descarrega lentamente e mantém o sinal de entrada na saída, praticamente constante, por certo intervalo de tempo. A taxa de amostragem do sinal é determinada pelo tempo de abertura e fechamento da chave.

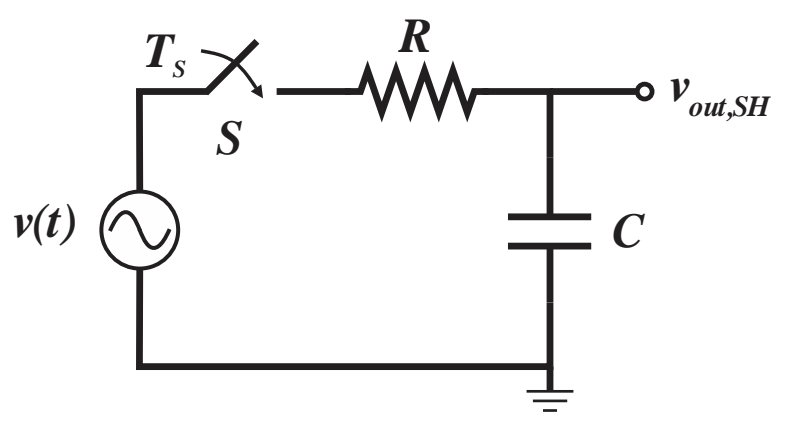

Figura 4.4- Circuito Sampler/Holder.

No modelo em análise, para a frequência fundamental de $60 \mathrm{~Hz} f_{0}$, determina-se a frequência de amostragem de no mínimo $120 \mathrm{~Hz} f_{N}$, de acordo com o critério de Nyquist, para que não ocorra a sobreposição de espectros, do inglês aliasing. A taxa de amostragem pode ser encontrada pela seguinte equação:

$$
T_{\text {amostragem }}=\frac{f_{s}}{f_{0}}
$$

Para relés usuais, utiliza-se o valor de $960 \mathrm{~Hz}$ para $f_{s}$. Assim, $T_{\text {amostragem }}=16$ amostras/ciclo. 
O período de amostragem também pode ser obtido, através de $f_{s}$, da seguinte forma:

$$
P_{\text {amostragem }}=\frac{1}{f_{s}}=1,0416667 \mathrm{~ms}
$$

Os blocos constituintes deste módulo de Aquisição de Dados são executados a cada período de amostragem, uma vez que considera a amostragem de sinais realizada no módulo de Condicionamento de Sinais. Este processo é feito através do comando TIMESTEP MIN: $1,0416667 \cdot 10^{-3}$, que é responsável por chamar um modelo de modo que este será executado toda vez que um contador interno atingir o valor prédeterminado, neste caso igual a $1,0416667 \cdot 10^{-3}$ segundos. A cada requisição do modelo, ele repassa à saída o valor recebido na entrada do circuito grampeador através do código sigOUT1:=sigIN1. O valor da saída permanece constante até que se passe mais um período de amostragem. No Quadro 4.2, pode-se visualizar o código do modelo Sampler/Holder.

Quadro 4.2 - Código do Modelo - MODEL Sampler/Holder.

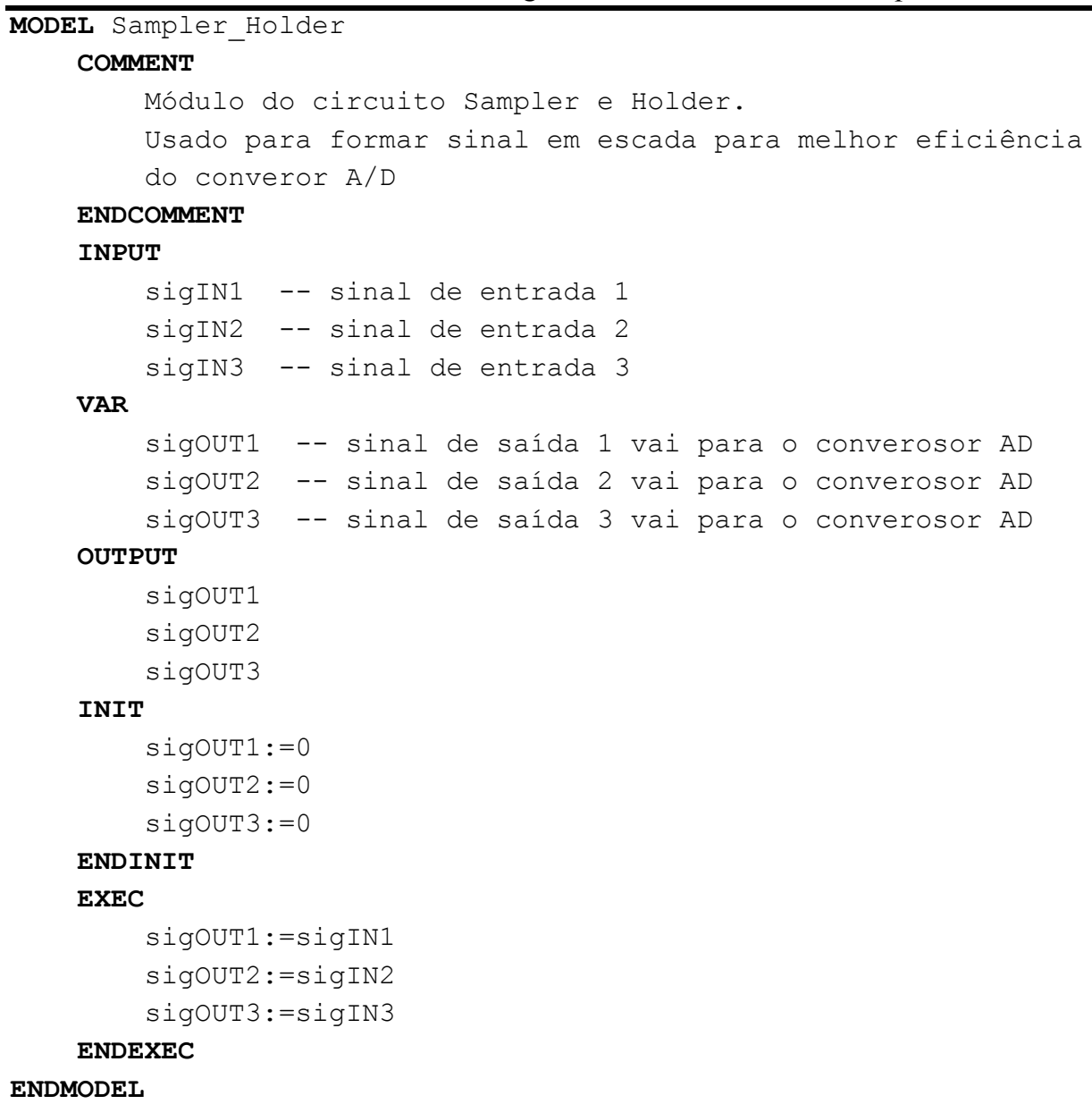




\subsubsection{CONVERSOR A/D}

Este é o submódulo capaz de quantizar o sinal vindo do submódulo Sampler/Holder. O sinal amostrado é convertido em uma palavra binária de 16 bits. $\mathrm{O}$ tamanho da palavra binária é de suma importância. Para maiores valores, o sinal digital se aproxima melhor do sinal analógico.

Entre as várias técnicas conhecidas de quantização, a utilizada neste trabalho é o Método das Aproximações Sucessivas.

Define-se a resolução do conversor como sendo o valor na base 10 correspondente ao bit menos significativo da palavra de $b+1=16$ bits. A resolução depende do valor de pico (Y) que é aceito pelo conversor sem que ocorra a sua saturação e se ele opera em modo monopolar, isto é, no intervalo $[0, \mathrm{Y}]$, ou bipolar ([$\mathrm{Y}, \mathrm{Y}]$ ). Para o caso bipolar a resolução do conversor A/D de $b+1=16$ bits pode ser determinada pela Equação 3.23[30]:

$$
\operatorname{Res}=\frac{Y}{2^{b}-1}
$$

Determinado os valores de $b+1=16$ e $Y=10$, obtêm-se a resolução do conversor igual a $3.0518 \cdot 10^{-4}$.

Os valores digitalizados $Z_{10}$, para valores positivos da entrada $x$, são obtidos pela Equação 3.24, através do truncamento INT ou arredondamento $R O N$.

$$
Z_{10}=\operatorname{INT} \text { ou } R O N\left(\frac{x}{R e s}\right)
$$

Os valores negativos da entrada $x$, são obtidos pela Equação 3.25, por complemento de dois.

$$
Z_{10}=I N T \text { ou } R O N\left(\frac{2 Y-|x|}{Y}\right) 2^{b}
$$

A partir do valor de $Z_{10}$, pode-se obter o seu equivalente binário, em ponto flutuante $(P F)$. Para valores positivos de $\mathrm{x}$, o ponto flutuante é dado por:

$$
P F=Z_{10} \cdot R e s
$$

Para valores negativos de $\mathrm{x}$, temos, portanto:

$$
P F=\left[Z_{10}-2^{b+1}\right] \cdot \operatorname{Res}
$$

Os valores obtidos representam a saída deste submódulo, onde já estão inclusos, os erros de quantização do conversor.

$\mathrm{Na}$ Figura 4.5, podem ser visualizadas as saídas dos submódulos do conversor A/D e do sampler/holder. 


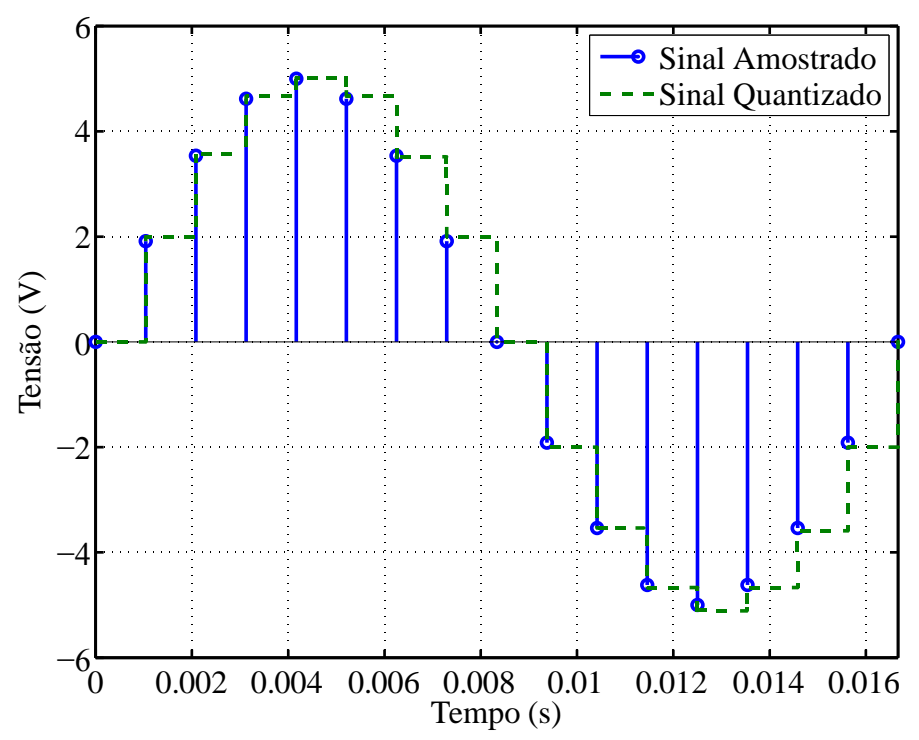

Figura 4.5 - Saídas do conversor A/D e do Sampler/Holder.

No Quadro 4.3 é apresentado o código do modelo do submódulo do Conversor A/D.

\subsubsection{ESTIMAÇÃO DE FASORES}

Os algoritmos de estimação de fasores podem ser também vistos como algoritmos de filtragem digital, uma vez que envolvem filtros ortogonais para a determinação das partes real e imaginária do fasor.

A primeira etapa da estimação é o processo de janelamento, conforme ilustrado na Figura 4.6. Na fase de pré falta, a janela de dados contém apenas amostras do sinal sem falta. $\mathrm{Na}$ fase de transição a janela contém tanto amostras do sinal sem e com falta. Já na fase de falta, a janela contém amostras do sinal somente com falta. Para cada instante de amostragem esta janela de dados é deslocada, de modo que a nova amostra seja incluída na janela [31].

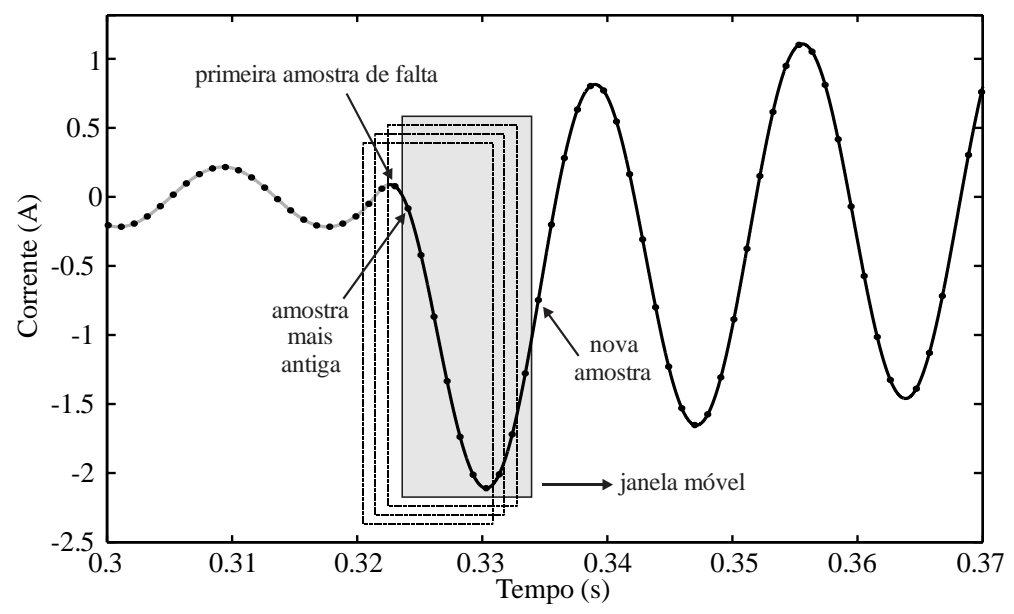

Figura 4.6 - Processo de janelamento de um sinal de corrente. 
Quadro 4.3 - Código do Modelo - MODEL Conversor A/D.

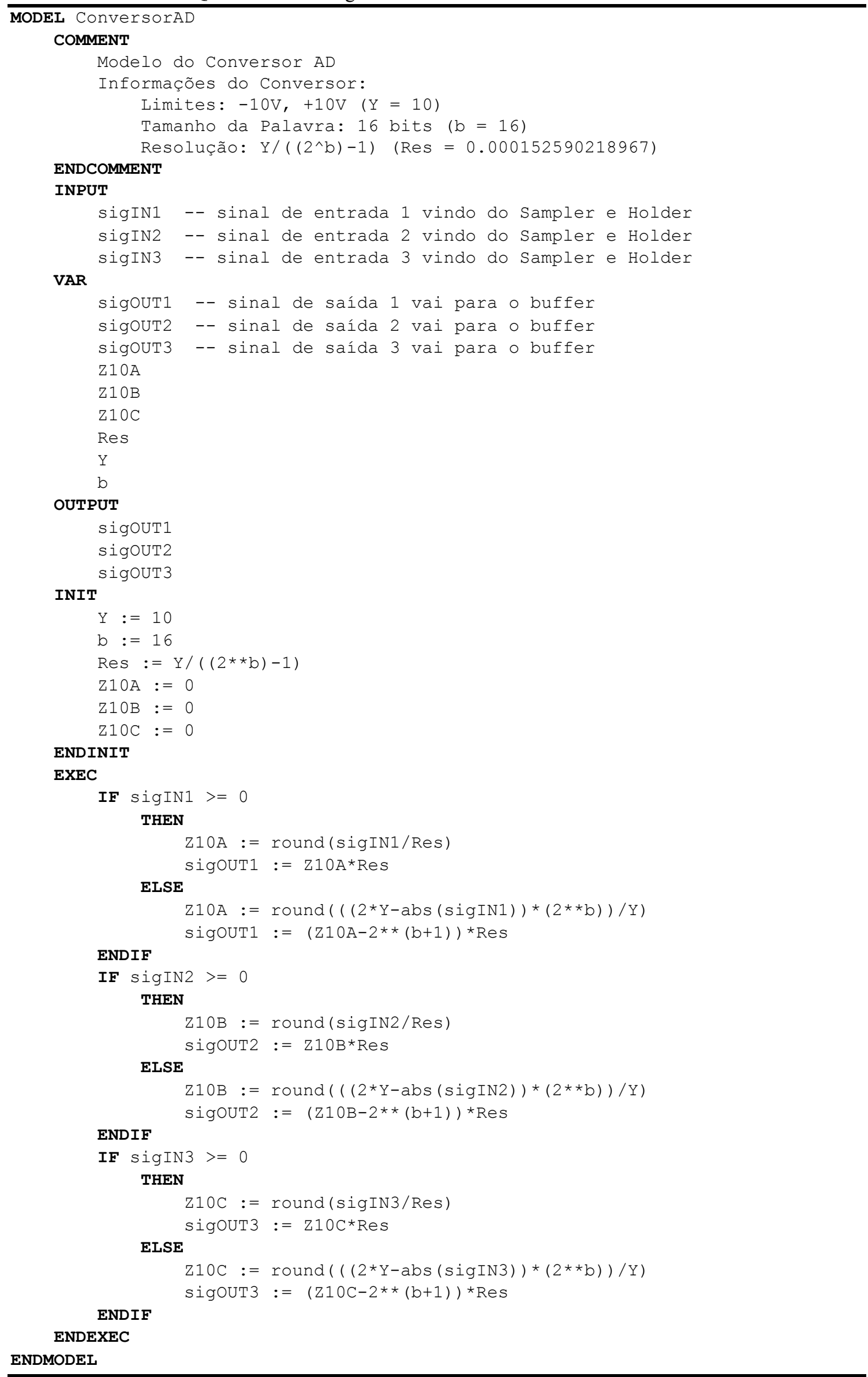


Neste módulo objetiva-se estimar a amplitude e a fase do fasor na frequência fundamental a cada janela.

A característica predominantemente indutiva dos sistemas elétricos de potência proporciona o surgimento de uma componente DC de decaimento exponencial em um sinal quando na presença de um chaveamento. Além desta, a presença de harmônicas inerentes a dispositivos não lineares nos sistemas de potências representam a grande dificuldade de se estimar de forma correta os fasores.

$\mathrm{O}$ algoritmo de estimação de fasores das componentes fundamental, de $2^{\mathrm{a}}$ e de $5^{\mathrm{a}}$ ordem utilizado neste estudo é o Filtro Cosseno Modificado proposto pela ABB [32], que é uma variação do algoritmo de Fourier de um ciclo.

\subsubsection{FILTRO COSSENO MODIFICADO DA ABB}

Hart et al. propuseram em [32] um novo algoritmo: o algoritmo do filtro cosseno modificado, patenteado pela $\mathrm{ABB}$. Os autores mostraram que a partir de duas saídas consecutivas do filtro cosseno de um ciclo de Fourier, aplicado um fator de correção a fim de obter a ortogonalidade entre as partes real e imaginária do fasor, era possível obter um resultado satisfatório na eliminação da componente DC [33].

A partir de dois termos $C_{1}$ (obtido da aplicação do filtro cosseno a uma janela de 16 amostras) e $C_{2}$ (obtido da aplicação do mesmo filtro a uma janela defasada de uma amostra), pode-se obter a parte real e a parte imaginária do fasor estimado, na qual:

$$
\begin{gathered}
C_{1}=\frac{2}{N} \sum_{k=0}^{N-1} x_{k} \cos (\delta k) \\
C_{2}=\frac{2}{N} \sum_{k=0}^{N-1} x_{k+1} \cos (\delta k)
\end{gathered}
$$

sendo $N$ é o número de amostras por ciclo, $\delta=\frac{2 \pi}{N}$ e $x_{k}$ o valor da amostra para a $k$ ésima posição da janela de dados;

O fasor de corrente é dado por:

$$
\widehat{X}_{1}=C_{1}+j\left(\frac{C_{1} \cos \delta-C_{2}}{\operatorname{sen}(\delta)}\right)
$$

Desta forma,

$$
\begin{gathered}
\operatorname{Re}\left\{\hat{X}_{1}\right\}=C_{1} \\
\operatorname{Im}\left\{\hat{X}_{1}\right\}=\frac{C_{1} \cos \delta-C_{2}}{\operatorname{sen}(\delta)}
\end{gathered}
$$

No Quadro 4.4, visualiza-se o código do modelo da Estimação de Fasores. 
Quadro 4.4 - Código do Modelo - MODEL Estimação de Fasores.

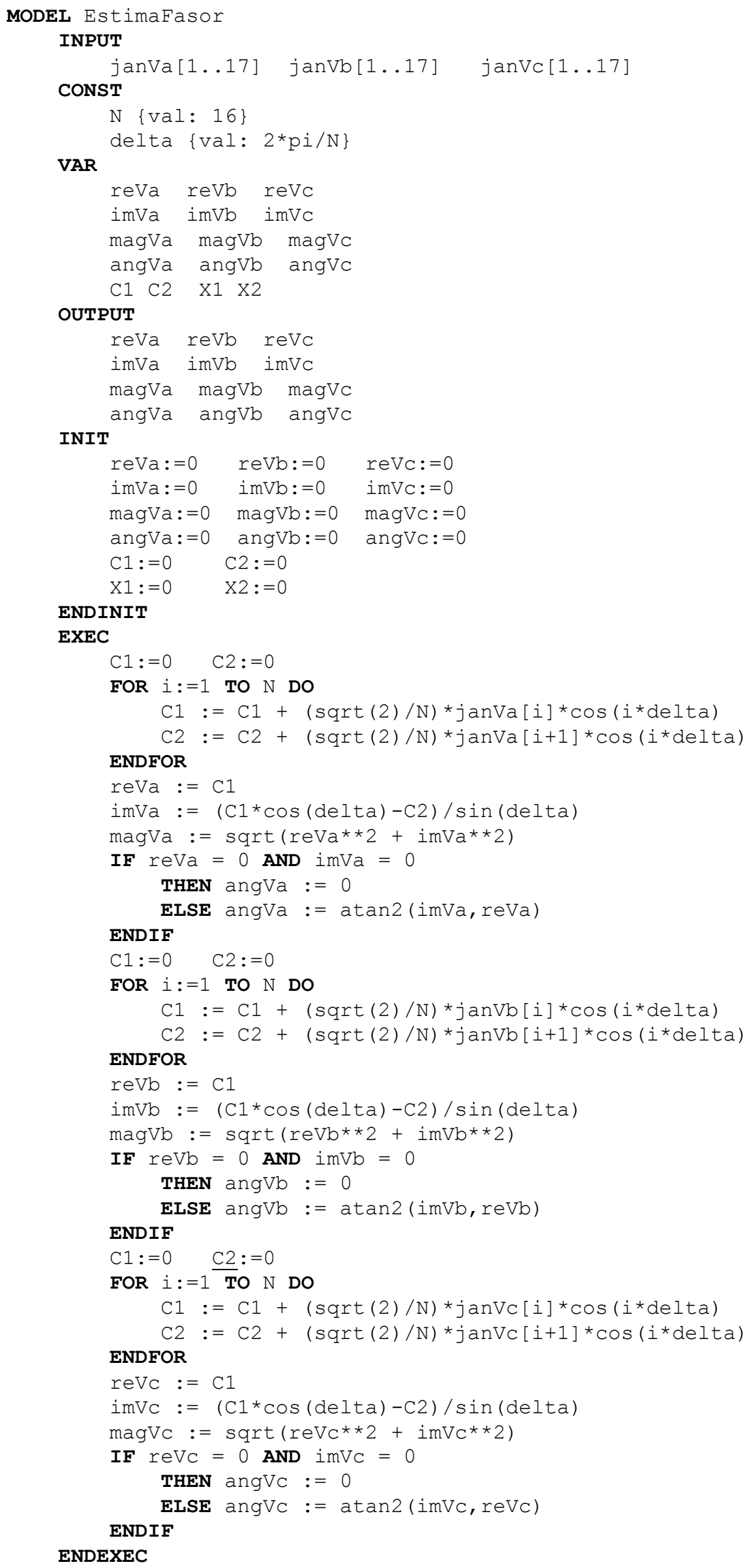




\subsubsection{BUFFER}

Submódulo de memória que armazena dados utilizados no submódulo do filtro cosseno, da etapa da estimação de fasores. O algoritmo do Filtro Cosseno Modificado, para uma taxa de amostragem de 16 amostras/ciclo, taxa utilizada neste modelo, necessita de que o buffer armazene 17 amostras. A criação de uma única janela contendo as 17 últimas amostras é obtida através do modelo, cujo código é exibido abaixo, a cada passo de cálculo.

O código do modelo do submódulo Buffer é apresentado no Quadro 4.5.

Quadro 4.5 - Código do Modelo - MODEL Buffer.

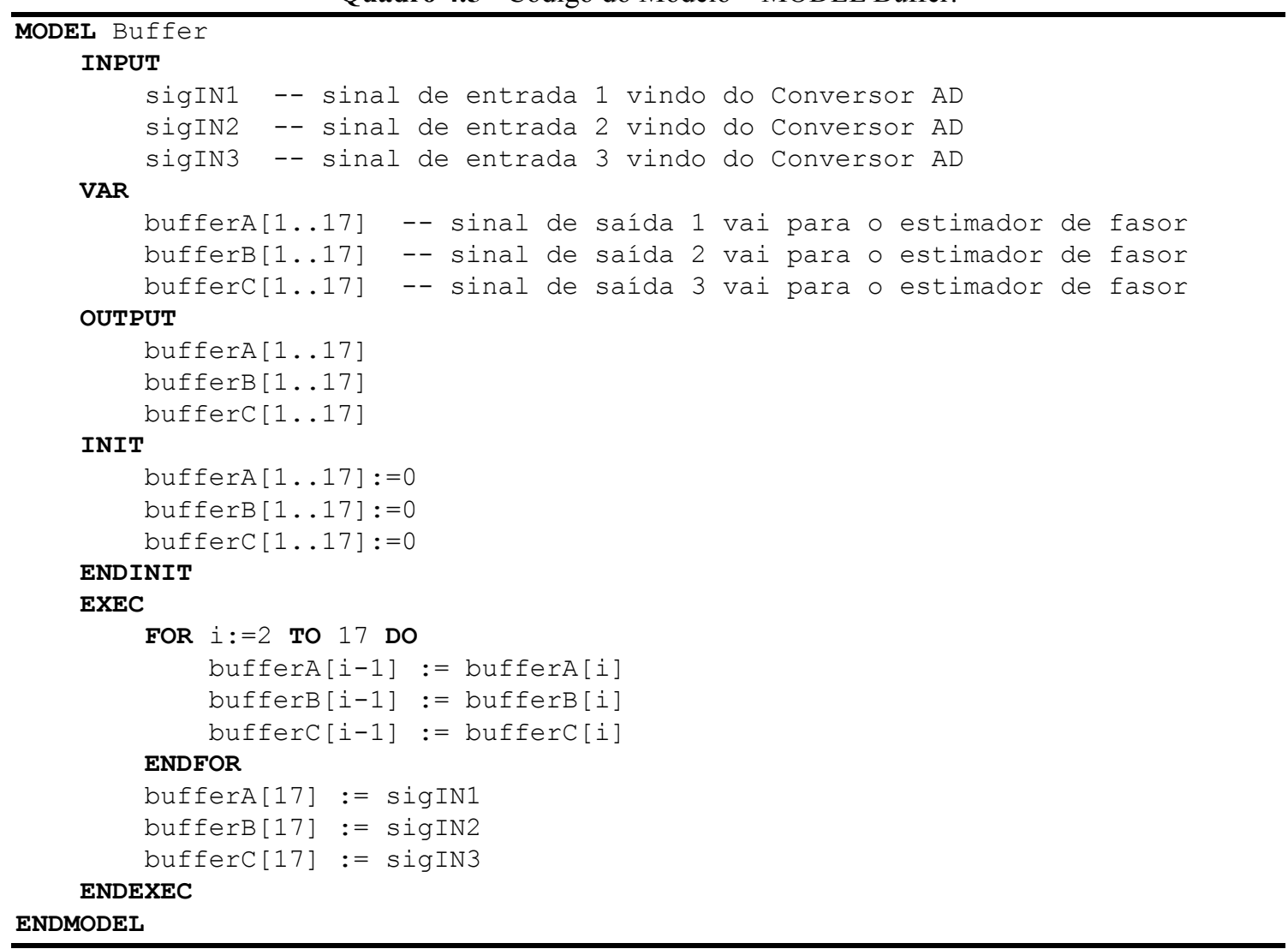

As amostras são recebidas pelo buffer (sigIN1) e então são utilizadas na estimação do fasor de corrente. Um vetor de 17 posições é criado (bufferA[1..17]) e guarda amostras à medida que elas chegam ao submódulo. Enquanto na posição 1 do vetor encontra-se a amostra mais antiga, na posição de número 17 encontra-se a mais recente. A cada nova amostra que chega, ela é acrescentada ao vetor e amostra mais antiga é, portanto, descartada. 


\subsubsection{ANÁLISE DIFERENCIAL}

De posse dos fasores na frequência fundamental, o relé diferencial de alta impedância de barramento avalia a tensão desenvolvida nos terminais no relé. Para curtos nos quais a magnitude da tensão é superior ao valor de $V_{\text {pick-up }}$, o relé envia um sinal de trip aos disjuntores, de modo a isolar a falta.

\subsection{DISJUNTOR}

O disjuntor é um dispositivo eletromecânico, dedicado a proteger o sistema elétrico contra surtos. Os disjuntores podem ser térmicos, magnéticos, termomagnéticos de alta e baixa tensão. Eles podem ser rearmados manualmente através de um dispositivo de manobra. Nas linhas de transmissão, eles estão localizados nas extremidades. São representados no Software ATP por chaves e comandados pelo relé. $\mathrm{Na}$ presença de curtos-circuitos e sobrecargas elétricas o relé envia um comando de trip aos disjuntores que abrem seus contatos isolando o sistema.

$\mathrm{O}$ modelo do disjuntor fornece o estado dos disjuntores presentes no sistema simulado. $\mathrm{O}$ atraso da abertura de um disjuntor real, que corresponde ao atraso devido à energização da bobina de abertura, abertura dos contatos e extinção do arco elétrico é referenciado no ATP como um atraso intencional. Este atraso foi considerado de 2 ciclos da frequência nominal de $60 \mathrm{~Hz}$, o que equivale a 33,333 ms.

O modelo de um disjuntor, apresentado no Quadro 4.6, está representando o atraso de atuação e a coordenação de abertura de cada fase pela passagem por zero da corrente. 
Quadro 4.6 - Código do Modelo - MODEL Disjuntor.

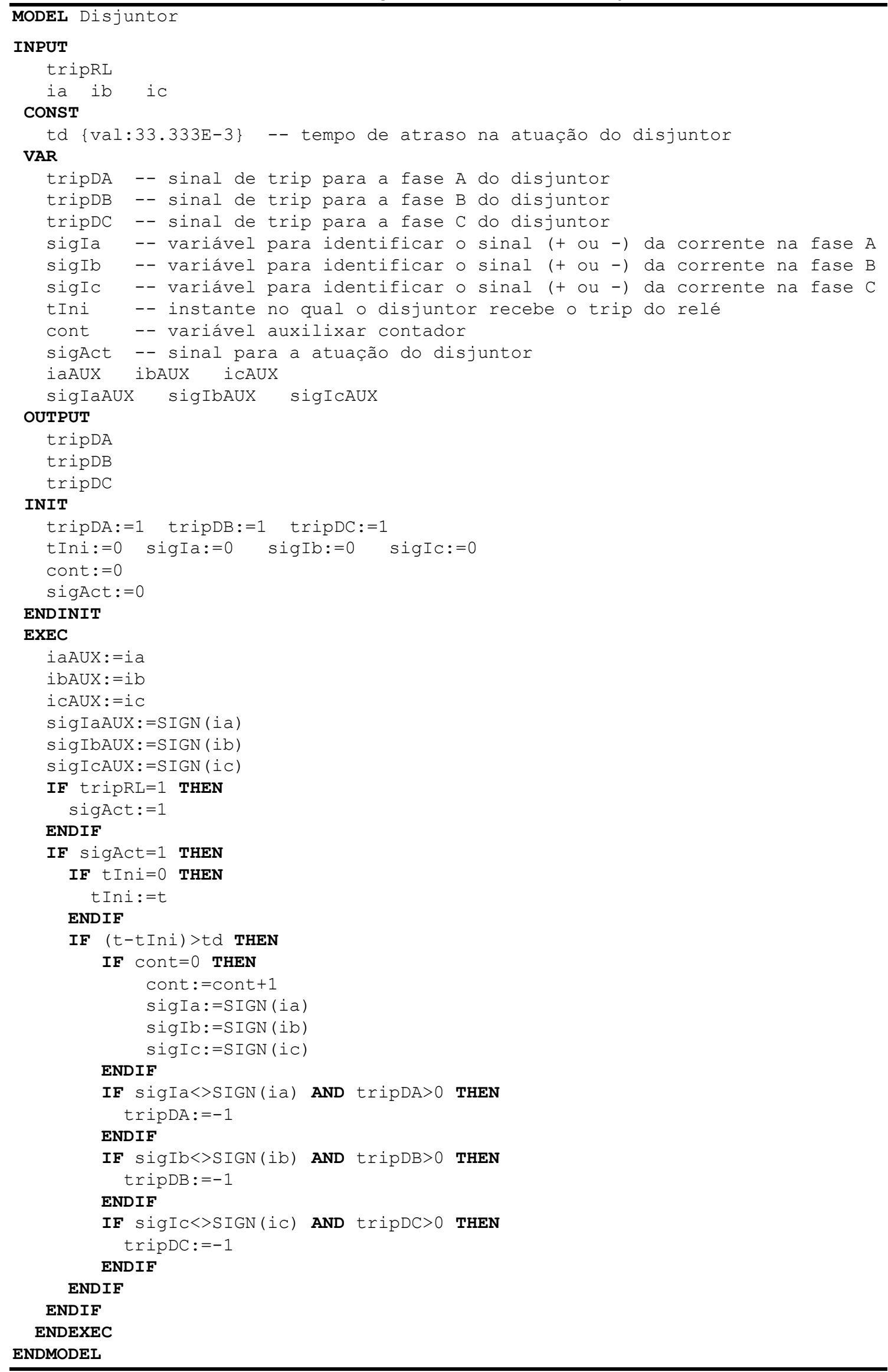




\section{CAPÍTULO 5}

\section{APRESENTAÇÃO E ANÁLISE DOS RESULTADOS}

\subsection{DESCRIÇÃO DO SISTEMA ELÉTRICO}

O diagrama unifilar do sistema elétrico de $230 \mathrm{kV}$ avaliado nesse trabalho de dissertação é ilustrado na Figura 5.1. O esquema se refere à configuração de barramento simples seccionado, sendo utilizado quando se deseja alguma seletividade. O barramento da subestação é seccionado utilizando um disjuntor e duas chaves seccionadoras.

As chaves seccionadoras possuem a função de promover a isolação do disjuntor quando se faz necessário realizar sua manutenção. Uma das desvantagens desse esquema decorre do fato de que na manutenção do disjuntor o circuito a ele associado deverá ser desenergizado. Entretanto, esse esquema apresenta inúmeras vantagens, quais sejam: pode funcionar com duas entradas de alimentação, apresenta maior facilidade na execução de serviços de manutenção, em casos de falha no barramento somente os circuitos conectados na zona afetada serão desligados, apresenta baixo custo de implementação, entre outros.

Estão conectados ao barramento dois transformadores e quatro linhas de transmissão de $100 \mathrm{~km}$, modeladas como perfeitamente transpostas, a parâmetros distribuídos e constantes com a frequência.

O Sistema foi simulado no software ATP e o seu sistema de proteção foi modelado na MODELS, conforme apresentado no Capítulo 4.

Os TCs utilizados são do tipo C800 2000-5A. As resistências do secundário e dos cabos dos TCs são, respectivamente, $R_{T C}=0,75 \Omega$ e $R_{l}=0,8 \Omega$. 


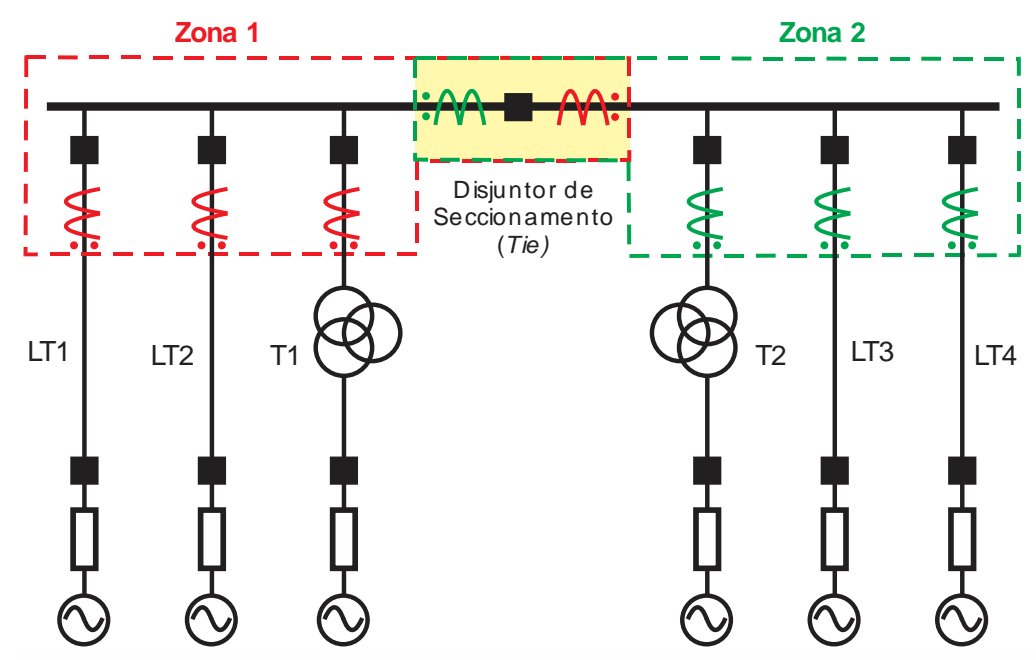

Figura 5.1 - Diagrama unifilar do sistema elétrico simulado.

A proteção do barramento é realizada em duas zonas, conforme ilustrado na Figura 5.1. Na zona 1 estão presentes os TCs da linhas de transmissão 1 e 2, do transformador 1 e do TC da barra posicionado a direita do disjuntor de seccionamento.

Com o disjuntor de seccionamento é possível melhorar a continuidade de fornecimento de energia, pois em caso de falha, somente o setor afetado é desligado. Ele também é capaz de flexibilizar manobras para manutenção e possibilitar uma maior continuidade operacional.

As curvas fluxo versus corrente dos transformadores T1 e T2 podem ser visualizadas nas Figuras 5.2 (a) e 5.2 (b) e seus parâmetros na Tabela 5.1. Os transformadores T1 e T2 utilizados são formados por um banco de transformadores monofásicos.

O esquemático da ligação em paralelo dos TCs pertencentes à zona 1 pode ser visualizado na Figura 5.3. De forma análoga estão conectados os TCs da zona 2.

Os parâmetros utilizados no circuito são mostrados nas Tabelas 5.2 e 5.3, nas quais os subscritos 0 e 1 fazem referência aos parâmetros de sequência zero e positiva, respectivamente. 


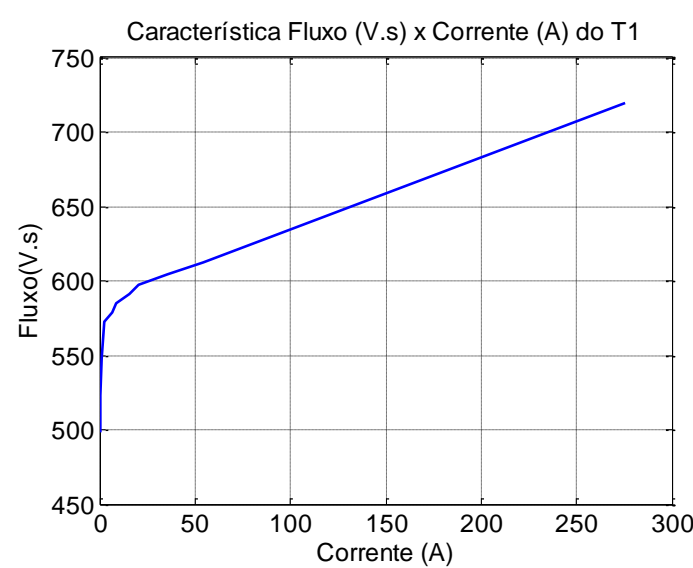

(a)

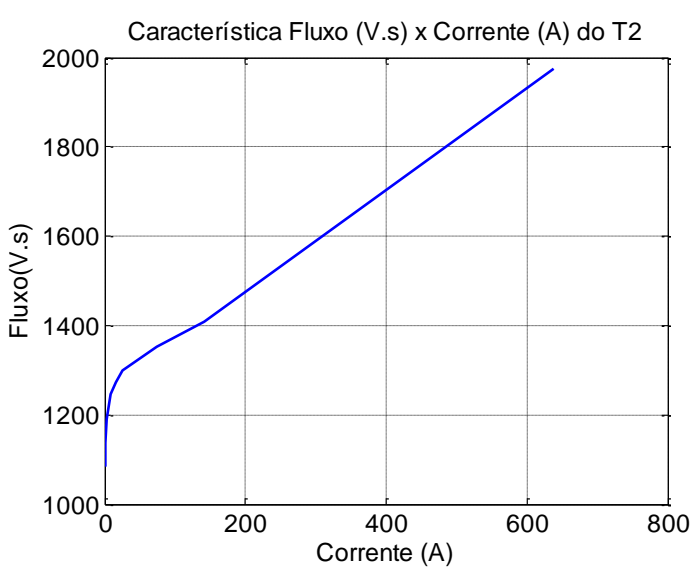

(b)

Figura 5.2 - Característica fluxo x corrente dos transformadores. a) T1. b) T2.

Tabela 5.1 - Parâmetros dos transformadores.

\begin{tabular}{lccc|ccc}
\hline \multicolumn{3}{c}{$T 1[230 / 69 / 13,8 \mathrm{kV}]$} & \multicolumn{3}{c}{$T 2[500 / 230 / 13,8 \mathrm{kV}]$} \\
\hline & $R[\Omega]$ & $X[\Omega]$ & $V_{\text {nominal }}[\mathrm{kV}]$ & $R[\Omega]$ & $X[\Omega]$ & $V_{\text {nominal }}[\mathrm{kV}]$ \\
\hline Primário & 1,43 & 38,03 & 230 & 0,347 & $-2,50$ & 500 \\
Secundário & 2,04 & $-12,5$ & 69 & 0,919 & 6,11 & 230 \\
Terciário & 0,04 & 1,13 & 13,8 & 0,009 & 0,858 & 13,8 \\
\hline
\end{tabular}

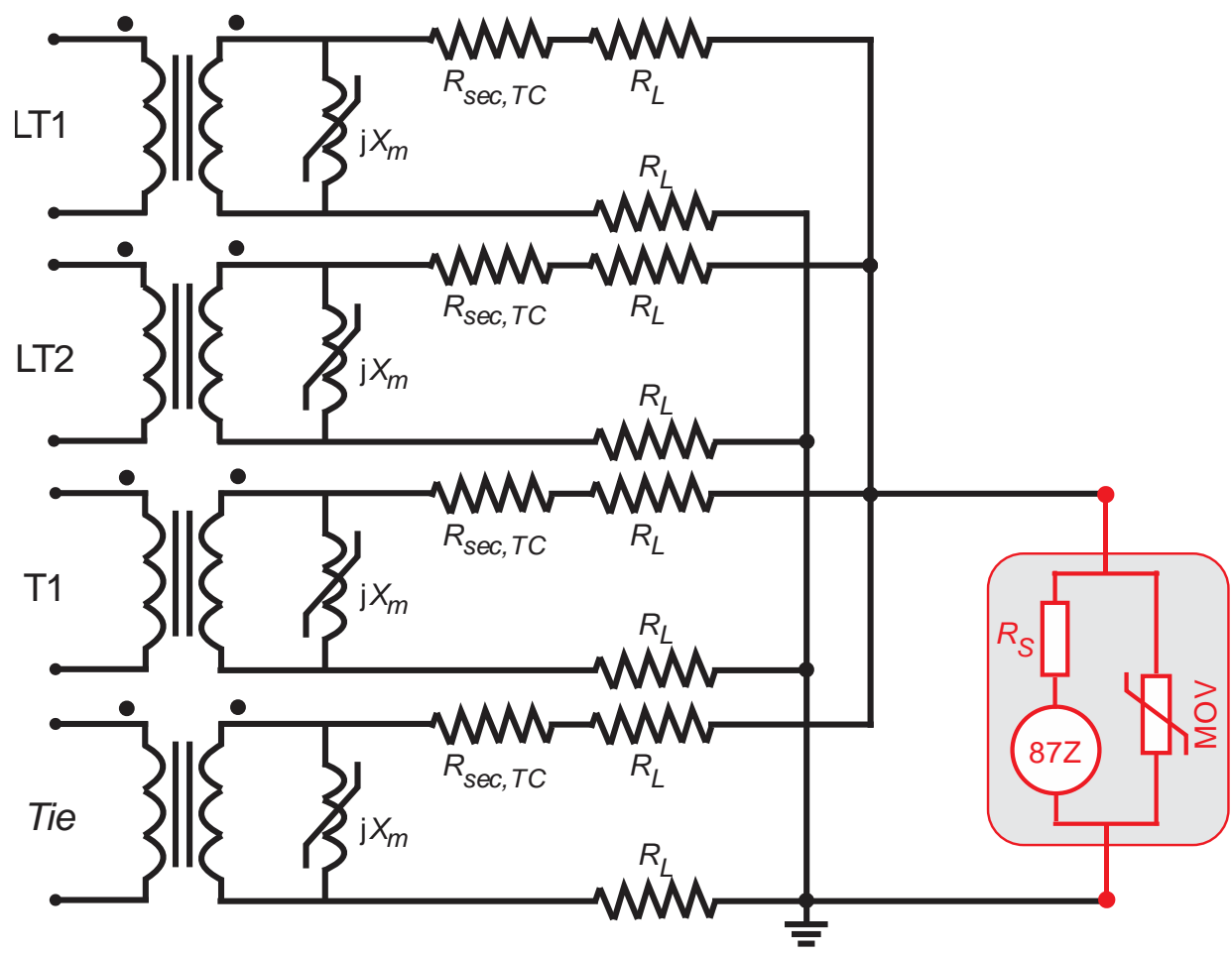

Figura 5.3 - Esquema de ligação da proteção diferencial de alta impedância de barramentos da Zona 1. 
Tabela 5.2 - Parâmetros das LTs.

\begin{tabular}{ccccc}
\hline & $Z_{0}[\Omega / \mathrm{km}]$ & $Z_{1}[\Omega / \mathrm{km}]$ & $Y_{0}[\mu \mathrm{S} / \mathrm{km}]$ & $Y_{1}[\mu \mathrm{S} / \mathrm{km}]$ \\
\hline LT1,LT2 & $0,532+\mathrm{j} 1,541$ & $0,098+\mathrm{j} 0,510$ & 2,293 & 3,252 \\
LT3,LT4 & $0,469+\mathrm{j} 1,289$ & $0,098+\mathrm{j} 0,506$ & 2,164 & 3,272 \\
\hline
\end{tabular}

Tabela 5.3 - Parâmetros das fontes de tensão.

\begin{tabular}{ccccc}
\hline & Fontes & $\mathrm{V}[\mathrm{pu}]$ & $Z_{f 0}[\Omega]$ & $Z_{f 1}[\Omega]$ \\
\hline LT1 & $\mathrm{S} 1$ & $1,01 \angle-30^{\circ}$ & $12,782+\mathrm{j} 19,917$ & $10,043+\mathrm{j} 15,649$ \\
LT2 & $\mathrm{S} 2$ & $1 \angle-30^{\circ}$ & $12,782+\mathrm{j} 19,917$ & $10,042+\mathrm{j} 15,649$ \\
$\mathrm{~T} 1$ & $\mathrm{~S} 3$ & $0,29 \angle-30^{\circ}$ & $3,1028+\mathrm{j} 4,6949$ & $4,5192+\mathrm{j} 7,0423$ \\
LT3 & $\mathrm{S} 4$ & $1 \angle-30^{\circ}$ & $11,587+\mathrm{j} 18,057$ & $9,2702+\mathrm{j} 14,445$ \\
LT4 & $\mathrm{S} 5$ & $0,99 \angle-30^{\circ}$ & $11,587+\mathrm{j} 18,057$ & $9,2702+\mathrm{j} 14,445$ \\
T2 & $\mathrm{S} 6$ & $2,06 \angle-30^{\circ}$ & $11,791+\mathrm{j} 18,371$ & $10,481+\mathrm{j} 16,329$ \\
\hline
\end{tabular}

O valor de $V_{\text {pick-up }}$ para cada zona de proteção foi calculado determinando-se as contribuições de corrente na barra a partir de curtos circuitos trifásicos e monofásicos nas zonas 1 e 2,considerando-se o pior caso para a tensão desenvolvida nos terminais do relé. Os valores das contribuições de corrente no barramento na zona 1 e na zona 2 podem ser observadas, respectivamente, nas Tabelas 5.4 e 5.5. As tensões trifásicas e monofásicas para a zona 1 e para a zona 2 foram obtidas conforme detalhamento na seção 3.5.2.1, Equações 3.10, 3.11 e 3.12. Desta forma, foram obtidos os valores de $V_{\text {pick-up }}$ para ambas as zonas igual a $150 \mathrm{~V}$, já sendo considerado o fator de sobretensão de 1,5, de modo a garantir uma margem de segurança à proteção.

\section{ZONA 1}

Tabela 5.4 - Contribuições de corrente no barramento.

\begin{tabular}{lcccc}
\hline Curto-Circuito & LT1 & LT2 & $T 1$ & $T I E$ \\
\hline Monofásico & $1295,2 \angle-72,19^{\circ}$ & $1295,2 \angle-72,196^{\circ}$ & $1039,8 \angle-52,3308^{\circ}$ & $9164,3 \angle-84,68^{\circ}$ \\
Trifásico & $2479,7 \angle-78,4015^{\circ}$ & $2479,7 \angle-78,4015$ & $1019,4 \angle-49,75^{\circ}$ & $1140,4 \angle-85,10^{\circ}$ \\
\hline
\end{tabular}

\section{ZONA 2}

Tabela 5.5 - Contribuições de corrente no barramento.

\begin{tabular}{ccccc}
\multicolumn{4}{c}{ Tabela 5.5 } & \multicolumn{4}{c}{ Contribuiçoes de corrente no barramento. } \\
\hline $\begin{array}{c}\text { Curto- } \\
\text { Circuito }\end{array}$ & LT3 & LT4 & T2 & TIE \\
\hline Monofásico & $1410,5 \angle 71,85^{\circ}$ & $1410,5 \angle 71,85^{\circ}$ & $6444,4 \angle-90,26^{\circ}$ & $3585,7 \angle-66,54^{\circ}$ \\
Trifásico & $2504,2 \angle-78,36^{\circ}$ & $2504,2 \angle-78,36^{\circ}$ & $6456,9 \angle-90,32^{\circ}$ & $5874,5 \angle-73,62^{\circ}$ \\
\hline
\end{tabular}


A fim de avaliar o desempenho da proteção diferencial de alta impedância modelada na MODELS, foram simulados diversos tipos de curto-circuito no sistema avaliado neste trabalho. A seguir, apresentam-se os resultados obtidos das simulações.

\subsection{RESULTADO DAS SIMULAÇÕES}

Para a implementação no ATP do esquema visualizado na Figura 5.1, não foram inseridos os relés de sobrecorrente 50/51 e o contato NA do relé de bloqueio 86, uma vez que não foram necessários para a realização da análise da eficiência e atuação da proteção diferencial de alta impedância de barramentos.

Foram plotadas em uma mesma imagem, para os diferentes tipos de curtoscircuitos, a tensão e a magnitude do fasor tensão nos terminais do relé. O relé da zona 1 deve atuar quando a magnitude do fasor tensão nos terminais deste excede o valor de $V_{\text {pick-up }}$ ajustado no relé, ou seja, excede o valor de $150 \mathrm{~V}$ e analogamente o relé na zona 2 atuará quando $V_{\text {pick-up }}$ exceder $150 \mathrm{~V}$.

Foram simulados curtos-circuitos internos e externos no barramento da Zona 1 e da Zona 2, conforme apresentado na Tabela 5.6. O barramento é protegidos pelo relé diferencial de alta impedância. Apresentam-se a seguir os diversos tipos de curtoscircuitos aplicados.

Tabela 5.6 - Casos de curtos-circuitos no sistema elétrico simulado.

\begin{tabular}{|c|c|}
\hline Caso & Descrição \\
\hline 1 & Curto-circuito Monofásico Franco na Fase A no Barramento - Zona 1 \\
\hline 2 & $\begin{array}{l}\text { Curto-circuito Trifásico em um Ponto Imediatamente a Frente do TC no T1 com o TC Saturado - } \\
\text { Zona } 1\end{array}$ \\
\hline 3 & $\begin{array}{l}\text { Curto-circuito Trifásico no Barramento na Presença de Manutenção do Disjuntor da LT1 - } \\
\text { Zona } 1\end{array}$ \\
\hline 4 & Curto-circuito Trifásico no Barramento com o TC da LT1 Curto-circuitado - Zona 1 \\
\hline 5 & $\begin{array}{l}\text { Curto-Circuito Monofásico na Fase A na LT1 em um Ponto Imediatamente a Frente do TC - } \\
\text { Zona } 1\end{array}$ \\
\hline 6 & Curto-circuito Trifásico no Barramento -Zona 2 \\
\hline 7 & Curto-circuito Trifásico na LT 4 em um Ponto Imediatamente a Frente do TC - Zona 2 \\
\hline
\end{tabular}




\subsubsection{CASO 1: CURTO-CIRCUITO MONOFÁSICO FRANCO NA FASE A NO BARRAMENTO - ZONA 1}

Conforme se pode visualizar na Figura 5.4 (a), o valor máximo da magnitude do fasor tensão nos terminais do relé é aproximadamente igual a $600 \mathrm{~V}$, sendo,

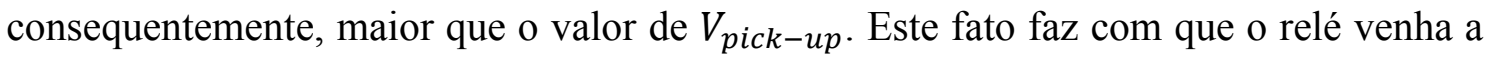
atuar fornecendo um sinal de trip a todos os disjuntores utilizados para conectar as linhas de transmissão ao barramento, uma vez que o trip é trifásico.

Na Figura 5.4 (a), observa-se o detalhe da tensão ceifada pelo MOV. Devido ao limite de tensão diferencial permitido de no máximo $1300 \mathrm{~V}$ em seus terminais, a resistência não linear ceifa a curva de tensão no relé de modo a protegê-lo. Altas tensões são capazes de ocasionar perda de isolamento nos terminais do relé. Neste caso, devido ao MOV, a forma de curva de tensão não é mais senoidal.

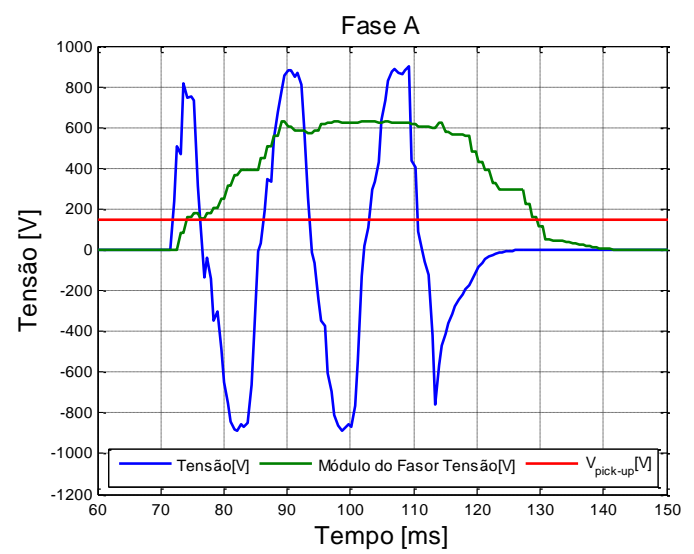

(a)

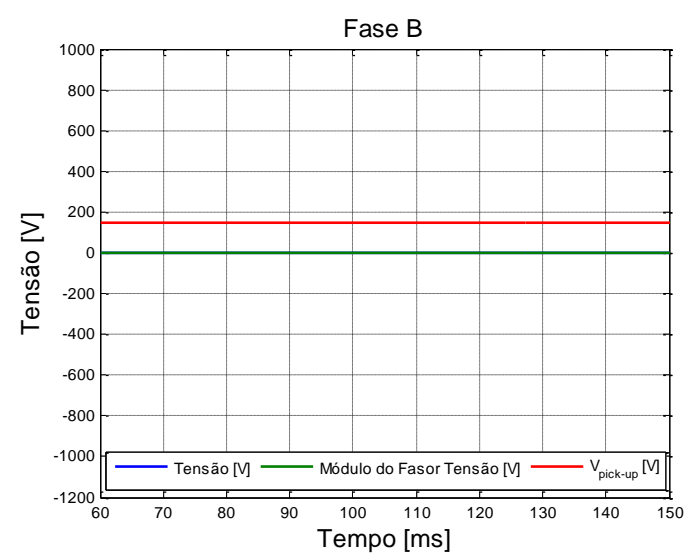

(b)

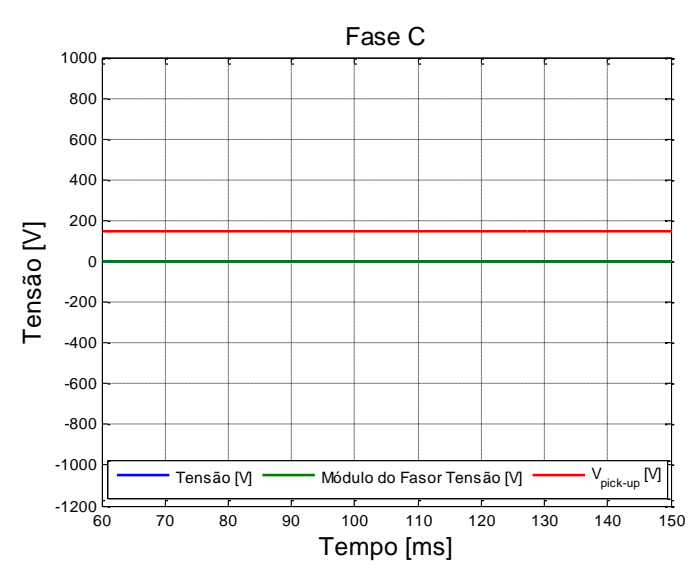

(c)

Figura 5.4 - Zona 1. Tensão nos terminais do relé quando de um curto-circuito monofásico franco na fase A no barramento: (a)Fase A. (b)Fase B. (c)Fase C. 
O tempo de atuação do relé $T_{\text {relé }}$ que corresponde ao tempo necessário para que o relé detecte a falta, o processo de estimação de fasores e o envio do sinal de trip aos disjuntores é de $4.1667 \mathrm{~ms}$ (ou 0,249 ciclos).

Conforme esperado, a zona 2 não é capaz de visualizar a falta e desta forma, a proteção não atua. A magnitude do fasor tensão na fase envolvida no curto-circuito é inferior ao valor de $V_{\text {pick-up }}$ como apresentado na Figura 5.5 (a).

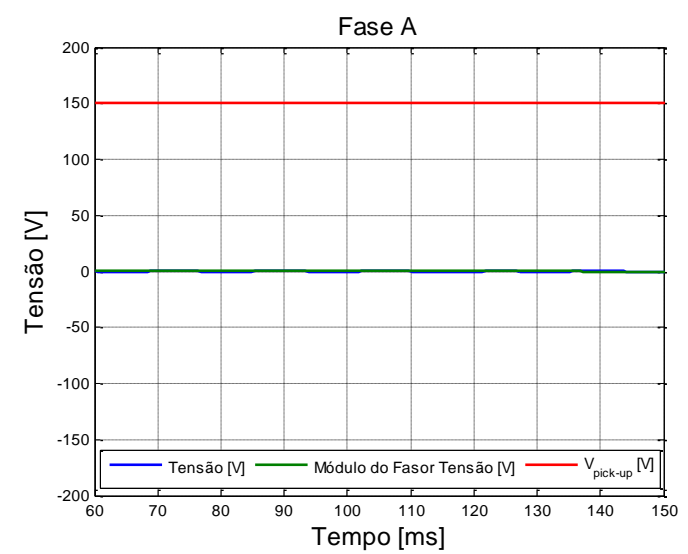

(a)

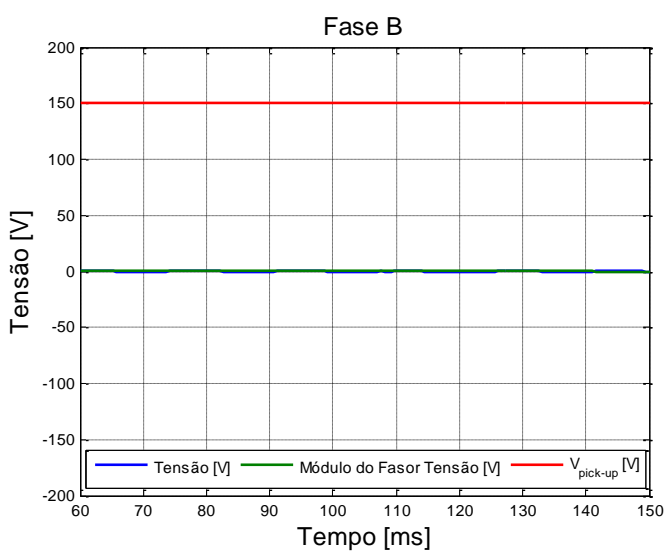

(b)

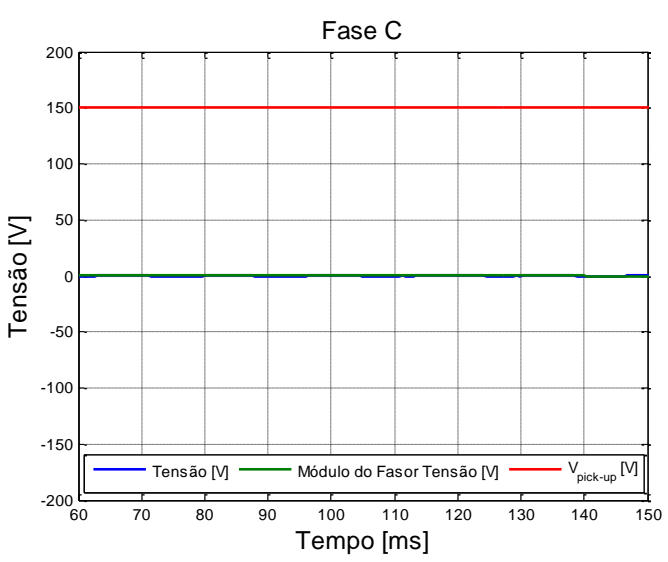

(c)

Figura 5.5 - Zona 2. Tensão nos terminais do relé quando de um curto-circuito monofásico franco na fase A no barramento: (a)Fase A. (b)Fase B. (c)Fase C.

\subsubsection{CASO 2: CURTO-CIRCUITO TRIFÁSICO EM UM PONTO IMEDIATAMENTE A FRENTE DO TC NO T1 COM O TC SATURADO - ZONA 1}

$\mathrm{O}$ curto-circuito trifásico, em um ponto imediatamente a frente do TC, no T1 configura a pior situação dentre todos os curtos-circuitos simulados na zona 1 realizados no sistema elétrico da Figura 5.1. 
O valor de $V_{\text {pick-up }}$ foi obtido, analisando um curto-circuito trifásico no T1, a partir das contribuições de corrente no barramento provindas da LT1, LT2 e TIE localizados na Zona 1.

Considerando o TC completamente saturado é possível verificar que o maior valor da magnitude do fasor tensão é aproximadamente $98,5 \mathrm{~V}$, conforme visualizado nas Figuras 5.6. Considerando o fator de sobretensão de 1,5 tem-se, portanto, o valor de $147,75 \mathrm{~V}$ que se aproxima do valor de $V_{\text {pick-up }}$ obtido de $150 \mathrm{~V}$.

Verifica-se desta forma, que o valor calculado para o $V_{\text {pick-up }}$ está apropriado e a proteção não atua para valores onde a magnitude do fasor tensão é inferior a tensão de limiar.

Mesmo com o TC completamente saturado a proteção diferencial de alta impedância de barramentos não atua conferindo imunidade à saturação do TC.

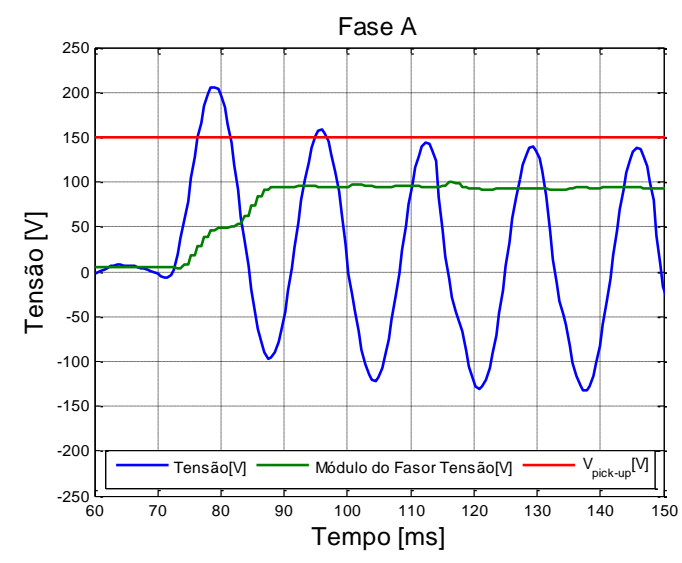

(a)

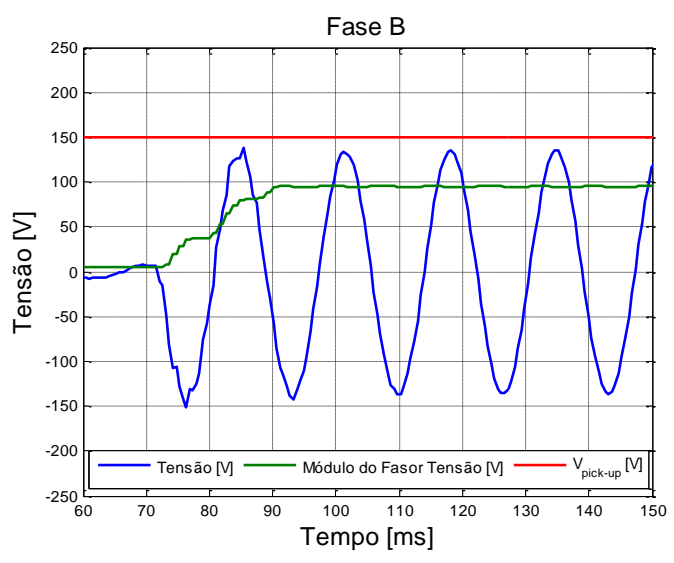

(b)

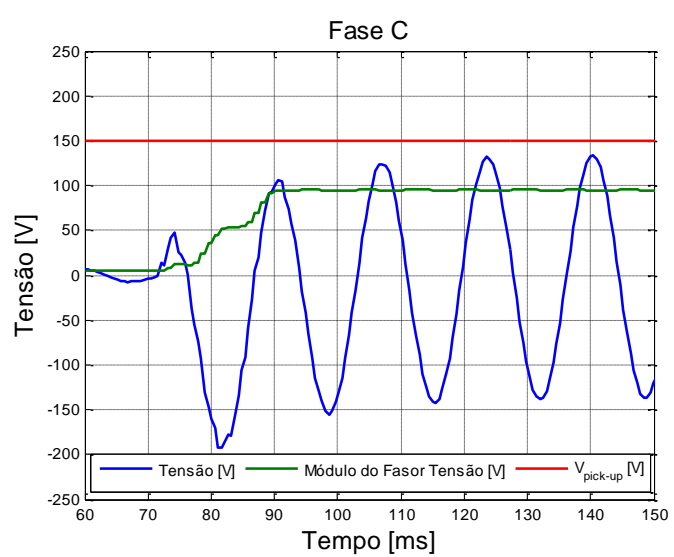

(c)

Figura 5.6 - Zona 1. Tensão nos terminais do relé quando de um curto-circuito trifásico em um ponto imediatamente a frente do TC no T1 com o TC saturado: (a)Fase A. (b)Fase B. (c)Fase C. 
Para um curto-circuito externo, a proteção da zona 2 não deve atuar. A magnitude do fasor tensão em todas as fases é nula, conforme apresentado nas Figuras 5.7 .

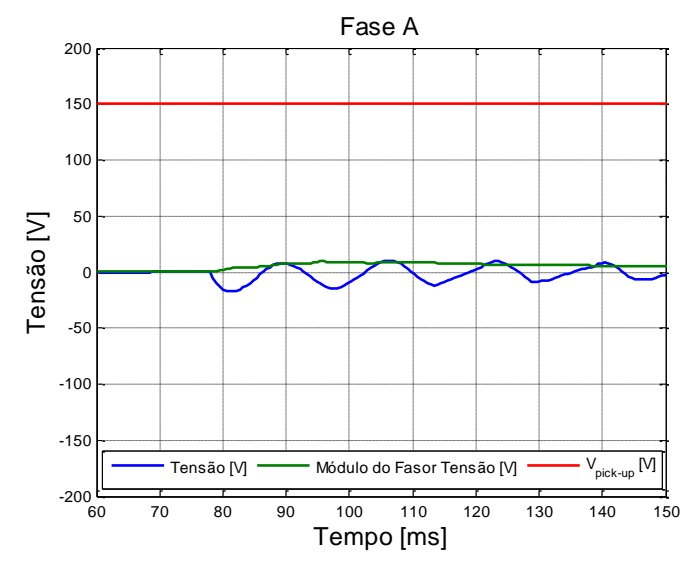

(a)

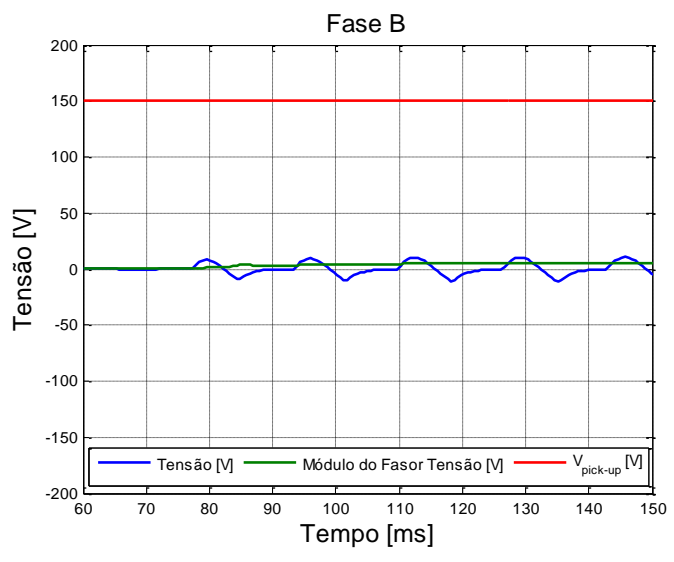

(b)

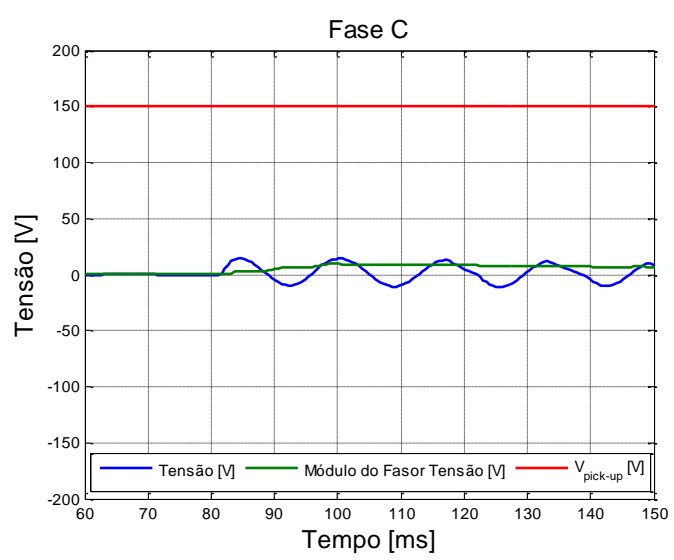

(c)

Figura 5.7 - Zona 2. Tensão nos terminais do relé quando de um curto-circuito trifásico em um ponto imediatamente a frente do TC no T1 com o TC saturado: (a)Fase A. (b)Fase B. (c)Fase C.

\subsubsection{CASO 3: CURTO-CIRCUITO TRIFÁSICO NO BARRAMENTO NA PRESENÇA DE MANUTENÇÃO DO DISJUNTOR DA LT1 - ZONA 1}

Quando da manutenção do disjuntor da linha de transmissão 1, mantendo seus terminais em aberto, foi simulado um curto-circuito interno no barramento da zona $1 \mathrm{e}$ verificada a atuação da proteção. Verifica-se que a corrente no ramo de magnetização do TC é muito pequena e, portanto, não é capaz de dessensibilizar a proteção. Não é necessário realizar o chaveamento do secundário do TC e retirá-lo da malha diferencial pois o mesmo não apresenta prejuízos para a atuação da proteção. Nas figuras 5.8, visualiza-se a magnitude do fasor tensão superior ao valor de $V_{\text {pick-up }}$. 


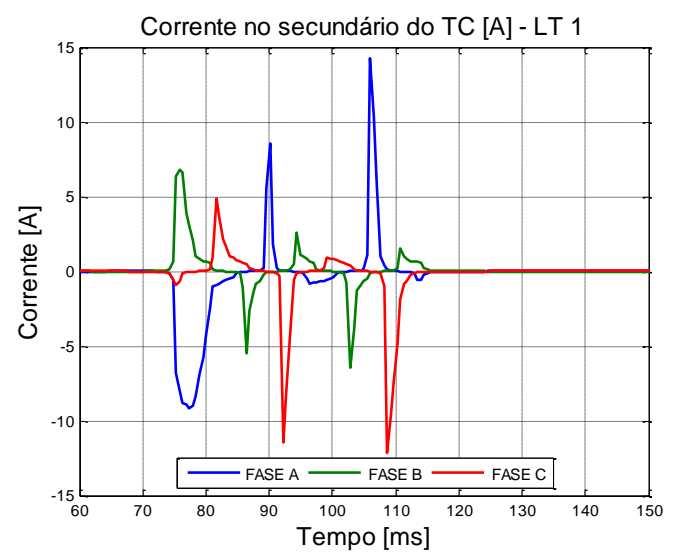

(a)

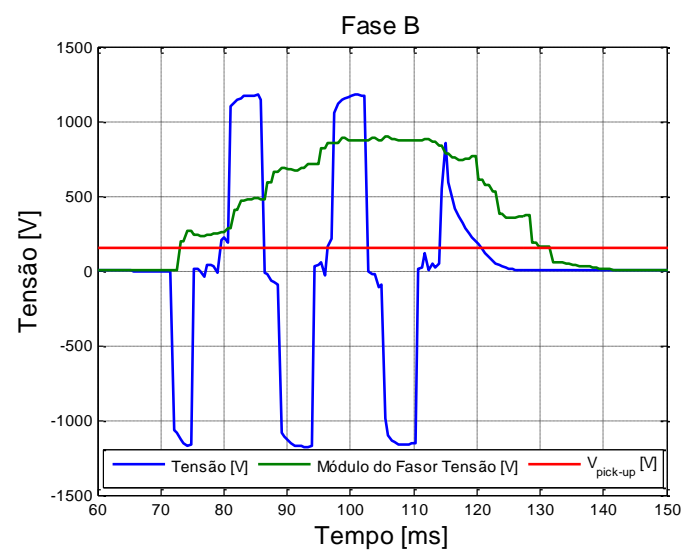

(c)

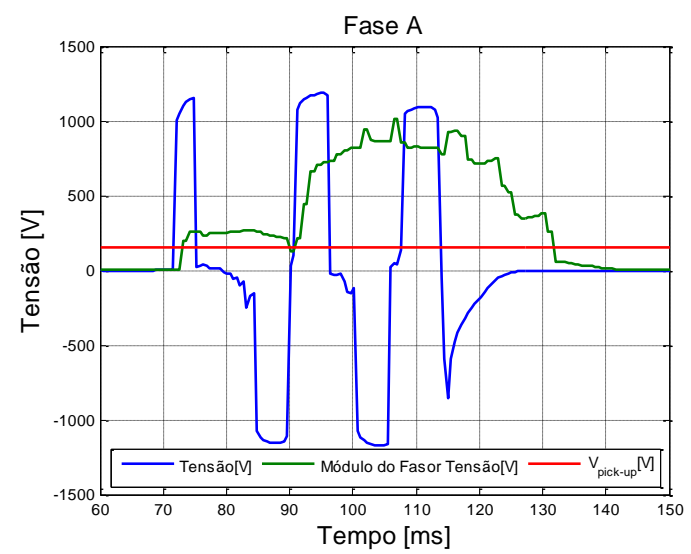

(b)

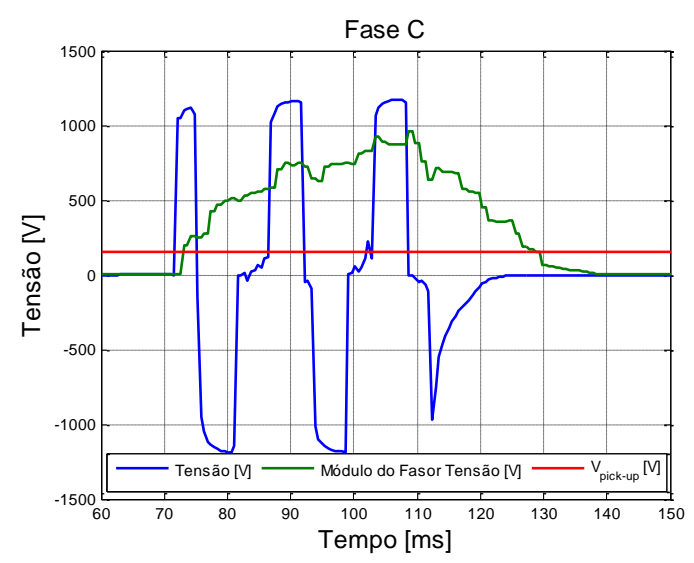

(d)

Figura 5.8 - Zona 1. Corrente no secundário do TC da LT 1 (a) Fase A, B e C. Tensão nos terminais do relé quando na manutenção do Disjuntor da LT1: (b)Fase A. (c)Fase B. (d)Fase C.

A proteção da zona 2 não atua para faltas no barramento da zona 1. Conforme verificam-se nas Figuras 5.9, o limiar da tensão de ajuste do relé não é alcançado. 


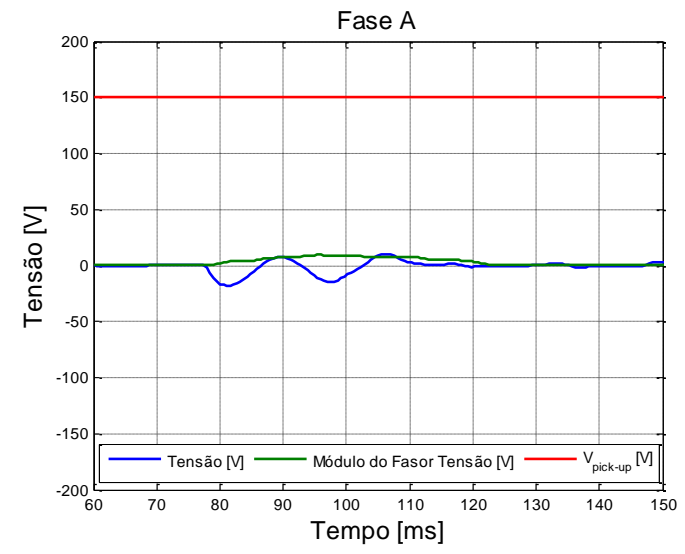

(a)

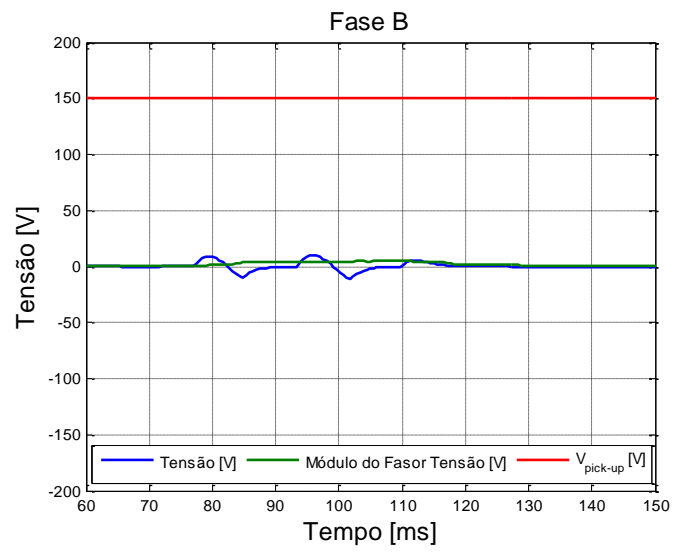

(b)

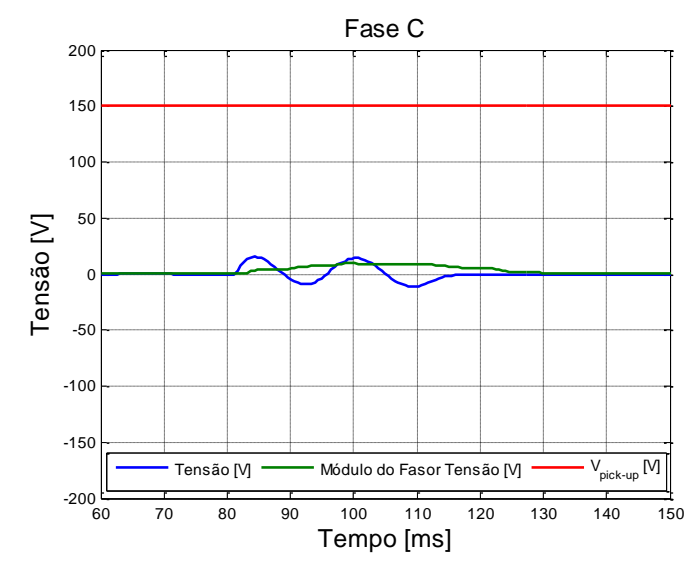

(c)

Figura 5.9 - Zona 2. Tensão nos terminais do relé quando na manutenção do Disjuntor da LT1: (a)Fase A. (b)Fase B. (c)Fase C.

\subsubsection{CASO 4: CURTO-CIRCUITO TRIFÁSICO NO BARRAMENTO COM O TC DA LT 1 CURTO-CIRCUITADO - ZONA 1}

Verifica-se nas Figuras 5.10 que no caso de um curto-circuito interno ao barramento a proteção não atua quando deveria atuar. Isto ocorre, pois a tensão nos terminais do relé é nula e a proteção não é capaz de detectar que um dos TCs do esquema está curto circuitado. Desta forma, a proteção não visualiza a falta e, portanto, não atua.

Uma maneira de detectar um curto-circuito em um dos TCs do circuito é aplicar uma pequena tensão alternada nos terminais do relé e medir a corrente através deste. $\mathrm{O}$ elevado valor da impedância do ramo de magnetização dos TCs e da resistência de estabilização sob condições normais de operação deve impedir que ocorra qualquer fluxo de corrente pelo relé, exceto quando um dos TCs está em curto. 


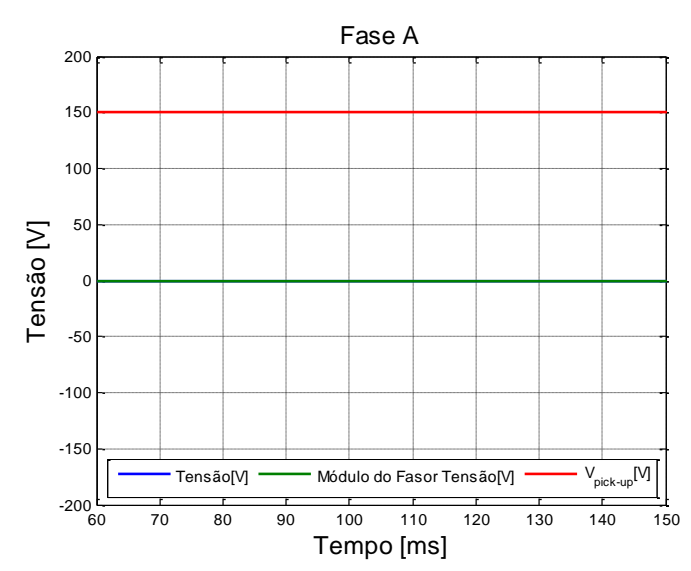

(a)

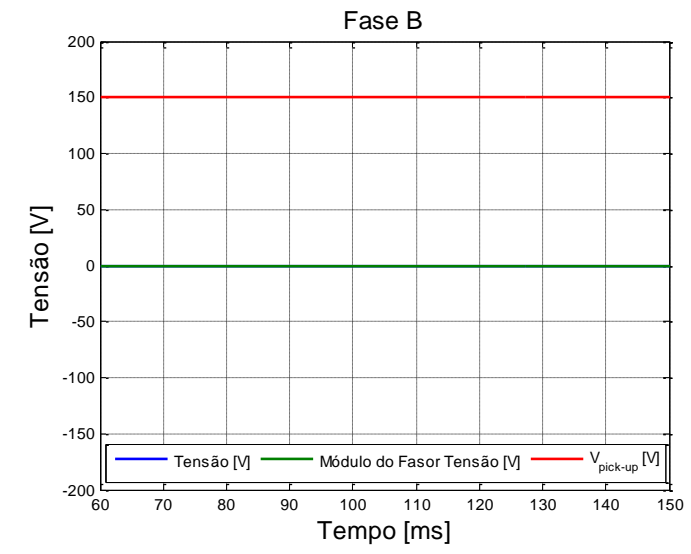

(b)

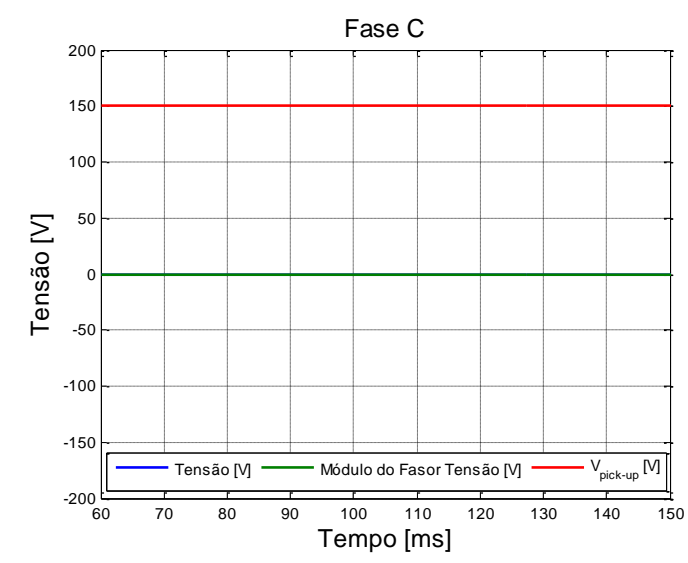

(c)

Figura 5.10 - Zona 1. Tensão nos terminais do relé quando de um curto-circuito trifásico no barramento com o TC da LT1 curto-circuitado: (a)Fase A. (b)Fase B. (c)Fase C.

Uma vez que a falta é ocasionada na zona 1, a zona 2 não percebe a falta e portanto, não atua. As Figuras 5.11 apresentam os resultados obtidos, onde se visualiza que a magnitude do fasor tensão em todas as fases é nula. 


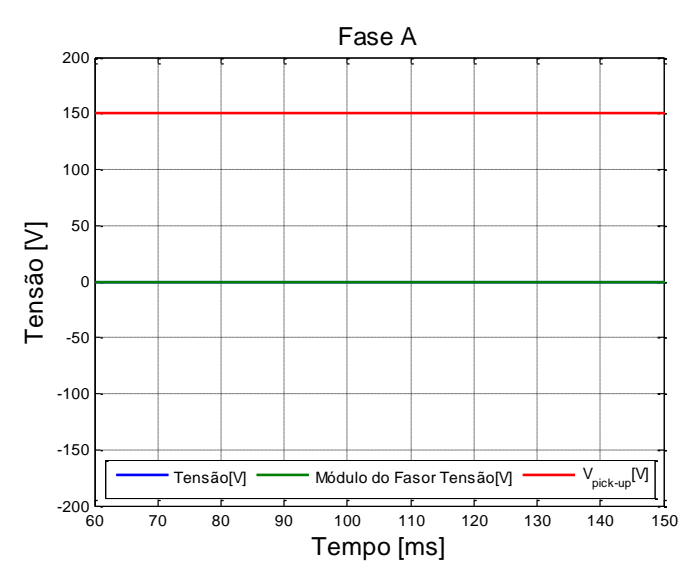

(a)

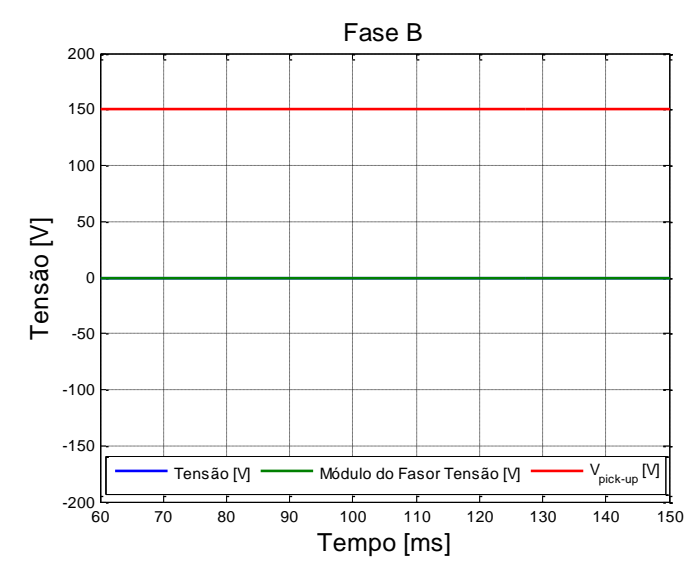

(b)

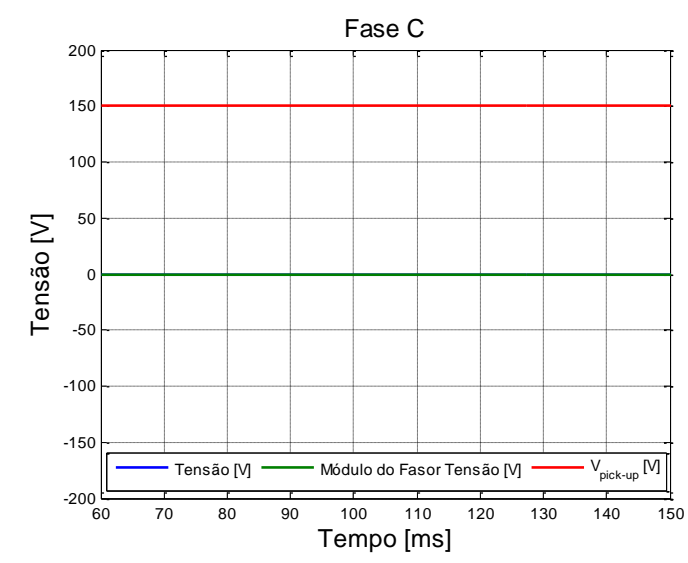

(c)

Figura 5.11- Zona 2. Tensão nos terminais do relé quando de um curto-circuito trifásico no barramento com o TC da LT1 curto-circuitado: (a)Fase A. (b)Fase B. (c)Fase C.

\subsubsection{CASO 5: CURTO-CIRCUITO MONOFÁSICO NA FASE A NA LT1 EM UM PONTO IMEDIATAMENTE A FRENTE DO TC - ZONA 1}

A falta foi aplicada na Linha de transmissão $1 \mathrm{em}$ um ponto imediatamente à frente do TC. Para um curto-circuito que ocorra fora do barramento, ou seja, fora da zona de proteção diferencial de alta impedância de barramento, o relé não deve atuar.

A partir da análise das Figuras 5.12, conforme esperado, o relé não atuou. $\mathrm{Na}$ Figura 5.12 (a) pode-se perceber que a magnitude do fasor tensão na fase A, parâmetro utilizado para verificar se a proteção deve atuar, já que se trata de um curto-circuito monofásico na fase A, é aproximadamente nula. Nessa situação, a proteção da linha de transmissão 1, não avaliada nesse trabalho, deveria atuar para extinguir o defeito. 


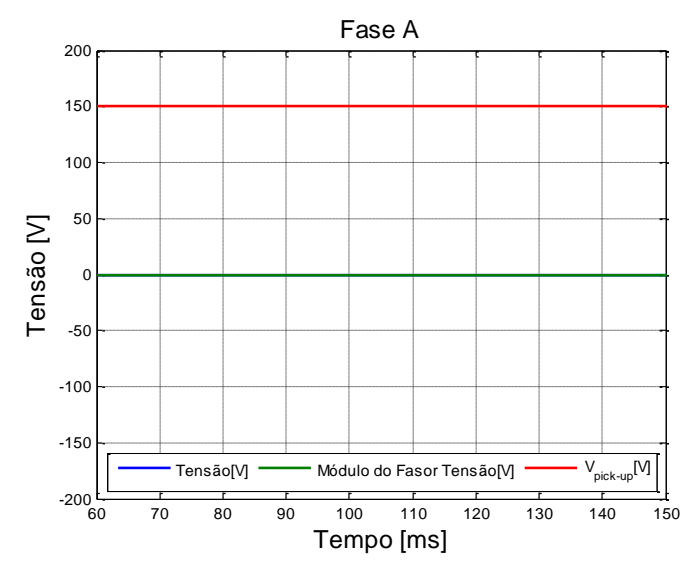

(a)

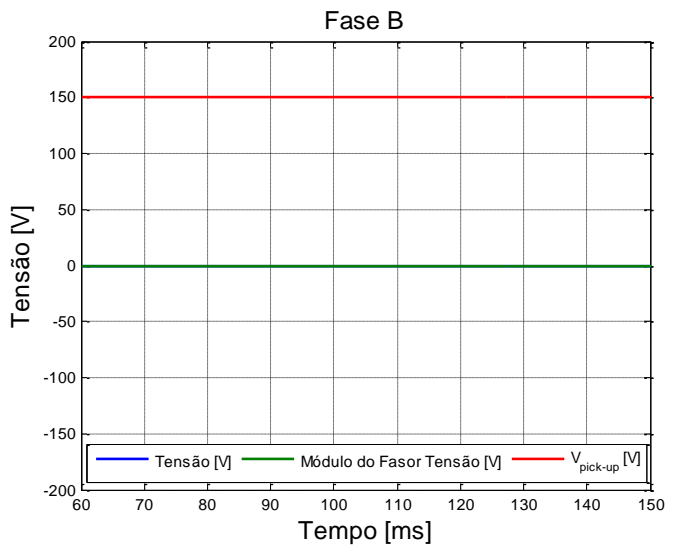

(b)

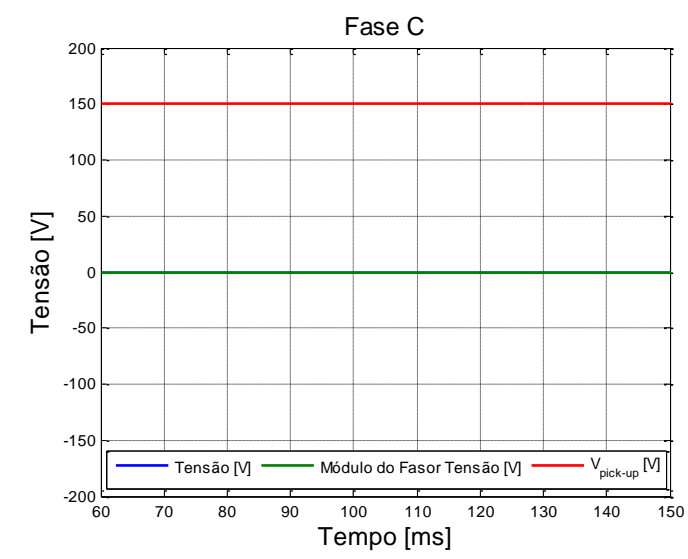

(c)

Figura 5.12 - Zona 1. Tensão nos terminais do relé quando de um curto-circuito monofásico na Fase A na LT1 em um ponto imediatamente a frente do TC: (a)Fase A. (b)Fase B. (c)Fase C. 
A zona 2 não é capaz de perceber o curto e, portanto, não atua. Nas Figuras 5.13 pode-se observar que a magnitude do fasor tensão em todas as fases é nula.

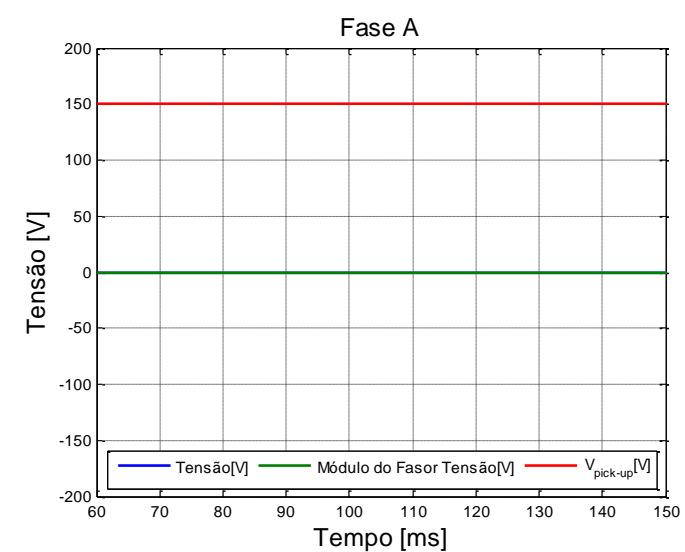

(a)

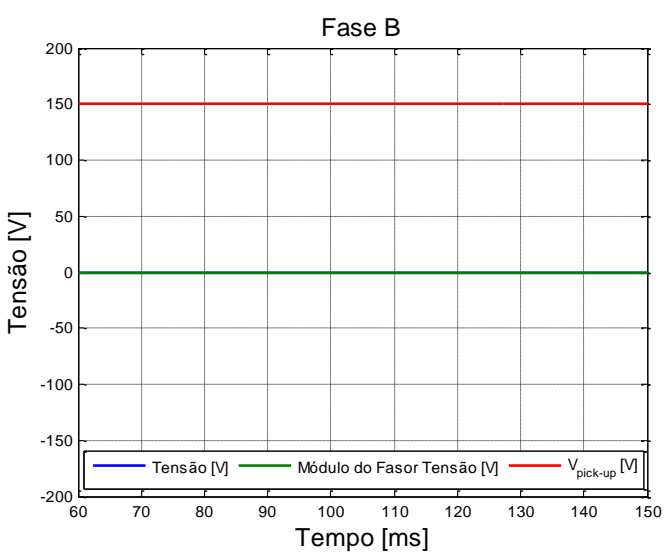

(b)

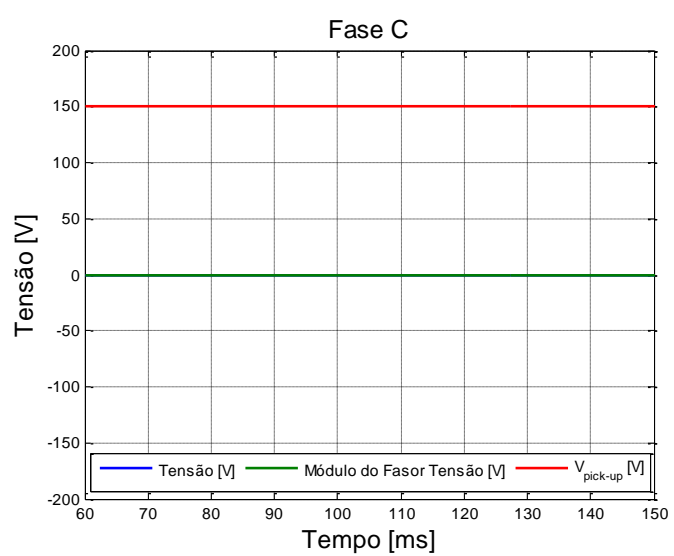

(c)

Figura 5.13 - Zona 2. Tensão nos terminais do relé quando de um curto-circuito monofásico na Fase A na LT1 em um ponto imediatamente a frente do TC: (a)Fase A. (b)Fase B. (c)Fase C.

\subsubsection{CASO 6: CURTO-CIRCUITO TRIFÁSICO NO BARRAMENTO - ZONA} 2

A falta trifásica aplicada no barramento na zona 2 não é capaz de sensibilizar a proteção da zona 1 a atuar, conforme o esperado. Conforme Figuras 5.14, a proteção não enxerga a falta e a magnitude do fasor tensão é nula em todas as fases. 


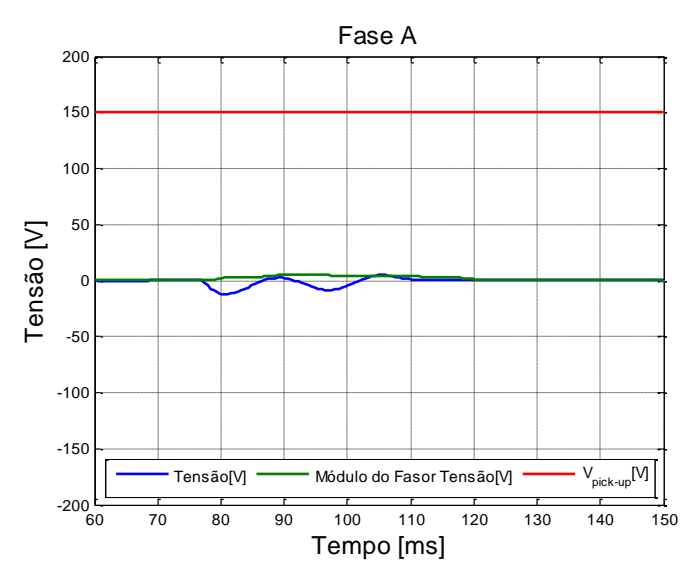

(a)

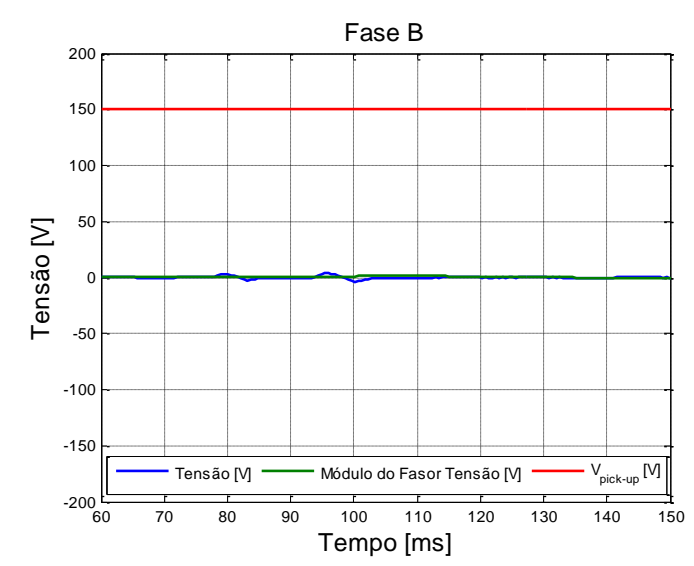

(b)

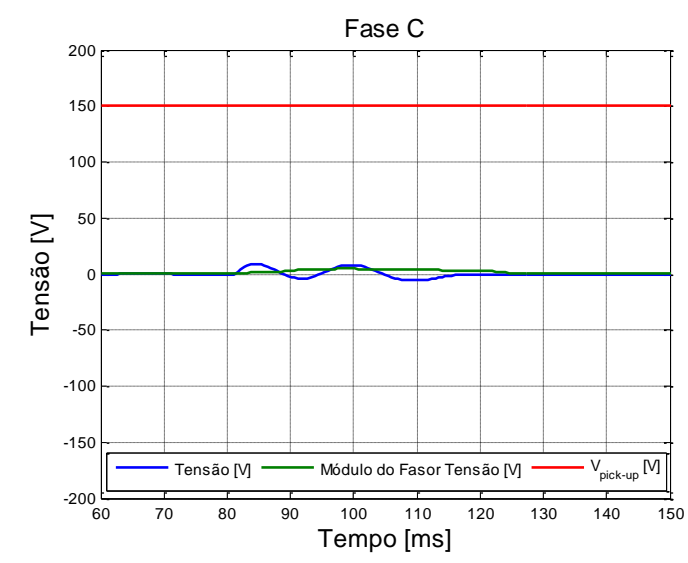

(c)

Figura 5.14 - Zona 1. Tensão nos terminais do relé quando de um curto-circuito trifásico no barramento: (a)Fase A. (b)Fase B. (c)Fase C.

Um curto-circuito trifásico no barramento é capaz de sensibilizar os relés em todas as fases. Nesta situação, conforme pode ser visualizado nas Figuras 5.15, o valor máximo da magnitude do fasor tensão nos terminais do relé excedeu o valor ajustado de $150 \mathrm{~V}$, fazendo com que a proteção atuasse corretamente.

Mais uma vez, a tensão nos terminais do relé, conforme as Figuras 5.15, é ceifada pelo MOV, devido ao limite de tensão de $1300 \mathrm{~V}$ de modo a garantir segurança ao relé. A forma de onda não é senoidal. O tempo de atuação do relé foi 2, $0833 \mathrm{~ms}$ (ou 0,124 ciclos). 


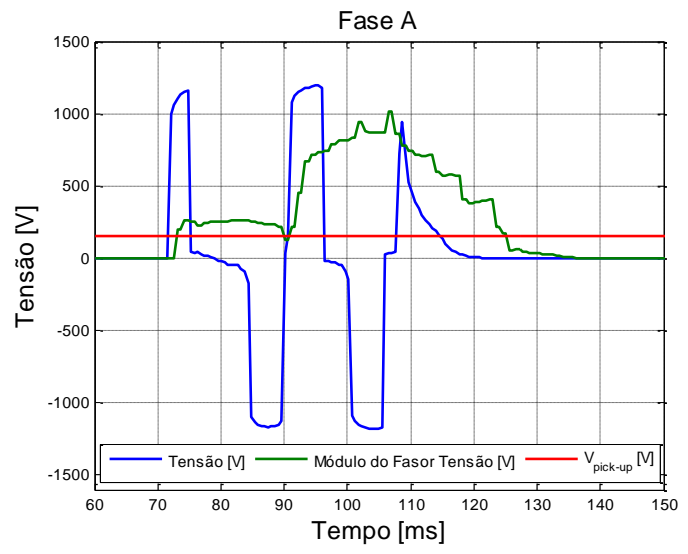

(a)

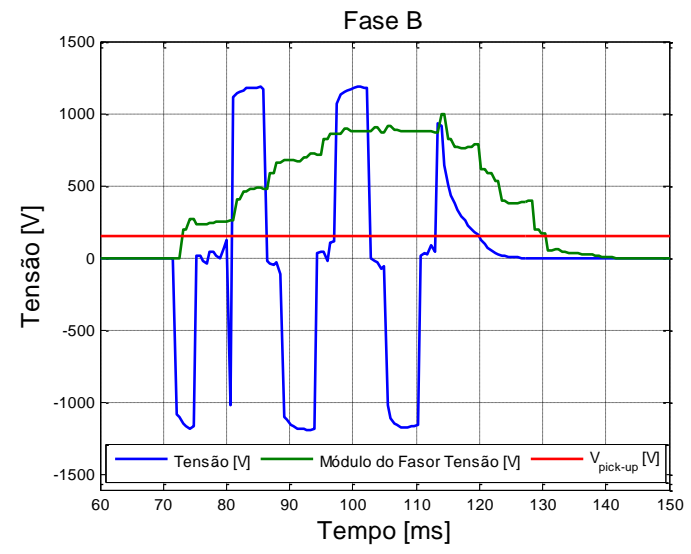

(b)

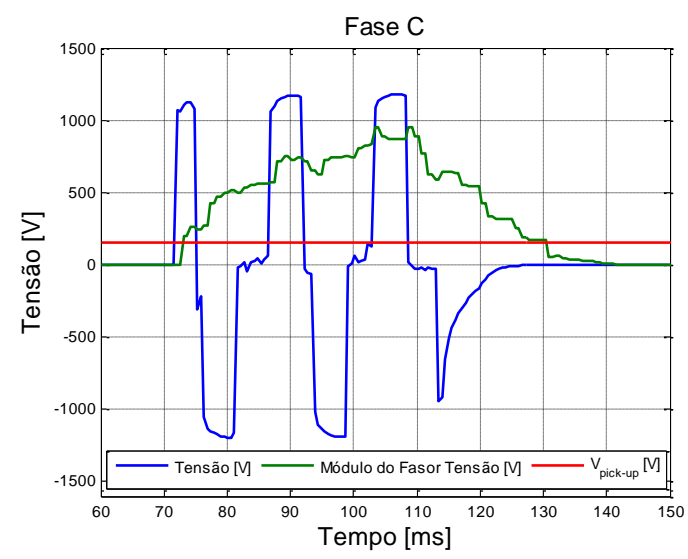

(c)

Figura 5.15 - Zona 2. Tensão nos terminais do relé quando de um curto-circuito trifásico no barramento: (a)Fase A. (b)Fase B. (c)Fase C.

\subsubsection{CASO 7: CURTO-CIRCUITO TRIFÁSICO NA LT 4 EM UM PONTO IMEDIATAMENTE A FRENTE DO TC - ZONA 2}

Uma vez que o curto-circuito simulado não ocorre no barramento, mesmo ocorrendo em um ponto próximo ao TC ele não é capaz de ativar a proteção diferencial de alta impedância a atuar. A magnitude do fasor tensão nos terminais do relé e a tensão nos terminais do relé em todas as fases apresentam valores muito baixos, conforme apresentado nas Figuras 5.16, não ultrapassando o valor ajustado do limiar de atuação da proteção. 


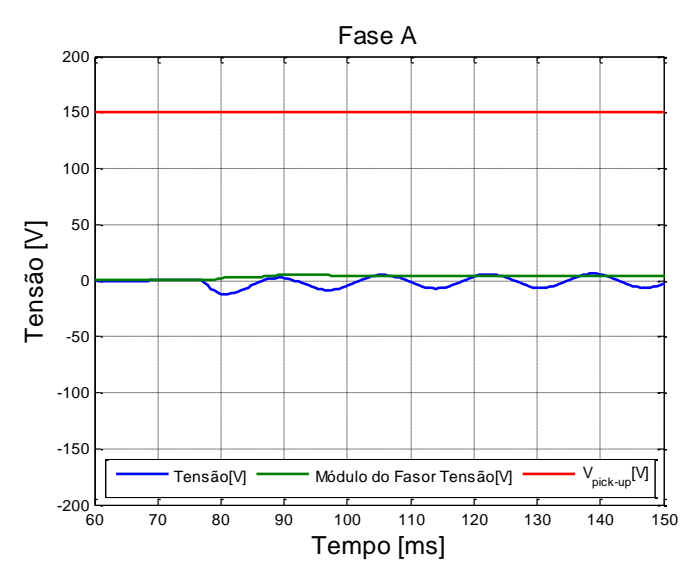

(a)

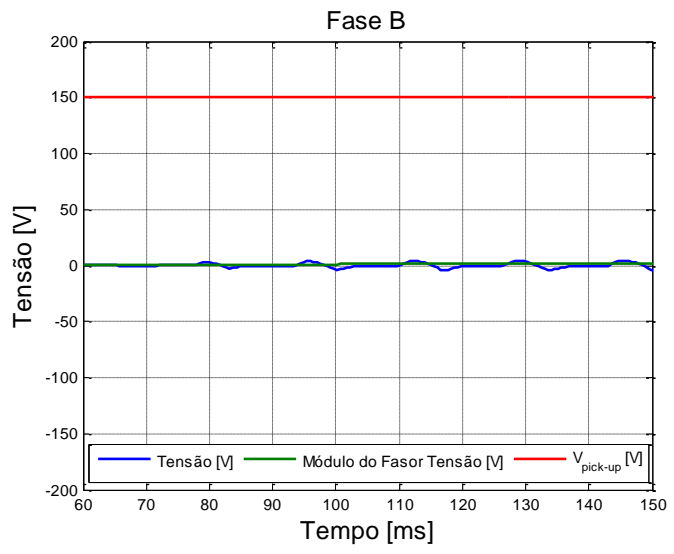

(b)

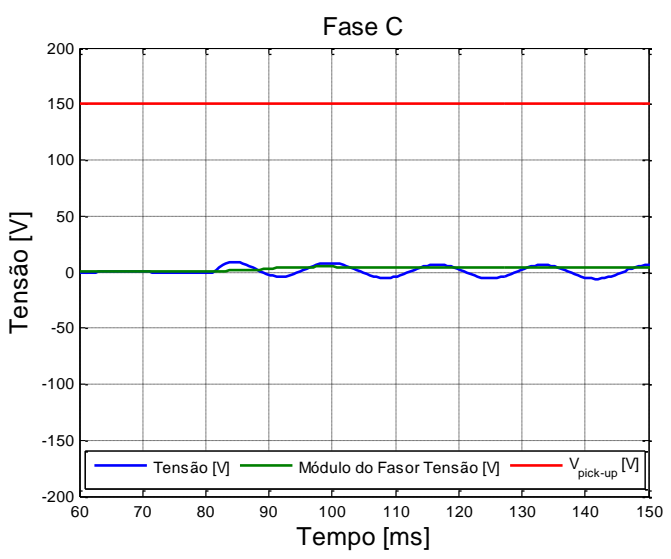

(c)

Figura 5.16- Zona 1. Tensão nos terminais do relé quando de um curto-circuito trifásico na LT $4 \mathrm{em}$ um ponto imediatamente a frente do TC: (a)Fase A. (b)Fase B. (c)Fase C.

A falta simulada não é capaz de sensibilizar a proteção da zona 2 a atuar para o caso de falta externa. Verifica-se nas Figuras 5.17 que a magnitude do fasor tensão nas três fases é inferior a $150 \mathrm{~V}$. 


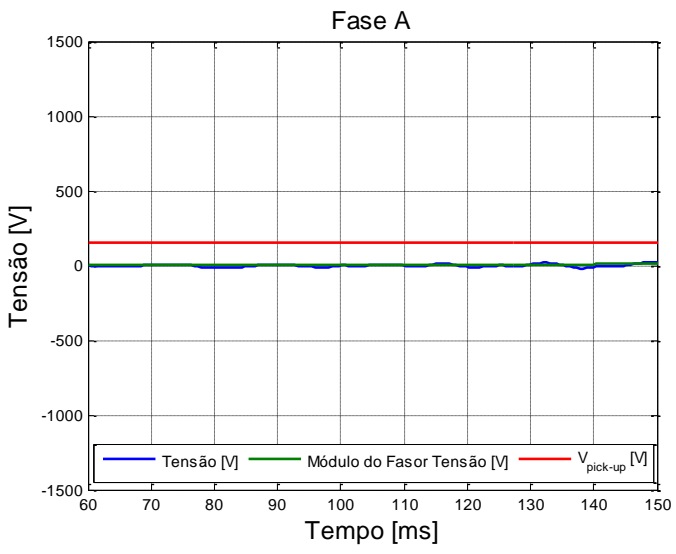

(a)

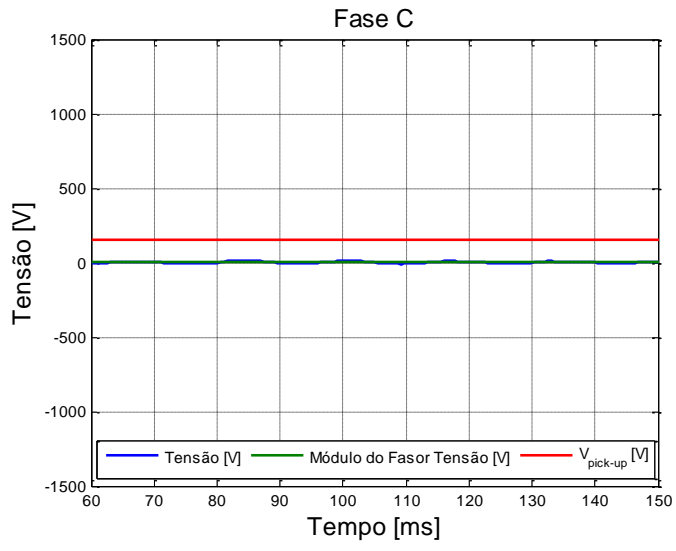

(b)

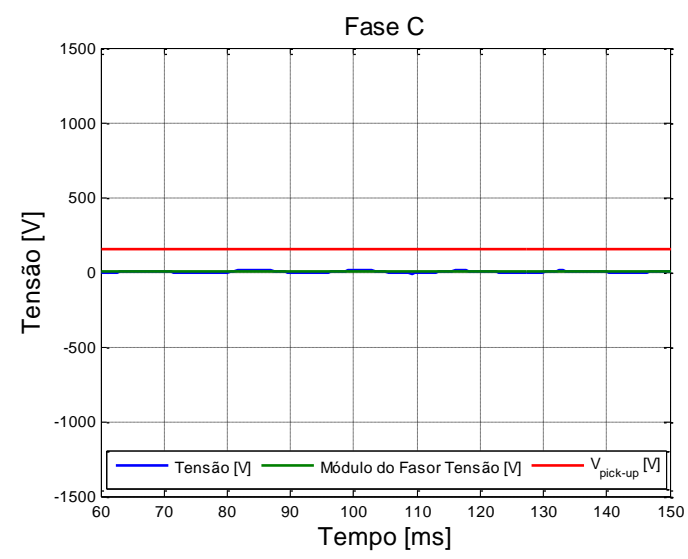

(c)

Figura 5.17- Zona 2. Tensão nos terminais do relé quando de um curto-circuito trifásico na LT 4 em um ponto imediatamente a frente do TC: (a)Fase A. (b)Fase B. (c)Fase C. 


\section{CAPÍTULO 6}

\section{CONCLUSÕES E PROPOSTAS DE TRABALHOS FUTUROS}

Nesta dissertação, foram apresentados os conceitos fundamentais da proteção diferencial de alta impedância, assim como a sua modelagem e implementação utilizando a linguagem MODELS do software ATP.

Foi apresentada a modelagem de um sistema elétrico com configuração de barramento simples seccionado, sendo sua proteção realizada utilizando duas zonas de proteção nas quais o disjuntor de seccionamento de barra é utilizado para isolar a falta na zona atingida.

Embora a proteção de barramentos de alta impedância apresente inúmeras vantagens em relação aos demais tipos de proteção, como por exemplo, em relação à saturação dos TCs, este tipo de proteção não oferece funções de proteção suplementar, tais como proteção da falha de um disjuntor ou proteção de fim de zona porque as medições de corrente em circuitos individuais são perdidas quando os TCs estão em paralelo. Tipicamente, este tipo de proteção é aplicada em barramentos de SEs, de extra alta tensão, cujo arranjo apresenta topologia fixa.

Para outros tipos de proteção de barramento, como a proteção diferencial de baixa impedância, a presença de componentes harmônicas e dc na corrente medida pelo relé devido à saturação do TC poderiam gerar um atraso considerável na operação do relé ou até mesmo bloqueá-la. Uma vez que a proteção em estudo é imune à saturação do TC, como dito anteriormente, ela atua de forma eficaz.

Uma vez que a atuação eficaz da proteção depende essencialmente da tensão desenvolvida nos terminais do relé, é de grande importância que os valores de $V_{\text {pick-up }}$, calculados para cada uma das zonas de proteção atuantes no sistema elétrico simulado seja escolhido de forma correta. Eles devem ser determinados pelas máximas contribuições de corrente no barramento, avaliando a possibilidade ou não da saturação completa do núcleo magnético dos TCs usados no esquema. Este fato evita que a proteção deixe de atuar no caso de faltas internas.

Através das simulações realizadas no ATP de curtos-circuitos internos e externos a zona 1 e a zona 2, a proteção diferencial de alta impedância de barramentos atuou 
conforme o esperado para faltas no barramento. As curvas obtidas não são mais senoidais e o valor máximo da tensão é limitado devido à presença do MOV. Caso o MOV não estivesse presente, a tensão nos terminais do relé seria consideravelmente alta, o que poderia ocasionar perda de isolamento em seus terminais. O relé envia um sinal de trip aos disjuntores, para que esses possam abrir e isolar a falta. Na presença de falta externa, o relé não é sensibilizado a atuar e a magnitude do fasor tensão em todas as fases independente do tipo de curto-circuito é aproximadamente igual a zero.

Conclui-se então, deixando como propostas de trabalhos futuros:

- Realizar estudos da proteção diferencial de alta impedância de barramentos para outro tipo de barramento, além do utilizado;

- Acrescentar além de linhas de transmissão, outros componentes ao barramento, como reatores, de modo a aproximar o esquema em estudo de sistemas reais.

- Implementar outros tipos de proteção de barramentos ao mesmo sistema, podendo-se comparar as vantagens e desvantagens que eles apresentam. 


\section{REFERÊNCIAS BIBLIOGRÁFICAS}

[1] K. M. SILVA. Estimação de Fasores Baseada na Transformada Wavelet para Uso na Proteção de Distância de Linhas de Transmissão. Tese de Doutorado, Universidade Federal de Campina Grande, Campina Grande - Paraíba, Abril 2009.

[2] P. M. ANDERSON. Power System Protection. Piscataway, New Jersey, EUA: John Wiley \& Sons, Inc., 1999.

[3] P. L. VIANNA, (2013). Modelagem e Simulação da Proteção Diferencial de Baixa Impedância de Barramentos no Software ATP. Dissertação de Mestrado em Engenharia Elétrica, Publicação PPGEE.DM-546/13, Departamento de Engenharia Elétrica, Universidade de Brasília, Brasília, DF, 71p.

[4] L. X. Bui, G. Morin e J. Reeve. EMTP TACS-Fortran Interface Development for Digital Controls Modeling. IEEE Transactions on Power Systems, Vol. 7, No. I, February 1992.

[5] A. K. S. Chaudhary, K. Tam e A. G. Phadke. Modeling and Validation of a Transformer Differential Relay in EMTP. IEEE International Conference on Systems, Man and Cybernetics, 1992.

[6] A. K. S. Chaudhary, K. Tam e A. G. Phadke. Protection System Representation in the Eletromagnetic Transients Program. IEEE Transactions on Power Delivery, Vol.9, No. 2, April 1994.

[7] M. T. Glinkowski e J. Esztergalyos. Transient Modeling of Eletromechanical Relays - Part II: Plunger Type 50 Relays. IEEE Transactions on Power Delivery, Vol. 11, No. 2, April 1996.

[8] D. V. Coury, P. G. Campos e M. C. Tavares. Modeling a Power Transformer for Investigation of Digital Protection Schemes. 8th International Conference on Harmonics and Quality of Power, October 1998.

[9] C. H. Kim, M. H. Lee, R. K. Aggarwal e A. T. Johns. Educational Use of EMTP MODELS for the Study of a Distance Relaying Algorithm for Protecting Transmission Lines. IEEE Transactions on Power Delivery, Vol. 15, No. 1, February 2000.

[10] P. G. McLaren, K. Mustaphi, G. Benmouyal, S. Chano, A. Girgis, C. Henville, M.Kezunovic, L. Kojovic, R. Marttila, M. Meisinger, G. Michel, M. S. Sachdev, 
V.Skendzic, T. S. Sidhu e D. Tziouvaras. Software Models for Relays. IEEE Transactions on Power Delivery, Vol. 16, No. 2, April 2001

[11]X. Luo e M. Kezunovic. Interactive Protection System Simulation Using ATP MODELS and $C++$. 2005/2006 IEEE PES Transmission and Distribution Conference and Exhibition, 2006.

[12] K. M. Silva, W. L. A. Neves e B. A. Souza. EMTP Applied to Evaluate ThreeTerminal Line Distance Protection Schemes. International Conference on Power Systems Transients (IPST'07), June 2007.

[13] D. Barbosa, U. C. Netto, H. M. G. C. Branco, D. V. Coury e M. leskovicz. Impacto do paralelismo na proteção diferencial de transformadores de potência. XX SNPTEE, Recife, 2009.

[14] R. G. F. Espinoza. Análise de proteção de linhas de transmissão através de relés numéricos e uso de models externos no ATP (Alternative Transient Program). Faculdade de Engenharia de Ilha Solteira, 2011.

[15] D. Barbosa, U. C. Netto, D. V. Coury e M. Oleskovicz. Power Transformer Differential Protection Based on Clarke's Transform and Fuzzy Systems. IEEE Transactions on Power Delivery, 2011.

[16] P. M. Miguel. Introdução à Simulação de Relés de Proteção Usando a Linguagem

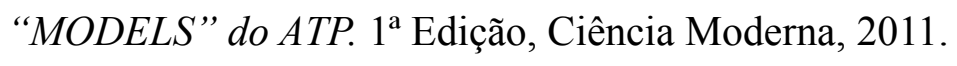

[17] E. C. Molas e K. M. Silva. Modelagem e Simulação da Proteção Diferencial de Linhas de Transmissão no ATP. IV SBSE - Simpósio Brasileiro de Sistemas Elétricos, 2012.

[18] ONS, Procedimentos de Rede - Submódulo 2.6: Requisitos Mínimos dos Sistemas de Proteção e Telecomunicações. Rio de Janeiro, 2008. Disponível em: http://www.ons.com.br/download/procedimentos/modulos/Modulo_2/Subm\%C3\% B3dulo\%202.6_Rev_1.1.pdf.

[19] Y. G. Paithankar e S. R. Bhide. Fundamentals of Power System Protection. Prentice-Hall, Nova Delhi, India, 2003.

[20] IEEE Power \& Energy Society. Power System Relaying Committee. IEEE Guide for Protective Relay-Applications to Power System Buses. New York, 2009.

[21] K. Behrendt, D. Costello e S. E. Zocholl. Considerations for Using HighImpedance or Low-Impedance Relays for Bus Differential Protection, proceedings of the 35th Annual Western Protective Relay Conference. Spokane, WA, 2008.

[22] J. L. Blackburn. Protective Relaying Principles and Applications. $3^{\mathrm{a}}$. ed. Nova 
York, 2006.

[23] G. Kindermann. Proteção de Sistemas Elétricos de Potência. 2a . ed. Santa Catarina: Edição do Autor, 2005.

[24] E. Schweitzer. Manual: Relé de Sobrecorrente de Alta Impedância 587Z. Disponível em: http://www.selinc.com.br/catalog/SEL-587Z.pdf

[25] S. E. Zocholl e D. Costello. Application Guidelines for Microprocessor-Based, High-Impedance Bus Differential Relays. Proceedings of the 63rd Annual Georgia Tech Protective Relaying Conference. Atlanta, GA, April 2009

[26] R. Rossi. Subestações Elétricas de Alta Tensão - Operação e Manutenção. Itajubá, 2004.

[27] Leuven EMTP Center. ATP - Alternative Transient Program: Rule book. Herverlee, Belgium, 1987.

[28] L. Dube. User Guide to Models in ATP. USA, Abr. 1996.

[29] G. Furst. MODELS Primer. Can/Am Electromagnetic Transients Programs, Canada, 1994.

[30] E. C. Molas. Modelagem da Proteção Diferencial de Linhas de Transmissão com análise no plano alfa usando o software ATP. Trabalho de Conclusão de Curso de Graduação, Universidade de Brasília. Brasília - DF, Julho de 2012.

[31] A. G. Phadke e J. S. Thorp. Computer Relaying for Power Systems. New York, USA: John Wiley\& Sons Inc, 1990.

[32] D. G. Hart, D. Novosel e R. A. Smith. Modified cosine filters, U.S. Patent 6,154,687, Nov. 2000.

[33] K. M. SILVA. Algoritmo do Filtro Cosseno Modificado. Nota de aula. Universidade de Brasília, Brasília, 2011. 


\section{ANEXO A}

\section{SUBESTAÇÕES}

Uma subestação é uma instalação elétrica composta por um conjunto de equipamentos de manobras, de proteção que exercem uma função específica como:

- Chaveamento de circuitos,

- Transformação de tensão (podendo ser de elevação ou abaixamento);

- Regulação de Tensão;

Além das funções citadas, as subestações são capazes de compensar reativos com a finalidade de melhorar a qualidade da energia fornecida aos consumidores e também controlar os fluxos de potência no sistema elétrico como um todo.

Características como função e nível de tensão são utilizadas para classificar os diferentes tipos de subestações. Elas podem ser classificadas quanto à função, portanto, em:

- Subestações elevadoras;

- Subestações de interligação;

- Subestações reguladoras;

- Subestações conversoras/inversoras;

- Subestações de subtransmissão e distribuição.

E quanto ao nível de tensão em:

- Subestações de extra alta tensão;

- Subestações de alta tensão;

- Subestações de média tensão;

- Subestações de baixa tensão.

As subestações também podem ser classificadas de acordo com o ambiente de instalação em subestação externa e abrigada. Elas são constituídas de 2 ambientes, pátio e sala de comando. No pátio estão localizados os equipamentos de grande porte, são eles: barramentos, transformadores, capacitores, disjuntores, seccionadoras, entre outros. Já na sala de comando estão presentes os relés, equipamentos de proteção e sinalização e medidores. 


\section{A.1. TIPOS DE ARRANJOS DE BARRAMENTOS}

Existem inúmeras arranjos de barramentos e cada um apresenta suas especificidades e é utilizada de acordo com a necessidade da subestação. Em uma subestação pode existir o que se chama de arranjo híbrido, que é a combinação de diferentes arranjos. Serão apresentados a seguir nove tipos de barramentos com suas vantagens e desvantagens.

\section{A.1.1. Barra Simples}

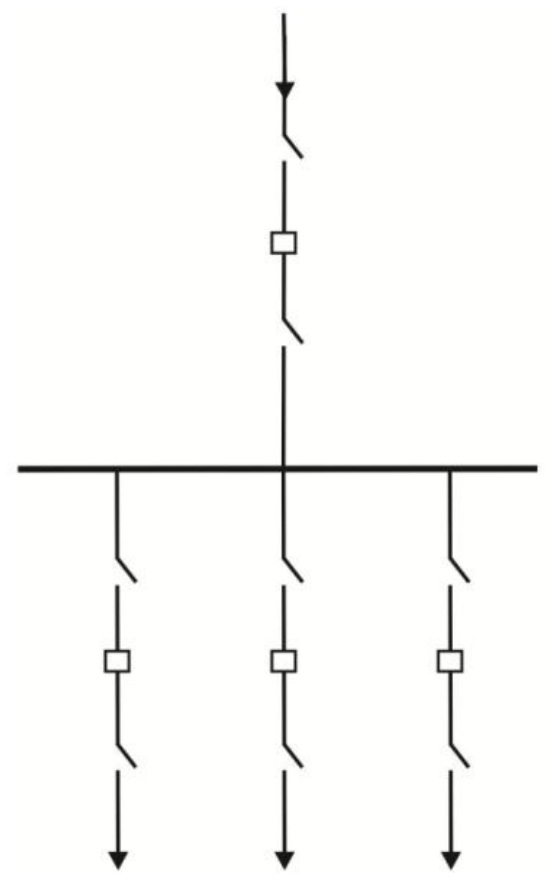

Figura A.1 - Barra simples.

Vantagens:

- Configuração mais simples e econômica;

- Configuração do tipo bypass pode ser utilizada para alguns ou todos os disjuntores. Possibilita que uma linha continue em operação, mesmo na retirada para manutenção de um disjuntor.

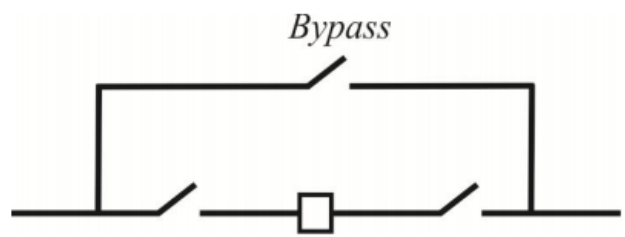

Figura A.2 - Configuração do tipo bypass. 
Desvantagens:

- Apresenta flexibilidade bastante restrita em relação à manutenção de equipamentos;

- Confiabilidade limitada;

- Não se pode estender o barramento sem antes desenergizar por completo a subestação.

\section{A.1.2. Barra Simples Seccionada}

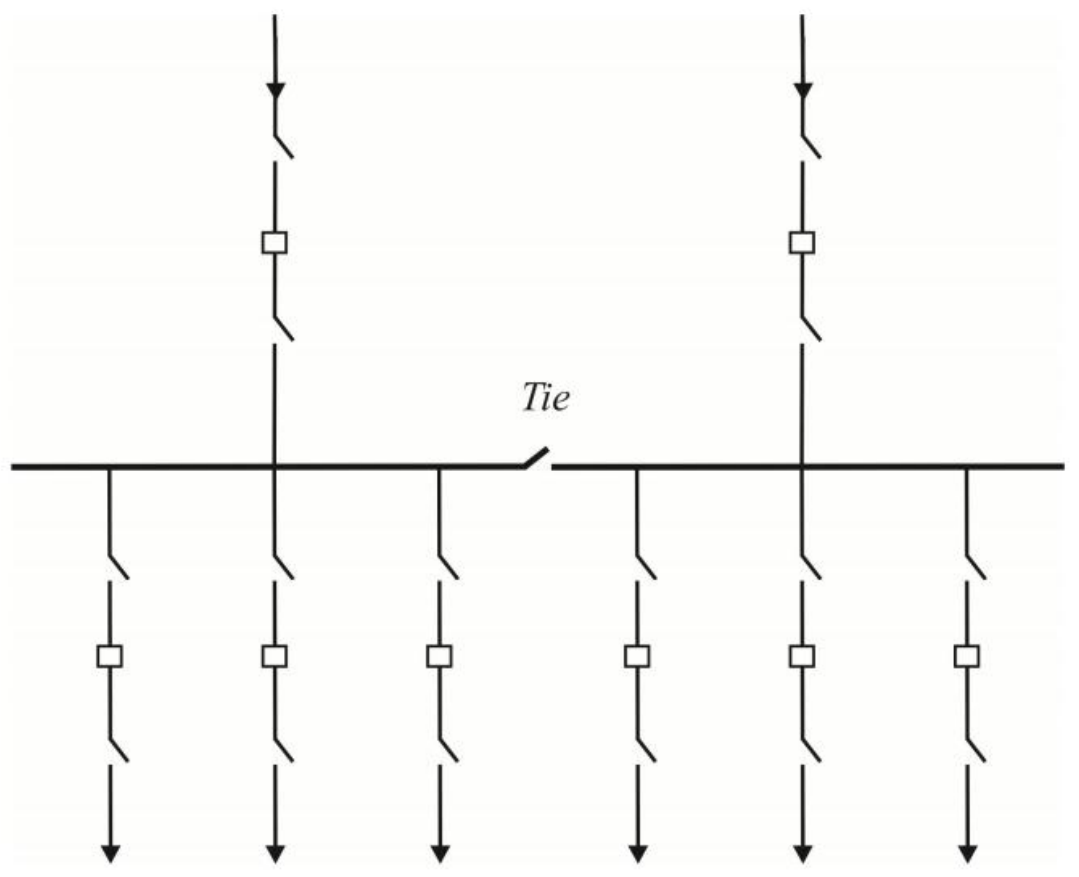

Figura A.3 - Barra Simples Seccionada.

Vantagens:

- Na presença de falhas ou manutenção, a quantidade de circuitos perdidos é reduzida;

- A chave interligadora que pode ser um disjuntor, como mostrado acima ou apenas uma seccionadora, possibilita aumentar a confiabilidade do sistema seccionando o barramento em dois (seccionamento simples) ou mais (seccionamento múltiplo), fazendo com que na presença de falha em um barramento o outro possa continuar em operação.

- Pode estender o barramento com desenergização parcial da subestação. 
Desvantagens:

- Em relação à configuração de barras simples, esta configuração é mais dispendiosa devido à inserção de um disjuntor de barras mais seccionadoras;

- Qualquer defeito na barra ou em um disjuntor leva parte da subestação a sair de operação;

- Dificuldade de manutenção e flexibilidade operacional reduzida.

\section{A.1.3. Barra Principal e de Transferência}

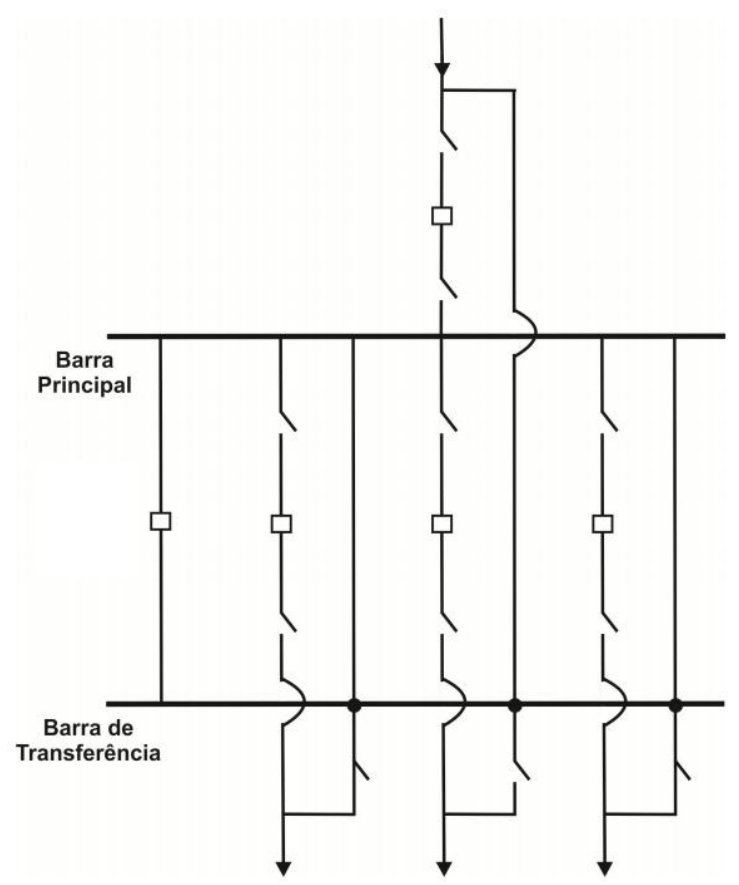

Figura A.4 - Barra principal e de transferência.

Vantagens:

- Apresenta a facilidade de bypass de disjuntores na presença de carga;

- Necessita de apenas uma zona de proteção de barramento;

- Equipamentos podem ser retirados ou adicionados à barra principal sem grandes problemas.

- Custos inicial e final baixos. 
Desvantagens:

- Necessita de um disjuntor extra para conexão com a barra de transferência;

- As manobras são consideravelmente difíceis de serem realizadas quando é necessário colocar um disjuntor em manutenção;

- Na presença de falhas no disjuntor ou no barramento a subestação deve ser desligada.

\section{A.1.4. Barra Dupla e Disjuntor Duplo}

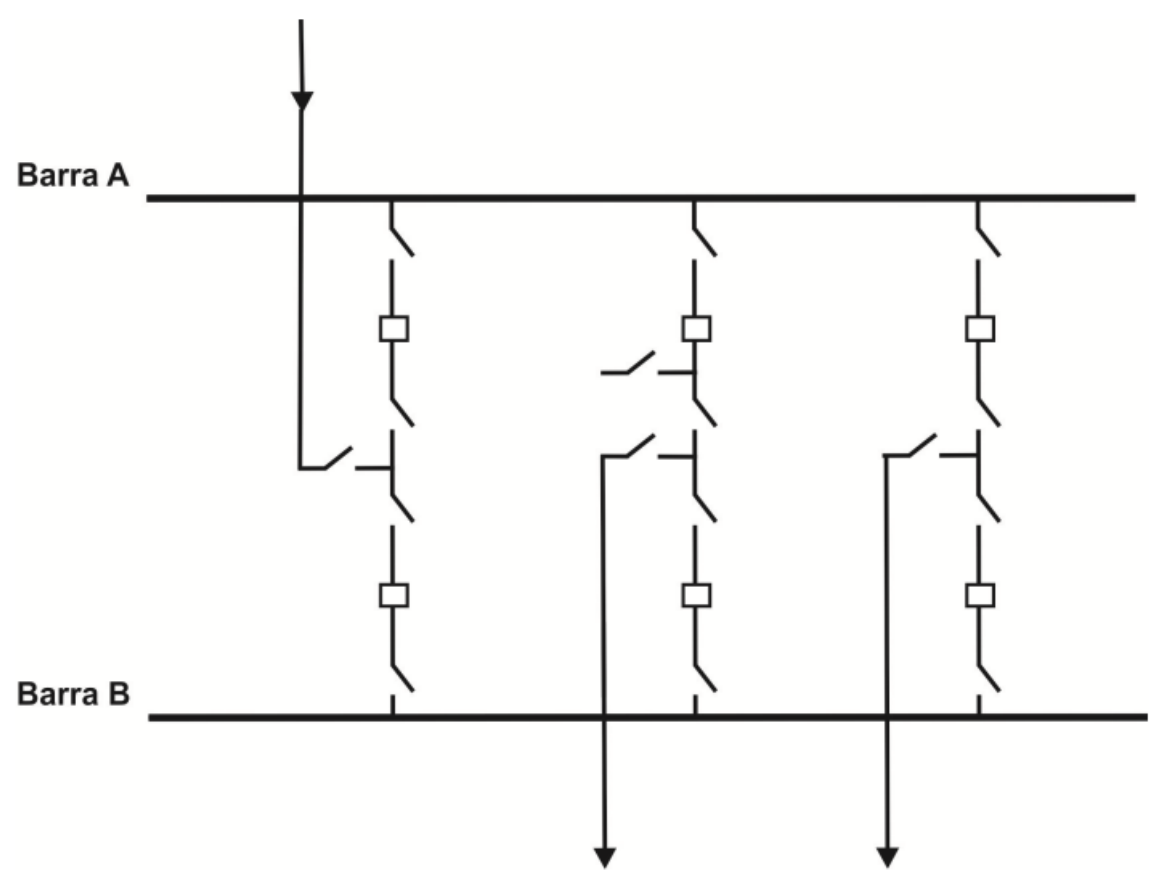

Figura A.5 - Barra dupla e disjuntor duplo.

Vantagens:

- Cada circuito tem dois disjuntores dedicados;

- Apresenta flexibilidade de manutenção e manobras;

- Possibilita que os alimentadores sejam conectados na barra A ou na barra B;

- A manutenção de qualquer disjuntor pode ser realizadas sem problemas;

- Alta confiabilidade.

Desvantagens:

- Esquema altamente dispendioso;

- Caso os circuitos não estejam ligados nas duas barras, com a ocorrência de defeito em um disjuntor, metade dos circuitos pode sair de operação. 


\section{A.1.5. Barra Disjuntor e Meio}

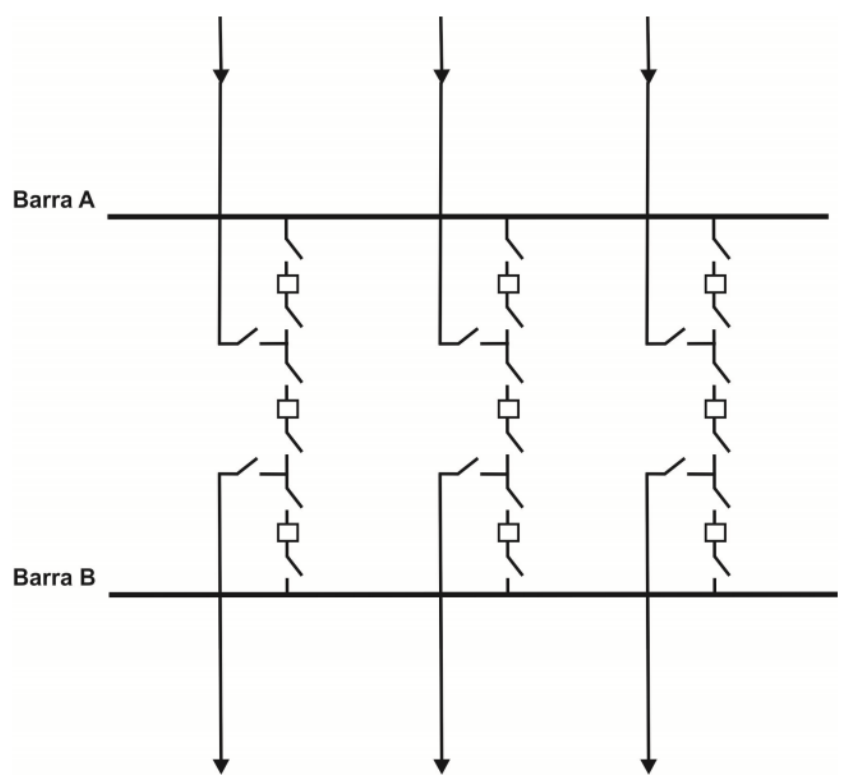

Figura A.6 - Barra disjuntor e meio.

Vantagens:

- Apresenta alto grau de confiabilidade e flexibilidade;

Desvantagens:

- Apresenta custos elevados, desta forma é empregado em subestações de extra alta tensão;

\section{A.1.6. Barra Disjuntor e um Terço}

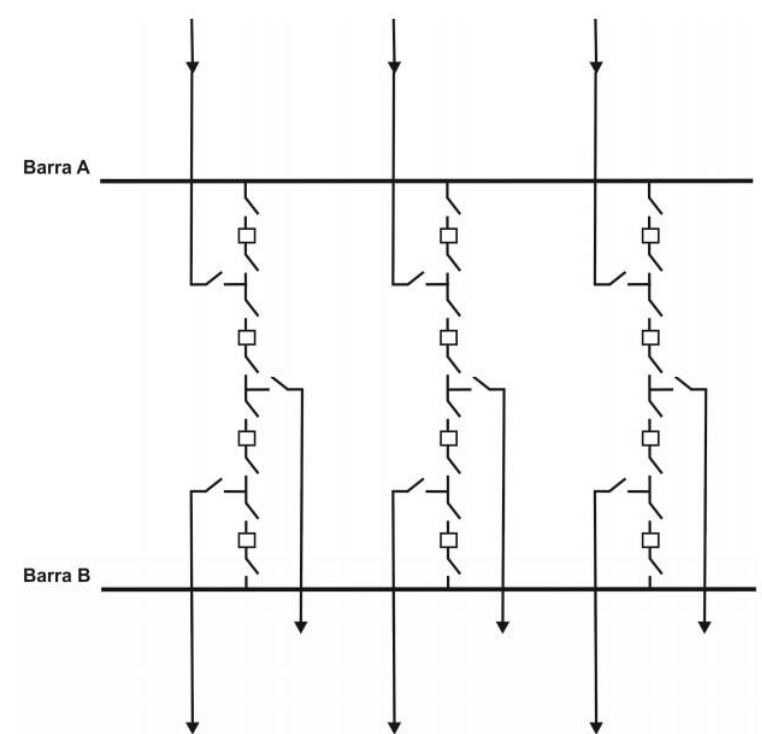

Figura A.7 - Barra disjuntor e um terço. 
Vantagens:

- Arranjo similar à configuração de barramentos disjuntor e meio.

\section{A.1.7. Barra Dupla e Disjuntor Simples a 4 Chaves}

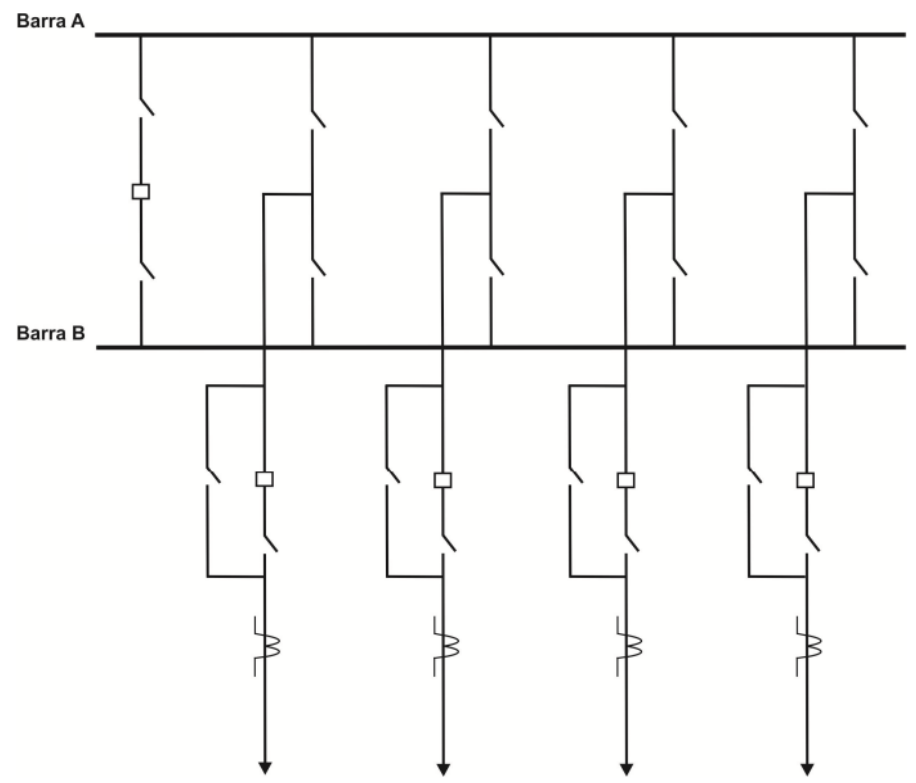

Figura A.8 - Barra dupla e disjuntor simples a 4 chaves.

Vantagens:

- Pode-se operar somente com uma barra, enquanto a outra pode ser utilizada como barra de transferência;

- Pode-se operar com as duas barras, o que possibilita uma grande diversidade de combinações;

- Alta flexibilidade, uma vez que possibilita que o sistema continue em operação mesmo na presença de defeitos na barra, no disjuntor ou em uma seccionadora.

Desvantagens:

- Apenas a barra B pode ser utilizada como barra de transferência;

- Grande quantidade de manobras deve ser realizada a fim de retirar um disjuntor para manutenção. 


\section{A.1.8. Barra Dupla e Disjuntor Simples a 5 Chaves}

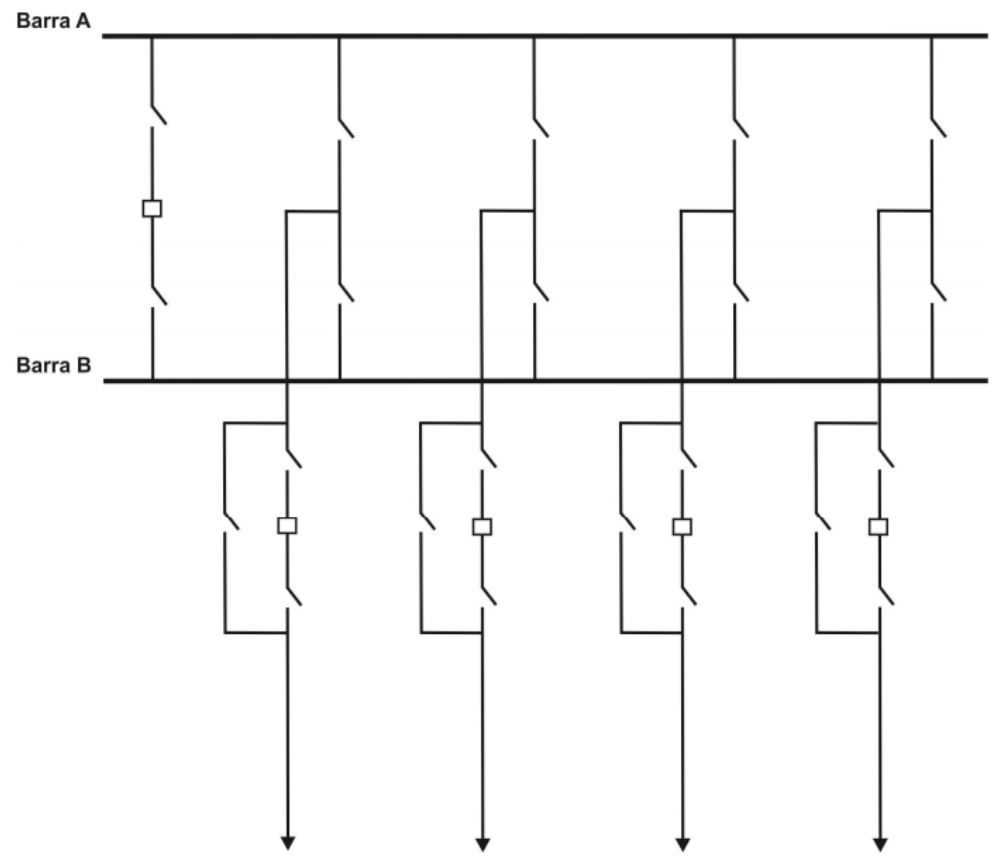

Figura A.9 - Barra dupla e disjuntor simples a 5 chaves.

Vantagens:

- Cada circuito do esquema pode ser conectado em uma ou outra barra dependo da necessidade;

- A seleção da barra A ou B pode ser feita sob carga;

- Os circuitos que estão conectados à uma barra na presença de uma falha podem ser transferidos para a outra barra;

- Ambas as barras podem ser utilizadas como barra de transferência.

Desvantagens:

- Todos os circuitos conectados à barra podem falhar na presença de falha na barra;

- Proteção consideravelmente complexa. 


\section{A.1.9. Barra em Anel Seccionada}

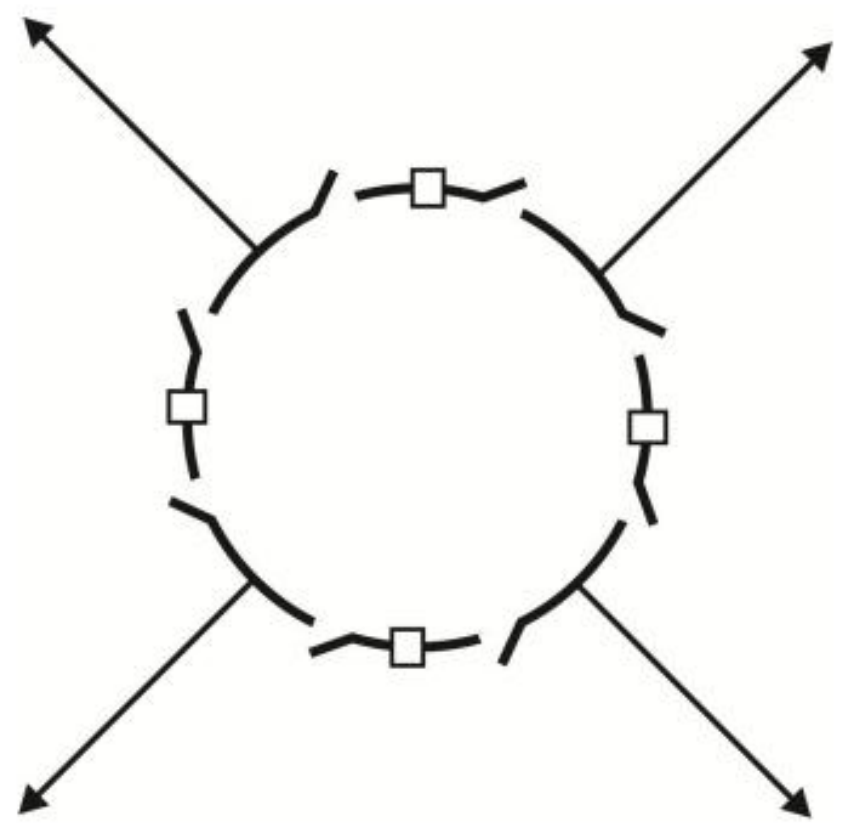

Figura A.10 - Barra em anel seccionada.

Vantagens:

- Tipo de barramento multi-seccionado onde é necessário apenas um disjuntor por circuito; Cada circuito de saída apresenta dois caminhos de alimentação, o que faz com que seja mais flexível;

- Apresenta um baixo custo inicial e final;

- A manutenção de qualquer disjuntor pode ser realizada sem a interrupção da carga.

Desvantagens:

- Comparando-se como arranjo de barra simples equivalente, este tipo de barramento necessita de uma área de pátio de subestação maior;

- Apresenta circuitos de proteção e religamento automáticos consideravelmente difíceis de serem implementados;

- Caso uma falta aconteça durante a manutenção de um dos disjuntores do esquema, o anel pode ser dividido em duas seções;

- Para que a manutenção de um equipamento seja feita, a proteção não irá atuar durante esse período. 


\section{ANEXO B}

\section{A LINGUAGEM MODELS}

O EMTP/ATP é um programa que permite a simulação de transitórios eletromagnéticos como curto-circuito ou abertura e fechamento de disjuntores em linhas de transmissão, transformadores, entre outros.

Esse software oferece a opção de programar funções de novos componentes através da MODELS, linguagem própria do ATP. A linguagem MODELS está apoiada em uma série de ferramentas que permitem ao usuário a elaboração de arquivos codificados de uma maneira bastante simplificada. Esta linguagem permite escrever rotinas para a representação de sistemas variantes no tempo. Em [27], mediante rotinas chamadas models que permitem uma interação dinâmica em tempo de execução com o ATP.

A rotina MODELS permite uma maior flexibilidade nas simulações, de modo que o estado do sistema pode ser modificado dinamicamente durante a simulação a partir de programas (ou modelos) implementados nesta rotina. A MODELS é uma linguagem de uso geral, baseada na descrição de estruturas, ou modelos, com características semelhantes à programação orientada a objetos. Os modelos podem ser desenvolvidos separadamente, agrupados em bibliotecas e usados em outros modelos como blocos independentes [27]

A seção MODELS no arquivo ATP deve possuir pelo menos três grupos maiores de códigos, cada um introduzido por uma palavra-chave, são elas: MODELS, MODEL e USE. A palavra-chave MODELS inicia a MODELS no arquivo ATP. Ela é finalizada com a palavra-chave ENDMODELS. As palavras-chave MODELS E USE são finalizadas por ENDMODEL e ENDUSE, respectivamente.

Após ENDUSE, pode ser utilizada a palavra-chave RECORD para inserir as variáveis de saída do sistema modelado. A estrutura da MODELS pode ser visualizada no Quadro B.1.

MODEL e USE são os dois grupos principais da MODELS que são divididos em seções iniciadas por palavras-chaves referidas por declarações, diretivas ou procedimentos. A estrutura da MODEL pode ser visualizada no Quadro B.2. 
Quadro B.1 - Grupos da MODELS.

\begin{tabular}{l}
\hline BEGIN NEW DATA CASE \\
MODELS \\
MODEL \\
ENDMODEL \\
USE \\
ENDUSE \\
RECORD \\
ENDMODELS
\end{tabular}

Quadro B.2 - Estrutura da MODEL.

MODEL Nome do Modelo

Comentários

DATA Declaração

Entradas

CONST Declaração

Entradas

HISTORY Diretivas

Entradas

DELAY CELLS Diretivas

Entradas

comentários

VAR Declaração

Entradas

INIT Procedimentos

Entradas

ENDINIT

Comentários

EXEX Procedimentos

Algoritmo de Simulação da MODEL

ENDEXEX

ENDMODEL 